\title{
Economy
}

\section{Entrepreneurship Education \\ Built Upon the Concepts \\ of Experience and Responsibility}

Agnieszka Kurczewska

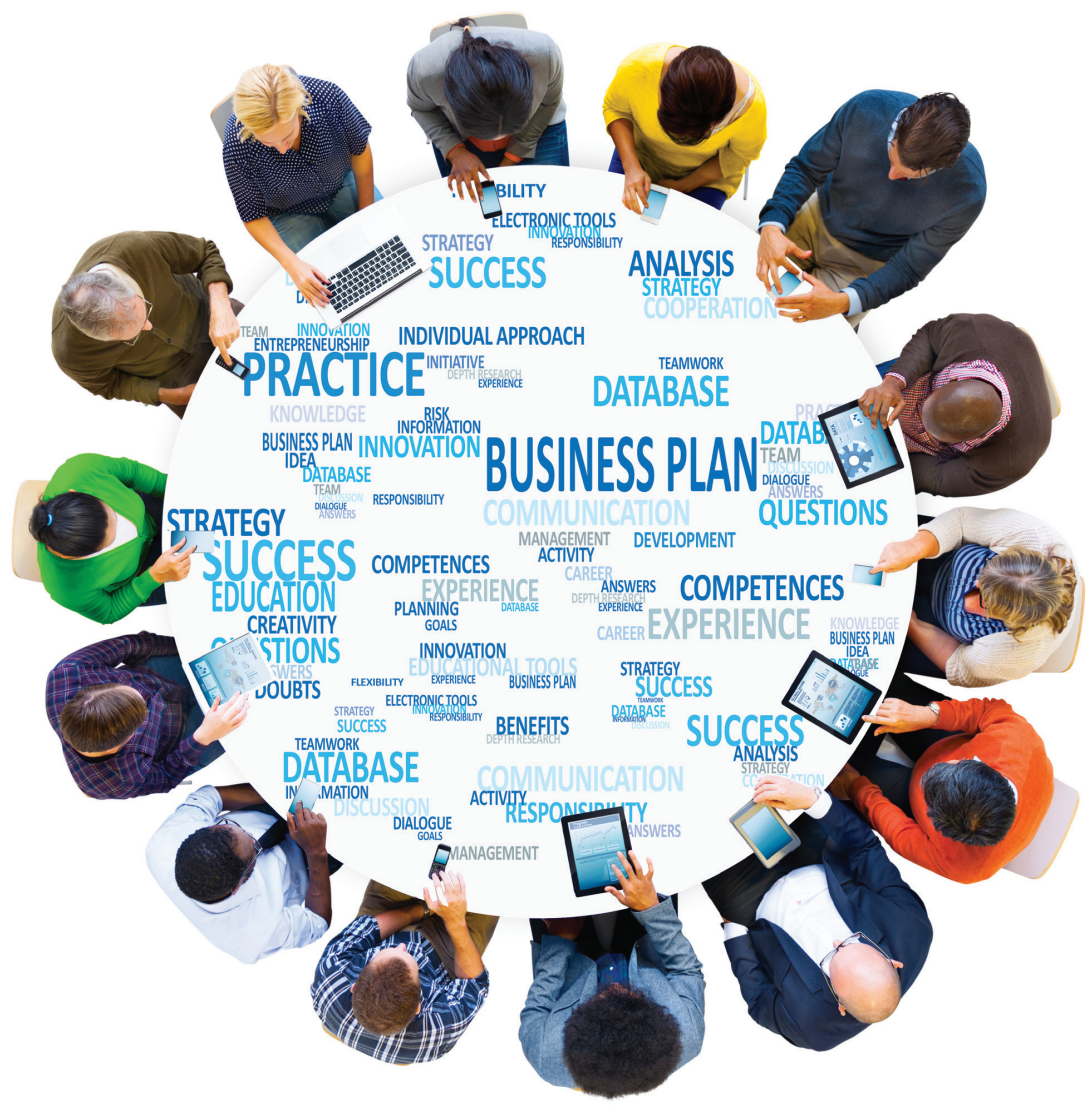




\section{Entrepreneurship Education}

Built Upon the Concepts of Experience and Responsibility 
盗 


\section{Economy}

\section{Entrepreneurship Education Built Upon the Concepts of Experience and Responsibility}

Agnieszka Kurczewska 
Agnieszka Kurczewska - University of Lodz, Faculty of Economics and Sociology 90-255 Łódź, 3/5 POW St.

REVIEWER

Eric W. Liguori

\author{
INITIATING EDITOR \\ Monika Borowczyk
}

PROOFREADING SERVICES
EuroDialog

TYPESETTING

AGENT PR

\title{
COVER DESIGN
}

Stämpfli Polska Sp. zo.o.

Cover Image: @ Shutterstock.com

The monograph is a result of the project Academic Entrepreneurship Education - concept of an education as a projection of a business life within Mobility Plus grant, financed by the Ministry of Science and Higher Education in Poland

$$
\text { Publication distributed free of chargé }
$$

The monograph is available online: http://scouting.uni.lodz.pl

(C) Copyright by Agnieszka Kurczewska, Łódź 2016

(C) Copyright for this edition by Uniwersytet Łódzki, Łódź 2016

Published by Łódź University Press

First Edition. W.07339.16.0.M

e-ISBN 978-83-8088-043-6

Publisher's sheets 11.0; printing sheets 10.875

Łódź University Press

90-131 Łódź, 8 Lindleya St

www.wydawnictwo.uni.lodz.pl

e-mail: ksiegarnia@uni.lodz.pl

tel. (42) 6655863 


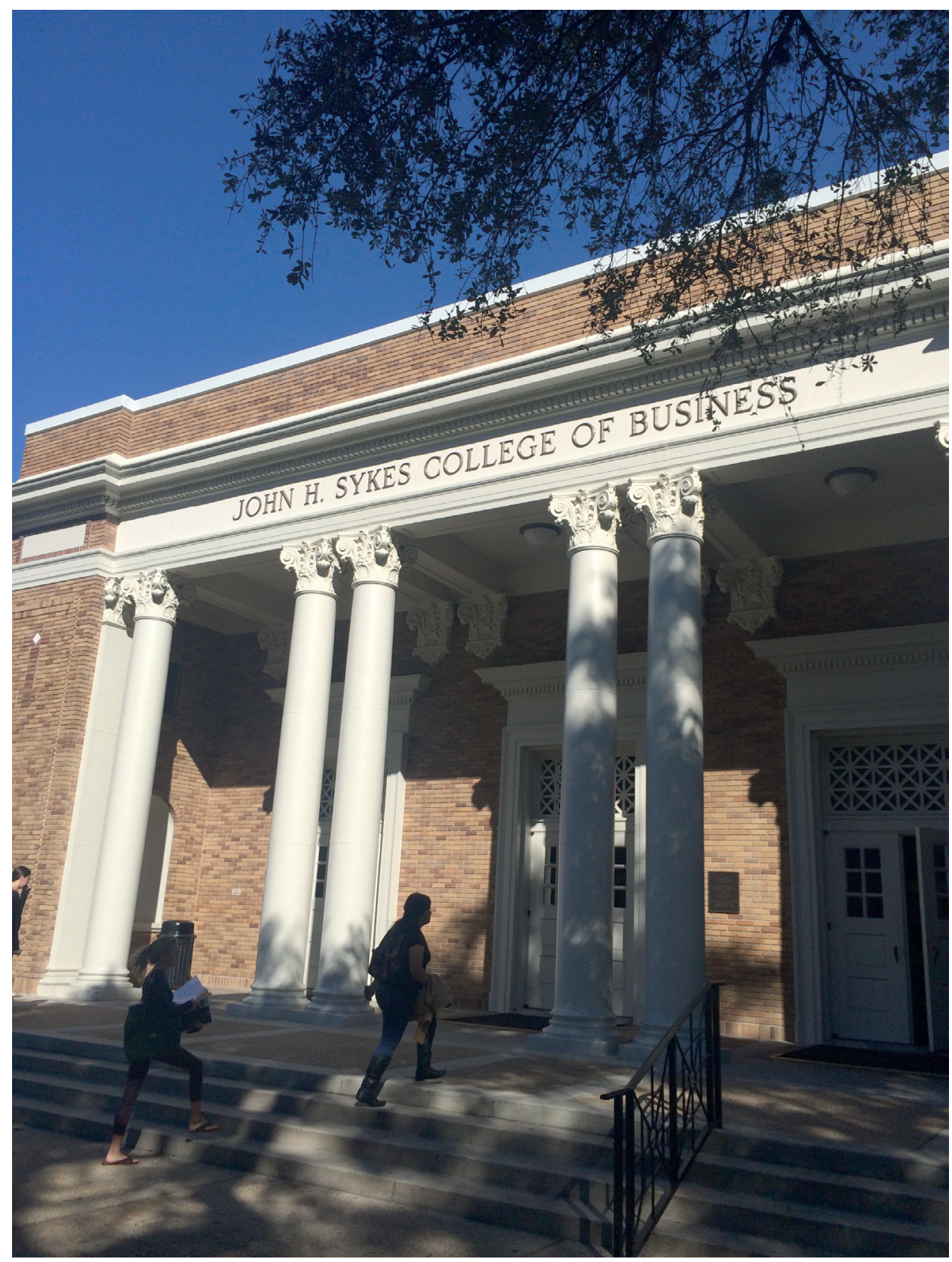

The University of Tampa, Florida, USA, November 2014 Photo: Agnieszka Kurczewska 



\section{Contents}

Introduction

Towards the practical but theory-driven approach in entrepreneurship education

Chapter I

The essence of entrepreneurship education

Introduction

1.1. Current research status of entrepreneurship education. Theory versus practice

1.1.1. Challenges and paradoxes of contemporary entrepreneurship and entrepreneurship education fields of study

1.1.2. Philosophical and practical approaches to entrepreneurship education and their evolutions

1.1.3. Pedagogies in entrepreneurship education

1.1.4. Common problems in practice of teaching entrepreneurship

1.2. Learning process as a core of entrepreneurial processes and entrepreneurship education

1.2.1. The characteristics of entrepreneurial learning process

1.2.2. Entrepreneurial thinking theories

1.3. Entrepreneurial intentions and opportunities in entrepreneurial learning process 51

1.4. The cognitive, conative and affective constructs in entrepreneurial learning 
Chapter II

The foundations of experience-based learning and education $\quad 59$

Introduction

2.1. The philosophical foundations of experience-based learning and education

2.1.1. Philosophy of education and experience - historical review from Ancient Greece up to $20^{\text {th }}$ century

2.1.2. $20^{\text {Th }}$ century: American pragmatism and Dewey's concept of experience and experience-based education

2.2. The psychological foundations of experience-based learning and education 75

2.2.1. Behaviouristic idea of learning from consequences 76

$\begin{array}{ll}\text { 2.2.2. Cognitive development through experience } & 78\end{array}$

$\begin{array}{ll}\text { 2.2.3. Cognitive load theory } & 79\end{array}$

2.2.4. Social psychology and experiential learning $\quad 80$

$\begin{array}{ll}\text { 2.2.5. Social learning theory } & 81\end{array}$

2.2.6. Self-regulated learning $\quad 83$

2.3. Pedagogy of experience 85

2.4. The concept of experience in contemporary education theories 89

2.4.1. Action learning $\quad 89$

2.4.2. Transformative learning and critical reflection 92

2.4.3. Learning as a cycle and different learning styles 95

2.4.4. Humanistic approach to learning from experience 103

$\begin{array}{ll}\text { 2.4.5. Modern constructivism and learning } & 104\end{array}$

2.5. The fundaments of experiential learning and experience-based education 106

Chapter III

Towards the theory of entrepreneurial praxis 111

Introduction 111

3.1. Different elements of the learning process in experience-based entrepreneurship education

3.1.1. Action in entrepreneurship education 113

3.1.2. Reflection in entrepreneurship education 114

3.1.3. Experiences in entrepreneurship education 116

3.2. Advanced learning perspectives in entrepreneurship field 117

3.2.1. Dynamic learning perspective of entrepreneurship and critical experiences 117

3.2.2. Experiential learning in the context of entrepreneurial opportunities 118

3.2.3. Entrepreneurial learning as an experiential process 119

3.2.4. Lessons from contemporary understanding of experiential learning in en$\begin{array}{ll}\text { trepreneurship education } & 123\end{array}$

3.3. Towards the entrepreneurial praxis $\quad 125$

3.3.1. Characteristics of entrepreneurial praxis $\quad 125$

$\begin{array}{ll}\text { 3.3.2. Entrepreneurship as a research field built on entrepreneurial praxis } & 128\end{array}$ 
Chapter IV

Responsibility and entrepreneurship education

Introduction

4.1. Reasons behind responsibility-based learning. Education for social purpose 132

4.2. The fundaments of entrepreneurial responsibility

4.2.1. Entrepreneur as homo ethicus

4.2.2. Retrospective and prospective entrepreneurial responsibility

4.3. Towards the theory of entrepreneurial responsibility in entrepreneurship education

Conclusions

149

References

List of tables

171

List of figures

173 

... how far superior an education that stresses independent action and personal responsibility is to one that relies on drill, external authority and ambition ...

Albert Einstein

\section{Introduction - Towards the practical but theory-driven approach in entrepreneurship education}

Learning is an eternal part of human life ensuring progress and development of individuals and any forms of their organization. It is a natural process that happens beyond any limits, set by time, place or structure, but essential for individuals to confront with the world. The most institutionalized form of learning is education. As Usher and Edwards (1994, p.4) wrote, it is the most important way we relate to the world, to the way we experience, understand and attempt to change the world and to the ways in which we understand ourselves and our relations with others.

However, different epochs or even decades bring new focus and new challenges, achieving which are expected by society and thus have to be learned. Education follows the needs of society, discovers its demands and, due to its performativity, prepares to deliver them. The question is: what is desired now? and how to make it happen? Among the most discussed and required competencies of today are the entrepreneurial ones. This view is shared by most of international institutions such as European Commission or the Organisation for Economic Co-operation and Development (OECD), educational institutions, entrepreneurship researchers and practitioners. Entrepreneurial competences are debated on all levels. Individuals aim to be entrepreneurial, companies and organizations want to be entrepreneurial, as well as governments, institutions, cities, regions or countries. Entrepreneurship is seen as a very positive force and the context of entrepreneurship is getting wider, much beyond traditional connotation of a small business and merely setting up a business. Entrepreneurial attitudes and values are supposed to lead to economic and social growth, innovation, job creation and sustainability. They are also regarded as a source of self-satisfaction and self-realization for ambitious 
and conscious individuals who make their dreamed venture creations happen. More recently, entrepreneurial processes started to be investigated from the learning perspective and entrepreneurial learning understood as a problem solving process centred on the acquisition, storage and use of entrepreneurial knowledge in long term memory (Rae and Carswell, 2001, p. 221). Companies and organizations are perceived as learning systems and entrepreneurial learning as an essential process to ensure individuals and companies' progress. In a natural way entrepreneurship becomes the zeitgeist. The role and the challenge of the research is then to understand better the complexity and dynamics of the entrepreneurial learning processes in order to support and enhance any form of entrepreneurial activity that brings value to the society and its members. The cult and cultivation of entrepreneurship results in interest and need for a sound and effective entrepreneurship education.

The premise of this monograph is that entrepreneurship education is above all the applied discipline, which serves societies and economies in a variety of ways by supporting individuals in becoming socially aware, proactive and reflective citizens realizing their ideas leading to their venture creations accomplishment and self-fulfilment. In this vein, to learn entrepreneurship means to participate consciously in meaningful entrepreneurial practices as much as it is possible at a particular level of education and life stage. Teaching entrepreneurship means to expose learners to situations where they can gain numerous different experiences, develop their analytical and reflective skills, build their self-efficacy and confidence, as well as for creating a supportive environment where they can obtain business knowledge, and form creative teams and networks. The applied profile of entrepreneurship education goes together with its social utility. Entrepreneurship education encourages learners to take entrepreneurial actions and stimulates their entrepreneurial thinking. Participating actively and consciously in economic and social reality gives some sense to the learner and brings back benefits also to other society members.

This practical approach naturally sheds the light into the concept of action and experience-based entrepreneurial learning. However, actions per $s e$, in the sense of just doing or accomplishing something, are not enough. As it will be argued, they should be accompanied with reflective thinking to realize their potential and result in entrepreneurial knowledge creation. This means that actions need to be followed by powerful reflections enabling learning to become deeper and sense-full, and resulting in both individual and collective development. Actions should also respect moral or ethical code and not harm any element of the entrepreneurial ecosystem, both in its social and economic dimensions. Setting up a new business and implementing new innovations are only desired when the entrepreneur 
is able to take responsibility for their consequences. Therefore entrepreneurship education should focus on learning through thoughtful, conscious and responsible doing. This is the guiding principle underpinning the theoretical choices and directing the discussions on entrepreneurship education in this monograph.

In consequence, in this monograph the importance of two concepts is claimed to be important in entrepreneurship education theory and practice. These two concepts are entrepreneurial experience and entrepreneurial responsibility. They both have a potential to enrich the discussion on entrepreneurial learning and enrich teaching practice. The choice of experience and responsibility as the important elements of entrepreneurship education and entrepreneurial learning is a consequence of reflections after reading the classic educative and philosophical and educative writings of Dewey, Freire, Revans, Mezirow, Jarvis, Kolb, Bandura, Zimmerman, and many others, as well as investigating the state of the art in entrepreneurship education field.

Surprisingly, both responsibility and experience are not sufficiently present in the discussion on how and why to learn and teach entrepreneurship. Although the value of experience is broadly recognized in entrepreneurship education, as it will be explained later, it is often misinterpreted or understood in too narrow or simplistic way, and the agenda of how to teach entrepreneurship through or by entrepreneurial experience remains ignored and trivialised. Responsibility is even less present while discussing aims and contents of entrepreneurship education. It appears only fragmentary while debating on ethics in entrepreneurship or while attempting to adapt corporate social responsibility into the small business context. In fact, economies and societies need entrepreneurs, but entrepreneurs who are not only able to use their knowledge and skills to make their ventures functioning but also who are responsible for the actions they take and for any consequences related to these actions. Innovativeness and creativity, often perceived as core of entrepreneurial mindset, are essential but only if accompanied with responsibility to act ethically and for a good purpose.

What is argued in this monograph is that learning focused on gaining meaningful experiences and creating responsibility in learners foster their entrepreneurial identity and enable them to take actions which "make the world better", even on a very microscopic scale. This approach directs attention towards how individuals may contribute to economy and society while exploiting opportunities and putting their ventures into life. Pedagogy articulated within the framework of experience and responsibility is also connected with the idea of individuals' emancipation through the intellectual development. 
This monograph is a result of the conviction that there is a need to introduce some new aspects of entrepreneurship education and clarify some concepts that could develop further the field and lead to new practices. As Morris (2014) notices, despite the unquestionable progress in entrepreneurship education as a field of study, there is still a growing gap between the demand for and growth of entrepreneurship education and what is known to work effectively in entrepreneurship education. The continuum of theory-practice in entrepreneurship education is not fully recognized on both ends. What is shared is that there is no canonical way of teaching entrepreneurship and that learning process is very diversified, as there are different learning paths and profiles of students. What is missing is a theory driven practice. New learning theories or concepts result in some shifts in focus of research but not necessarily always lead to new practices of teaching. Although the entrepreneurship education should be practical at its core, some theoretical concepts or frameworks are not translated into practical teaching solutions ready to apply in the classroom. The idea is then to explore, clarify and bring into entrepreneurial learning the concepts that are practical but built on the deep research practice. Both experience and responsibility are the concepts often brought by many entrepreneurs in more and less formal discussions. However, without interpreting them through theoretical frameworks, they become too literally and too simplistically understood and so lose potential as an explicative medium.

\section{Facing the new challenge - the power and art of relationships}

From the contemporary perspective, learning means experiencing profound changes by the learner and making the learner more conscious individual being able to direct his or her life. In an entrepreneurship education context, educators face the problem of what and how to teach to make students prepared and committed to become entrepreneurs and considering it as a valuable career option or even life strategy and philosophy. Looking back in history, it is easy to identify that in the past a good start into business was guaranteed by propriety of land and accumulation of capital. More recently knowledge has become a powerful tool to gain competitive advantage over others. Knowledge meant data, information, technology, expertise as well as their creative and useful usage. Nowadays, while knowledge has become much more accessible and global, it seems that other factor starts to determine a business success. This element might be relationships. The world becomes more dynamic and interconnected than ever. The entrepreneurial opportunities multiply and 
are more accessible for more individuals despite their origin, background and capital at disposal. At the same time entrepreneurship researchers highlight the critical role of context of entrepreneurship (see for example Welter, 2010). They emphasize the importance of interactions between entrepreneurs and their environment. In this sense, becoming an entrepreneur is a process where individual learning takes place in a certain social context, certain environment and with certain resources. The success of entrepreneurs depends on their ability to observe, understand and react on what is happening around them. The identity of an entrepreneur, his or her attitudes and motivation are born and developed in a particular environment shaped by other individuals, networks and institutions. As Kyrö (2008, p. 42) writes: 'Proactive behaviour in complexity assumes that learning is simultaneously individual and social, relating to the dynamics between individual and collective human processes.'

The power of creating valuable relationships becomes important to exploit business opportunities. Being able to make relationships ensures a better access to actual information, enables flexibility and broader catalogue of life and professional choices. Often it seems to be much easier to obtain even very specialized knowledge than to get to know people who are meaningful to make a business successful. Relationships are created with all of stakeholders of entrepreneurial ecosystem: employees, customers, suppliers, capital providers, and competitors. In the same vein, an entrepreneur is no longer perceived as a lonely individual, bold enough to set up the business, but as a part of some entrepreneurial ecosystem and community, profiting from it and bringing back some value to it. This means that entrepreneurs should not be analysed in a separation from their relationships.

The significance of the entrepreneur's environment and its crucial meaning for shaping entrepreneurial processes provoke changes in teaching agenda. The role of higher education institutions, being part of the social and cultural landscape, need to be redefined. Next to teaching business literacy, socialization processes need to be better recognized and enhanced in education. The contemporary world is understood as global and hyper-connected. More focus on dialogue, social interactions in different contexts and group settings appears to be a way to enhance social skills and self-awareness, and develop reciprocity of relationships between student, teacher and all other group members. This has a chance to be achieved by construction, not assimilation. Entrepreneurship is a dialogic process by nature. It is interactive, intellectual and authentic. The nature of entrepreneurship makes experience-based entrepreneurial learning particularly relevant as experiencing does not happen in a vacuum but in a particular context and situation. Relationships facilitate experiencing process. 


\section{Entrepreneurship education. Theory versus practice battle}

Entrepreneurship is en vogue. Entrepreneurship education is even more en vogue. The past years have seen a remarkable growth of interest in entrepreneurship education all over the world and its legitimization among other research disciplines. The interest in entrepreneurship education has its roots in American students' initiatives and their determined calls for more practical approach to teaching business and inclusion of entrepreneurship courses in university curricula. Nowadays entrepreneurship education is cultivated at almost all universities all over the world, not only at business schools but any higher education institutions of various backgrounds, including engineering, medical or art schools. The popularity and accessibility of entrepreneurship courses reflect its nature. Entrepreneurship is about diversity. As Landström (2010, p. ix) notices: entrepreneurs start their ventures from all kinds of backgrounds, with a variety of business ideas, and their way of starting a venture varies considerably. People differ; emerging companies vary so the entrepreneurial processes, leading from idea generation to its exploitation, have to be various. The challenge of entrepreneurship education is to cover all these diverse processes and accept heterogeneity.

Because of this challenge entrepreneurship education experiences theoretical and practical struggles. There is a growing need for more intellectual foundations, both at the theoretical and methodological levels (Fayolle, 2013). A lot has been done to advance and legitimize the discipline. Worldwide, higher education institutions implemented courses and even degrees in entrepreneurship. However, there is also still a noticeable gap between the growing demand for entrepreneurship education and the understanding of teaching and learning of entrepreneurship (Morris, 2014). There are some other problems entrepreneurship education struggles with. Just to mention three of them, which seem to be reasons for this gap. First of all, there is still no sound theoretical grounding in entrepreneurship education. Practice of teaching entrepreneurship is not often supported by and does not derive from theoretical foundations. There are also not enough critical stances to what has been achieved so far in theories and what is actually taught in practice. Secondly, existing theories do not match pedagogies actually used in classrooms, so there is a gap between what theories suggest and what is taught. Although the need to educate through entrepreneurship is broadly recognized, there is an inconsistency between what is taught and what entrepreneurs actually do (Edelman et al., 2008). As Neck et al. (2014, p. 5) write, in entrepreneurship 
education a "theory-practice "continuum and tension continues to exist. Thirdly, despite huge advancement of the field in recent years, it rather bases on drawings from general education than creates its own solutions to educative problems, thus has not formed own identity and specifics. Profiting from established theories and concepts is not a limitation, but an asset, as this is a natural consequence of the situation when the discipline is young and needs to catch up fast to receive recognition and legitimization. The problem is the lack of deepness of studies and excessive easiness with which even very complex concepts are applied. The solution to this could be trying not to rush in research, but tracing back the roots and carefully exploring what is already achieved in broader sense, not only in education but also in philosophy, psychology or sociology. Only after, investigating specifics of entrepreneurship education is possible.

From the outset, entrepreneurship education was different than other management oriented educations. It was also more directed towards human development and enterprising self. On the theoretical level, entrepreneurship education was action oriented and focused on teaching how to act as entrepreneurs. In contemporary entrepreneurship, particularly important are the concepts of learning by doing (Cope and Watts, 2000) and experimental learning (Kolb, 1984, Politis, 2005). In the action-based approach, the learning process is associated with "doing" (Fiet, 2001) and entrepreneurship means putting ventures into life. Educators through their courses or trainings stimulate students' actions (Rasmussen and Sorheim, 2006). They induce entrepreneurial intentions and give students tasks leading them to generate knowledge, instead of passively receiving the information (Ewell, 1997). The contemporary view on entrepreneurship education puts emphasis on learning, where the learner is a key element, and which is aimed at increasing the number and quality of entrepreneurial opportunities.

Action-based entrepreneurship education corresponds to the constructivist approach to education. According to Löbler (2006), the constructivist approach in practice takes place when learning is a self-governed on-going process where teaching supports learning, thus the learner is an active producer and the teacher is an assistant. In this sense, the learner acts and takes responsibility for the learning process. The constructivist approach is often combined with an idea of transformative learning (Mezirow, 1991, 1995, 1999, 2000) where transformation leads to more entrepreneurial thinking and behaviour. Transformative learning is regarded as deep learning, where participants, due to critical reflection, give meaning to and understand meaning of the learning process and their lives. 
How does the practice of entrepreneurship education look like? Entrepreneurship education is not just business literacy. The scope of teaching interventions in entrepreneurship is very broad and more and more often realized beyond traditional curriculum. Next to traditional courses basing on lectures and business planning, the activities include: setting up own businesses, meeting with entrepreneurs (as potential role models and mentors), talking with entrepreneurs (for example interviewing them), working with entrepreneurs and experts (in form of common projects or traineeships), contacting accelerators, incubators, technology centres or start-up centres, forming entrepreneurs' clubs or associations, pitch competitions, participating conferences, workshops or meetings enabling creation of networks and new relationships. Teaching entrepreneurship does not mean communicating abstract information and providing merely theoretical concepts but supporting learning process by initiating practical activities.

Entrepreneurship education is one of the branches of education that relates to venture creation and entrepreneurial mindset. Taking into consideration that entrepreneurship education has been developed for no more than a few decades and general education for several centuries, the former cannot ignore the rich output of the latter. It means there is a need for tracing the roots of education and philosophy of education for the backbone and inspirations. It is a limitation to develop the field of entrepreneurship education without going back to the roots of education. This may implicate risks of misinterpretation of basic concepts, unnecessary simplifications and redundancies. The entrepreneurship education is very often regarded as very specific and different from other disciplines. Consequently, it is still weakly connected with general education and it happens that entrepreneurship educators are "inventing the wheel", instead of digging deeper into classic educational writings. Much entrepreneurship research is based on evaluation of methods and tools applied in practice, although these methods or tools were not developed in line with any educational theory but rather are based on creativity and experience of teachers. They are not further decontextualized and are not theorized either. They often work well in the classroom but they lack the necessary theoretical grounding to make entrepreneurship education a mature discipline. To develop entrepreneurship education both knowledge on entrepreneurship domain and general education is required. Although most of entrepreneurship scholars teach, they focus rather on entrepreneurship than on entrepreneurship education research and occasionally investigate topics related to entrepreneurial learning and education. 


\section{"All true learning is experience, everything else is just information" - Albert Einstein}

The common wisdom says that human beings learn by and through experiences. From the research perspective, the value of experiences cannot be overrated. Experience is closely linked to learning processes and developing intellectual capacities of the learners. It gives authentic dimension to the learning and provides the voice to the learners. Experiential learning ${ }^{1}$ accepts differences and contradictions. It means exposition and confrontation with different situations and different contexts. Through experiences, knowledge is generated and acquired but not in isolation to emotions or personal motivation and will. Looking at knowledge from an experience perspective, it does not have to be universal but rather relative, that is along with the postmodern view, personalized, subjective and local. It is not as much directly transmitted but rather individually created (which needs some effort), interpreted (which needs some attention) and structured (which needs some systematic approach and competences). Experiences come from the past and are used at present to ensure a better future. Students, usually young people without long life history, lack experience. The role of education is then first to enable students to create their experiences or expose them to different situations, and then also to make these experiences meaningful and appropriate. Although the value of experience is intuitively understood in general, as a research concept, experience has rarely been thoroughly investigated in the entrepreneurship education field. In consequence, the practice of a sound experience-based education is missing or is marginalized.

The idea of this monograph is that the theory of entrepreneurial learning might be built upon the concept of experience and experiential pedagogy. The book attempts to introduce experiential learning as an equal and legitimate form of educating alongside others form of learning and teaching entrepreneurship. To a large extent, the American pragmatism movement inspires this approach to learning and teaching. It is particularly influenced by John Dewey's claims about important relations between the processes of actual experiences and education. Applying the lenses of pragmatism prioritizes the significance of personal experience, allows identifying more effective learning tools and supports more future-orientated education. As it will be elaborated in the second chapter, there are different notions and connotations of experience. The

1 Both experiential learning, learning from experience, and learning through experience are treated as equal terms. 
concept has evolved over time and exists in countless intellectual traditions and streams. The dualistic character of experience, i.e. its action and reflection orientation, should be more reflected in entrepreneurship education. It is not enough to create pedagogy on only one of these concepts or on two concepts separately, since both of them take part in the development of the learner and ensure progress. To learn from experience, an individual acts and reflects, and as the result of acting and thinking the new knowledge is generated.

\section{"Man is condemned to be free; because once thrown into the world, he is responsible for everything he does. It is up to you to give a meaning" - Jean-Paul Sartre}

In general sense, education should serve developing a more socially just world (Itin, 1999; Breunig, 2005), where individuals take responsibility for what they do and are conscious of the consequences of their behaviours, in order to make the world a better place to live for all. The socially just world is not just a high-flown slogan, which sounds very promising but remains only as a nice composition of words. Education should refer to the actual problems of societies and communities and ensure their continuity and sustainable development. Education cannot be just a technical art of providing knowledge but has to contribute to communities that learners derive from. It cannot be delivered in isolation to human needs and problems. To achieve that, more responsible students who are conscious of the learning process are needed. Moreover, the accumulated knowledge should not only take form of facts, numbers, theories or history, but also include some actions to enable collecting experiences. Knowledge is being passed from generation to generation, from past to future through experiences of responsible individuals. Responsible accumulating and sharing experiences enable progress of societies. Social flavour of education is particularly important but not always considered in everyday practice of teaching.

Entrepreneurship belongs to and depends on society. Among many roles and functions that entrepreneurship serves, it might be also regarded as a kind of method to address social needs (Sarasvathy and Venkataraman, 2010). Entrepreneurship education brings value for the economy but also society and individuals (O'Connor, 2012). However, entrepreneurship and entrepreneurship education discourses have so far to large extent remained immune from responsibility-focused discussion. Setting up a new business and implementing new innovations are only desired when an individual is able to take responsibility for their consequences. 
Entrepreneurship education brings valuable results for society and the economy and it has to include responsibility issue in its contents and methods. There is no need for more entrepreneurs, but more responsible ones. The idea of the monograph is to present individual responsibility concept in entrepreneurship education and suggest some steps to introduce it into learning and teaching practice.

\section{The outline of the monograph}

The monograph consists of four chapters. The first chapter presents a discussion on the current research status of entrepreneurship education. It discusses challenges and paradoxes of contemporary entrepreneurship education, as well as philosophical approaches to entrepreneurship education and their evolutions. It also includes review of pedagogies in entrepreneurship education and common problems emerging in practice of teaching entrepreneurship. The first chapter examines the learning process as the core of entrepreneurial processes and entrepreneurship education. It also introduces the cognitive, conative and affective constructs in entrepreneurial learning.

The second chapter of the monograph relates to the theoretical underpinnings of experiential learning. It includes the discussion on experience in the light of works of great philosophers, psychologists and education theorists. It traces the philosophical foundations of experience-based learning and education from Ancient Greece up to $21^{\text {st }}$ century, with a particular attention on American pragmatism and Dewey's concept of experience. It also presents the psychological side of experience-based learning and education, including: behaviouristic idea of learning from consequences, cognitive development through experience, cognitive load theory, social psychology, social learning theory self-regulated learning. Among contemporary learning theories related to experience, the chapter covers the issues of: learning as a cycle, action learning, transformative learning, problem-based learning, humanistic approach to learning from experience, modern constructivism and learning. Basing on philosophical, psychological and educational theoretical grounds the fundaments of experience, experiential learning and experience-based education are discussed.

The third chapter concerns the theory of entrepreneurial praxis, that is the theory deriving from investigating the concept of experience and its components in context of entrepreneurship and entrepreneurship education. It discusses the intersections between entrepreneurship education and experience, action, reflection, and knowledge. In this chapter 
all major experience-based learning frameworks presented in entrepreneurship education field are described and synthesized. The critical stance on experiential learning in entrepreneurship education leads to translating its research dimension into teaching practice.

The final chapter of the monograph is devoted to the concept of responsibility and its meaning for entrepreneurship education. It explains the reasons behind responsibility-based learning and education for social purpose. It introduces the concepts of the entrepreneur as homo ethicus, as well as the idea of retrospective and prospective entrepreneurial responsibility. The chapter initiates the first steps to build the concept of entrepreneurial responsibility in entrepreneurship education.

The heart of this monograph is to revisit existing knowledge on experiential pedagogy and then combine it with somehow forgotten concept of responsibility in order to enhance the fundaments of entrepreneurship education. This monograph aims to contribute to the dynamically developing field of entrepreneurship and entrepreneurship education. This contribution is a refreshed, experience and responsibility-based, view into the learning process. Including these two concepts into theory and practice of entrepreneurship education and also investigating them from different perspectives may result in rethinking and advancing the way entrepreneurship education is executed.

\section{Research approach and its limits}

The monograph insists on the process approach to entrepreneurship and entrepreneurial learning. Learning is understood as a directed progression that can be enhanced and facilitated at each stage. It is seen as an open process, not only as the contents or outcomes, but rather the way to achieve them. There are many factors influencing learning processes and well as their various forms and categorizations. They relate to learners and their personal characteristics and learning styles, the learning environment, and the learning per se. All constructs of intelligence and personality are engaged in learning - cognition, affection and conation. Learning appears on different levels. It may be intentional or incidental, implicit or explicit. It may happen through reasoning, association or observations. It is impossible to refer to all of them, as the catalogue is endless.

Traditionally, learning can be looked through three different mainstreams. Till the 1960s, the dominant view of learning processes was behaviourism. In behaviourism, learning is based on the learners' responses to environmental stimuli (Skinner, 1976) and transmission 
of knowledge from a more expert teacher to a more novice learner. Radical behaviourism is laid on the assumption that human behaviour might be explained in terms of its functional relations with environmental events (Heward and Cooper, 1992). Behaviourism became less popular when researchers tried to match it less with stimuli but more with mental activity thus thinking. In consequence it was pushed back by cognitivism. In cognitivism the learner takes more responsibility for learning process and is more active actor. The learning process takes place as a result of processing information, "connecting the dots", that is when the mental connections are made. In more recent years, late 80 and 90 s, more attention was brought to constructivism and social constructivism in learning. This came together with a conviction that social aspects of learning should also be taken into consideration in discourses on learning. In constructivism, learners are constructing their own understandings and interpretations about the world, constantly confront their views and reflect, thus knowledge is gained and structured through experiences and reflecting on them. As a mental representation, learning processes are subjective and depend on environment. In natural ways, in the constructivist perspective social interactions and cultural aspects become more critical. The change from behaviourism to constructivism in education means the change of the role of teacher from instructor to mediator and knowledge from being transmitted to being created. To synthetize the trends in perceiving learning, there is a clear tendency to put learners more in the centre of this process, make them more active, participative, individualistic, autonomous and independent, but also allow them to be responsible for learning. Taking into consideration traditionally regarded as rivalry views of constructivism, behaviourism and cognitivism, it is difficult to make a clear-cut position of this monograph. The understanding of the concept of experience may be drawn from each of these approaches. However, the final concept of entrepreneurship education is closer to constructivism and its assumptions. Following Löbler (2006), the constructivist paradigm may serve as a theoretical grounding for entrepreneurship education. It does not mean that a mixture of progressive and traditional tools cannot be implemented in practice.

This monograph does not trace back an already a bit obsolete dispute whether entrepreneurship can be taught (Kirby, 2004; Fiet, 2001) but takes it for granted. It is assumed that the entrepreneurial competences, attitudes and knowledge may be gained, enhanced and further developed through learning and education. The focus of the monograph is to reflect on what is expected to be achieved through entrepreneurship education, how entrepreneurship can be best taught and how to develop responsible 
and entrepreneurially aware entrepreneurs. There is not much separation between learning and teaching, but as Kyrö (2008) suggests they are combined in one process. An inclusive view on learning process might be more promising if the focus is put on entrepreneurial learning facilitators which entrepreneurial experiences and responsibility are.

The monograph is an attempt to look at entrepreneurship education as a research field by drawing from entrepreneurship, philosophy, psychology and general education. However, obviously, it does not cover all potential issues related to experience- and responsibility-based education. It presents a subjective view on learning, pedagogy and education. First of all the subjectivity relates to the choice of intellectual traditions, philosophers, social scientists and educators. The monograph includes only a selection of threads, concepts and theories related to the concepts in question. However, any trials of including all of them would be doomed to failure. The synthetized collection is offered with some logic, in terms of chronology and meaning, which is gradually unveiled during reading.

The presented view of entrepreneurial learning is rather broad. Learning is part of life, not a separate phenomenon, occurring only in a classroom or only at school or university. It is a lifelong process. It is valuable and efficient if the generated knowledge comes from experiences, i.e. actual and purposeful actions supported by reflective and analytical thinking. Learning cannot be limited to any space or time. It is on-going process with no time horizon and no particular place to happen. At the same time, learning cannot be a random experience. It needs to be intended, systematic and, importantly, should consciously give meaning to the learner. The meaning of experience, as Saunders (1992) notices, cannot be simply provided to the student by the teacher. It has to be created by the learner through experience. Therefore, there has to be a continuing dialogue between what a learner does and what a learner thinks. Only through this dialogue the learning process is complete and a new knowledge can be generated. Accepting this view enables to touch the essence of learning, but at the same time challenges many learning theories and teaching methods.

Investigating intricacy of entrepreneurship education does not mean that the imperative is to discover one universal method of teaching. The existence of different perspectives on learning and pedagogy are the consequence of not only development of research but also of differences in human needs, expectations, motivation and potentials of the learners. It would be naïve to think that one approach would suit all learners. Contrary, the complexity and dynamics of human nature make it impossible to find one universal and effective way how to learn and teach. There are multiple facets of learning and the challenge is to feed them all to some 
extent. As Fayolle (2010) writes: There is no magic method, only methods which are more or less well adopted to a set of factors such as the pedagogical objectives, the characteristics of the audience, the institutional, cultural and organizational constraints.

Above all, the monograph is not dogmatic in any sense but it is an invitation to the discussion on entrepreneurship education and its foundations. It tries to provide some answers to numerous questions, but also leaves a lot of them open, thus stimulates further reflections and research, exploring different nuances of experiences and responsibility and their roles in entrepreneurship education. The monograph rather provokes to think than gives ready-made solutions. It invites to seek some new ways to move forward with the understanding of entrepreneurial learning and conducting entrepreneurship education.

\section{The audience}

The potential audience of this monograph is quite broad. It is recommended to entrepreneurship educators conducting research on various aspects of learning process and to practitioners trying to excel their teaching practices and reflect on their sense and meaning. It might be of interest to all who are concerned about both education and entrepreneurship. The monograph is aimed to look at entrepreneurial learning and education through two concepts that potentially may enhance its understanding - entrepreneurial experiences and responsibility. This can provide some more ideas how to improve teaching both "about", "through" and also "for" entrepreneurship (Heinonen and Hytti, 2010). 


\section{Acknowledgments}

The inspiration for writing this monograph I owe to two people, to whom I would like to address a special recognition. The first one is professor Paula Kyrö with whom I worked at the Entrepreneurship Unit in Aalto University School of Business in Finland in 2010 and 2011 and who is one of the pioneers in entrepreneurship education research in Europe. Professor Kyrö has greatly impacted my understanding of entrepreneurship and entrepreneurship education. Many discussions held with her during our research collaboration helped me to refine interests and gave the belief that entrepreneurship can also be regarded as a pedagogic form. The second person is my reviewer professor Eric Liguori from The University of Tampa. Eric's knowledge as well as his intriguing views and opinions, stimulated me to read more and work harder.

This monograph would not be published without the generosity of the Ministry of Science and Higher Education in Poland, which provided me with a scholarship to spend 10 months in the USA and soak into American culture of experiential learning and experience-based education. The "Mobility Plus" grant enabled me to focus on the problems of entrepreneurship education and confront my European understanding of learning process and education with American ones.

I am also very thankful to The University of Tampa in Florida for agreeing to host me for so many months, especially to Professor Rebecca T. White and her team from the Sykes College of Business who helped me to integrate with American university culture and to understand the American way of perceiving entrepreneurship education. A special acknowledgment is also given to the University of Lodz for allowing me ten months sabbatical. 


\section{Chapter I \\ The essence of \\ entrepreneurship education}

It is becoming clear that entrepreneurship, or certain facets of it, can be taught. Business educators and professionals have evolved beyond the myth that entrepreneurs are born, not made.

Donald Kuratko (2005, p. 580)

\section{Introduction}

In recent years entrepreneurship education has received an increased attention for its value for development of individuals, societies and economies but also some criticism for lower than expected theoretical advancements and problems with evaluating its effectiveness in practice. This creates potential for further endeavours to work on new educational theories and to discover new pedagogies.

From the outset entrepreneurship education was alternative, comparing to its older relatives in management education. It represents a rather constructivist approach to learning, putting more stress on action-oriented learning (learning by doing), experiential learning (learning by experiencing) and problem-based learning (learning by solving problems), and situating the student and the learning process in the centre of attention. Among entrepreneurship research scholars, there is an overall agreement that more traditional pedagogy alone is not enough to develop entrepreneurial thinking and doing. As a result there is an increased demand for more innovative models of teaching and types of pedagogy that would facilitate and enhance entrepreneurial learning process. Traditional methods and approaches are regarded as not suitable for entrepreneurial context, which is characterized by high volatility, complexity and uncertainty. The situations where entrepreneurs find themselves are unique, emotional and not always involving only rational thinking. They demand insights and critical reflections. The entrepreneurial learning process takes place if there is a room for practice, as practice confronts the learner with the real business life. 
One of the biggest challenges in entrepreneurship education is that there are two streams of knowledge on how to learn and teach entrepreneurship education, not necessarily bringing the same results. One stream is more formal and is developed through a theory of entrepreneurship education (usually by borrowing from other educational disciplines) and the second, less formal, derives from its practice. It is difficult to reunite and combine them into one and coherent knowledge, theory-based and practical at the same time. Moreover, entrepreneurship education still lacks some methodological rigor; it is highly fragmented both in respect to theories and pedagogies.

The chapter starts with the review of current research status of entrepreneurship education. It discusses challenges and paradoxes of contemporary entrepreneurship education. This chapter presents philosophical approaches to entrepreneurship education and their evolution, as well as revisits pedagogies used in entrepreneurship education and common problems appearing in practice of teaching entrepreneurship. It takes the perspective of the learning process as a core of entrepreneurial processes and entrepreneurship education. Therefore, it includes the characteristics of entrepreneurial learning process, and effectuation and bricolage as some representations of learning processes. Entrepreneurial learning could be interpreted as learning how to identify, evaluate and exploit opportunities (e.g., Lumpkin and Lichtenstein, 2005; Venkataraman, 1997). The chapter also includes a discussion on entrepreneurship education and entrepreneurial intentions and opportunities. Entrepreneurs do not operate without emotions and they make their decisions in line with their motivation and will. They act both rationally and irrationally. To understand the role of different personality and intelligence constructs in learning, the cognitive, conative and affective sides of entrepreneurial learning are described in last section of this chapter.

\subsection{Current research status of entrepreneurship education}

\subsubsection{Challenges and paradoxes of contemporary entrepreneurship and entrepreneurship education fields of study}

In discussions about the status of entrepreneurship education in terms of research, it seems to be important to start by referring back to the condition of entrepreneurship as a field of study, for the simple 
reason that entrepreneurship education in natural ways draws from achievements in entrepreneurship domain. The starting point is to find an answer to the question on what makes entrepreneurship a separate and distinctive domain? Despite a few decades of the presence of entrepreneurship on research arena this dilemma stays valid, as the field is not yet fully structured, has problems with forming its boundaries and is still building its academic identity. Scholars provide countless answers trying to find utmost convincing argument legitimizing entrepreneurship on the research map. What they share in general is that difficulties with answering are related to the dynamics of human behaviour (which is difficult to predict) and the complexity of entrepreneurial processes (which are difficult to capture due to their diversity). Plurality of answers is a result of multi-, inter- and cross-disciplinary profile of entrepreneurship research. When the question about the object or the core of entrepreneurship research is asked, a long list appears, embracing answers such as: a process, entrepreneurial individuals (with their qualities, values, actions and behaviours), objects created (venture innovation, product, market, company), an environment (ecosystems, networks). Not only a young scholar just entering the field might get confused trying to sort out the entrepreneurship realm.

The intention is not to represent an orthodox position and to support traditional and rigorous division of disciplines. On the contrary, drawing from other disciplines brings necessary progress and advancement. However, a phase of progressive atomization of science and research is taking place for more than a couple of years now. It is accompanied by a very narrow specialization of research themes, making the field highly fragmented and contextualized. It seems to be a right moment then to call for some solutions to avoid incommensurability of research and eliminate the feeling of being uprooted from mainstream entrepreneurship, which is, paradoxically, impossible to identify unequivocally. This very dynamic and challenging moment in the history of science requires more critical reflections on its consequences for research output. It is also justified by a tremendously growing number of articles and journals on entrepreneurship, which are impossible to follow, and an overwhelming stress of many scholars to lose an integral picture of the domain. The scientific ferment, taking place currently throughout academia, strengthens the need for more simplification and unification of the bases of entrepreneurship.

A broad scope and diversity research is essential for building grounds for any academic domain. However, richness of concepts and approaches in entrepreneurship, even if typical for emerging field and in line with post-modernistic tendency to hybridize different systems and orders, 
makes the field blurry, not to say, too blurry. As a consequence of permeation of different logics represented by different disciplines intertwining with entrepreneurship, many borrowings and incorporations, the field might suffer from opposite to intended results, such as: loss of individuality and autonomy, and lack of responsibility for the discipline development. The suggestion of Johnstone (2006) should be followed that the time has come to give back the borrowings from other disciplines and start entrepreneurship to contribute to their development. Achieving that would suggest that entrepreneurship researchers share some universal basics built upon one or a set of coherent concepts providing roots to majority of sub-domains and approaches.

The field still lacks the "common denominator" which could be a starting point or at least a point of reference for many different studies in entrepreneurship. In other words, the challenge is to find more universal and generic concepts, which could be a springboard for further research. Opportunity concept could immediately serve as one of the best examples of this kind of concepts. However, although opportunities changed the entrepreneurship domain, there is a growing wave of doubts whether opportunities should be regarded as basic units of analysis in entrepreneurship research, or maybe it should be actions as Klein (2008) suggests or ventures as Davidsson advocates (2013). In fact, opportunities per se are not panacea for all entrepreneurship problems. The basic problem is still the lack of common understanding of opportunity construct, as well as a lack of convincing measures of opportunity concept. What represents the domain better is the opportunity process and investigations of how opportunities emerge and evolve. However, again, the phases of this process with their diverse dynamics, fuzzy boundaries and multi-stages are not fully clear, despite more than a decade of an intensive research. The review of the entrepreneurship literature shows no impressive progress on the intersection between individuals and opportunities (Davidsson, 2013), although they are believed to find their meaning in context of human action (McMullen et al., 2007). One of the reasons might be the fact that mainly analytical approach has been applied to study opportunities, which required full clarity and refinement of precise argumentation.

Entrepreneurship education struggles with analogous problems and challenges to entrepreneurship. The tradition of entrepreneurial education as an academic discipline is not long. The first programs of entrepreneurship education was created in the 1940s at Harvard University but their real expansion took place in the 1980s, first in the US and then in Western Europe. The first entrepreneurship course was led in the US 
by Myles Mace at Harvard's Business School in February 1947. It was attended by 188 out of 600 students of the second year of MBA (Katz, 2003). In 1994 more than 120 ooo students in the US were involved in courses related to entrepreneurship or small business (Katz, 1994). Interest in teaching entrepreneurship has become greater when the university authorities and society become interested in small businesses as a driving force of economic progress and the concept of the knowledge-based economy. In the 1980s, business schools in the US and Europe continued to prepare students to work mainly at the level of senior management in large or global corporations. Klapper and Tegtmeier (2010) reported that one of the earliest researches on teaching entrepreneurship was conducted in the early 1980s, and it has resulted in several publications issued at Baylor University. Another important event for the institutionalization of entrepreneurship education was a conference held at Harvard University titled Entrepreneurship: What It Is and How to Teach It in 1985. However, the real explosion of entrepreneurship education took place in the 1990 .

Nowadays, entrepreneurship education is in the flourishing phase, both in theory and practice (Fayolle, 2013). The value and need for entrepreneurship education, as well as it its basic assumption about being teachable, is rather not disputable. Nevertheless, the pedagogy - methods, ways and strategies of teaching entrepreneurship are still not developed enough. What most researchers and practitioners agree on is that entrepreneurship education needs active and innovative approaches to teaching and learning. In fact, on the theoretical level, entrepreneurship education has borrowed many concepts from general education discipline, like the concept of the experimental learning (Kolb, 1984), the action learning (Revans, 1980), the transformative learning (Mezirow, 1991; Mezirow, 1995) or the self-regulated learning (Zimmerman, 1990). However, the problem is that practitioners rarely draw their inspiration for educating from theories or they interpret them in a too simplistic way. In describing their methods they use theoretical concepts but not deeply enough to follow their full sense and meaning. One of the examples could be experiential pedagogy term. This results in an evident gap between the theory and practice of entrepreneurship education.

The aim of entrepreneurship education does not seem to be controversial, although it is articulated with different foci. In general, it is to make the learners more entrepreneurial. The problem is that the process behind becoming more entrepreneurial and nature of effective teaching interventions supporting entrepreneurial activity are not recognized enough. As it was emphasized in the Introduction, the challenge that entrepreneurship education is struggling with is that it has to be built on deep theoretical foundations but at the 
same time has to meet the criteria of relatively easy application and be related to actual entrepreneurial processes taking place in a continuously changing environment. The problem is to reconcile the past with the future. As Neck and Greene (2011, p.55) write: The current approaches to entrepreneurship education are based on a world of yesterday-a world where precedent was the foundation for future action, where history often did predict the future. This means that entrepreneurship education offered today, although based on the research on past ventures, has to be relevant for the actual problems of aspiring entrepreneurs and their future.

The next important challenge in understanding entrepreneurship education is to match and integrate its two different facets. Although the general aim of entrepreneurship education is to make individuals more entrepreneurial, the reasons and ideology of this aim may be very varied. Dualistic character of entrepreneurship may be noticed depending whether more neoliberal or more human and social values are regarded as the founding ones. The first facet follows high growth objective and a need for technology development that is to realize economic objectives of entrepreneurship. From this side promotion and support for innovation, technical advancement, economic progress is desired. From the other side, entrepreneurship serves the development of human and social values. In this sense, entrepreneurship education goes beyond the conventional understanding of starting up a business and also focuses on active individuals consciously behaving in entrepreneurial way and creating new opportunities (Hjorth, 2003). The development is aimed at strengthening active citizenship, emancipation and democracy. Nevertheless, these two different facets are possible to reconcile, if the rhetoric of "either or" is replaced by including both within teaching interventions. This may be an argument for what Pittaway and Cope (2007) call holistic education. From this view, including both social and economic aspects ensures completeness and adequacy of education. In the classroom it means providing courses both on venture creations, social entrepreneurship and ethics.

\subsubsection{Philosophical and practical approaches to entrepreneurship education and their evolutions}

\section{Transformations in perception of education}

The last decade or two brought many transformations in a way education and the role it plays in a modern society are perceived. The changes may be noticed in the way basic concepts and issues discussed 
in education field are understood, like: knowledge, learning, teaching practices, learning outcomes and their evaluations, role of teachers and learners etc. Table 1.1 shows two polar views on education. The first is a traditional one where learning is more passive, teacher-centred with standard practices and instructions. The second is more post modernistic, where learning is progressive, active, learner-centred and where innovation and creativity matters. The trend is to move from a traditional type of education towards a more modern one. It does not mean that education in the future will follow the second view completely. The education system seems to be in transformation stage towards this direction, however not necessarily achieving it. These are the tendencies, being result of changes of social, political and economic environment. However, these trends are particularly true and up-to-date for social sciences and humanities, as these fields are more flexible in adapting new approaches, methods and tools. By following this table, it becomes clear that "new" education has to be built on some new fundaments and there is not enough done to translate it into practice. It also becomes evident how well the specific nature of entrepreneurship education suits the profile of modern education.

\begin{tabular}{|l|l|l|}
\hline \multicolumn{1}{|c|}{ Criteria } & \multicolumn{1}{|c|}{ Traditional view } & \multicolumn{1}{c|}{ Postmodern view } \\
\hline Knowledge & $\begin{array}{l}\text { Universal, } \\
\text { Objective, } \\
\text { Transmitted; }\end{array}$ & $\begin{array}{l}\text { Relative, } \\
\text { Contextual, } \\
\text { Subjective, } \\
\text { Constructed; }\end{array}$ \\
\hline Learning & $\begin{array}{l}\text { Oppressive, } \\
\text { Teacher focused, } \\
\text { Pre-defined, } \\
\text { Passive, } \\
\text { Outside-directed, } \\
\text { Mass learning; } \\
\end{array}$ & $\begin{array}{l}\text { Pearner and learning } \\
\text { focused, } \\
\text { Natural, } \\
\text { Active, } \\
\text { Self-directed, } \\
\text { Personalization } \\
\text { of learning; }\end{array}$ \\
\hline Role of education & $\begin{array}{l}\text { Preparation for a particular } \\
\text { profession, } \\
\text { Education answers the needs } \\
\text { of the state, } \\
\text { Education enables survival; }\end{array}$ & $\begin{array}{l}\text { Emancipation, development } \\
\text { and liberation of learners, } \\
\text { Education answers the } \\
\text { needs of societies and } \\
\text { communities, } \\
\text { Education enables sense } \\
\text { making; }\end{array}$ \\
\hline Outcome of education & Effective learning; & $\begin{array}{l}\text { Self-development of the } \\
\text { learner, his or her transfor- } \\
\text { mation and satisfaction; }\end{array}$ \\
& & \\
& &
\end{tabular}




\begin{tabular}{|l|l|l|}
\hline \multicolumn{1}{|c|}{ Criteria } & \multicolumn{1}{|c|}{ Traditional view } & \multicolumn{1}{c|}{ Postmodern view } \\
\hline Role of teacher & $\begin{array}{l}\text { Instructor and expert, } \\
\text { Teacher dominates and } \\
\text { controls; }\end{array}$ & $\begin{array}{l}\text { Assistant, } \\
\text { Mediator, } \\
\text { Partner, } \\
\text { Voice given to learners } \\
\text { Learners and teacher co-cre- } \\
\text { ate learning space and are } \\
\text { responsible for it; }\end{array}$ \\
\hline Role of reason & $\begin{array}{l}\text { Dominance of rationality and } \\
\text { reason in learning; }\end{array}$ & $\begin{array}{l}\text { Acceptance of irrationality } \\
\text { and emotions in learning; }\end{array}$ \\
\hline Learning practices & $\begin{array}{l}\text { Standard practices, } \\
\text { Instructions, } \\
\text { Discipline, } \\
\text { Established order; }\end{array}$ & $\begin{array}{l}\text { Innovative practices, } \\
\text { Building relationships } \\
\text { Autonomy, } \\
\text { Constructed order; }\end{array}$ \\
\hline Educative contents & $\begin{array}{l}\text { Facts, } \\
\text { Assessments and judgments; }\end{array}$ & $\begin{array}{l}\text { Interpretations and } \\
\text { meanings, } \\
\text { Constructions and } \\
\text { deconstructions; }\end{array}$ \\
\hline Criteria of evaluation & Correctness; & $\begin{array}{l}\text { Authentic nature of learning } \\
\text { experience; }\end{array}$ \\
\hline Risk/uncertainty & $\begin{array}{l}\text { Avoiding risk and striving for } \\
\text { clarity and harmony; }\end{array}$ & $\begin{array}{l}\text { Accepting uncertainty, } \\
\text { disharmonies and } \\
\text { contradictions. }\end{array}$ \\
\hline
\end{tabular}

Table 1.1. Characteristics of changes from traditional education towards more contemporary one Source: own compilation.

Higher education institutions around the world offer many courses, specialization, and even degrees in entrepreneurship. However, the effectiveness of academic education does not only depend on the curriculum. Kyrö (2008) notes that the focus of entrepreneurship education is moving out from contents towards learning and teaching. Entrepreneurship education therefore requires the inclusion of learners into the learning process, and from educators to create the framework for such a process and facilitate it.

\section{Constructivist approach}

In general, there are two approaches to education: constructivism and a more traditional one (sometimes also called transmission approach). Contemporary approach to entrepreneurship education suggests that entrepreneurial learning is constructivist in its nature. In the traditional approach, education is teaching-centred and knowledge is transmitted to the learner 
in a rather passive way. In practice this means more static lecturing and lack of deeper interaction-based interventions. This approach leans on knowledge provision and memorization. In the constructivist approach, education is learning-centred (Krueger, 2009). As Löbler (2006, p.19) notices, students create and govern their own learning process, which is open for any content, style, goal, experience, etc., and allows them to take every opportunity to answer the question in concern. This approach is more focused on deeper understanding than knowing and acquiring information. It is also related to developing awareness and consciousness, taking critical stance, questioning and reflecting. The constructivist approach to education is consistent with postmodern view on learning.

\section{Models of entrepreneurship education}

Entrepreneurship education has a quite broad meaning. It comprises differently directed types of learning: learning to understand entrepreneurship, to become entrepreneurial, and to become an entrepreneur (Heinonen and Poikkijoki, 2006; Hytti and O'Gorman, 2004). All of them have different objectives, diverse contents and distinctive pedagogies. Relating to this division, Hytti and O'Gorman (2004) propose a model of education, describing different roles of enterprise education. Their conceptual schema is based on three interdependent mindsets that focus on:

- 'Learning about' which is aimed at increasing the understanding of what entrepreneurship is about and its role in economy and society,

- 'To become entrepreneurial' in order to make individuals responsible about their learning, careers and lives,

- 'To become an entrepreneur' - to act as an entrepreneur and to manage to start up new business;

The basic questions determining the philosophy of all of these three types of entrepreneurship education are presented in Table 1.2

\begin{tabular}{|l|l|l|}
\hline $\begin{array}{l}\text { Learn to Understand } \\
\text { Entrepreneurship }\end{array}$ & $\begin{array}{l}\text { Learn to Become More } \\
\text { Entrepreneurial }\end{array}$ & $\begin{array}{l}\text { Learn to Become an } \\
\text { Entrepreneur }\end{array}$ \\
\hline $\begin{array}{l}\text { What do entrepreneurs do? } \\
\text { What is entrepreneurship? }\end{array}$ & $\begin{array}{l}\text { I need to take responsibility of } \\
\text { Why learning, career and life }\end{array}$ & $\begin{array}{l}\text { Can I become an } \\
\text { entrepreneur? } \\
\text { needed? }\end{array}$ \\
$\begin{array}{l}\text { How many entrepreneurs } \\
\text { do we have? }\end{array}$ & How do I take responsibility? & $\begin{array}{l}\text { How to become } \\
\text { entrepreneur? } \\
\text { How to manage the } \\
\text { business? }\end{array}$ \\
\hline
\end{tabular}

Table 1.2. Three basic models of entrepreneurship education Source: Hytti and O'Gorman (2004). 
To this catalogue of learning types also "learning through entrepreneurship" might be added. This approach could be part of "to become entrepreneur" type of learning or learning by doing as it involves developing entrepreneurial skills by active involvement and hands-on learning (Leitch and Harrison, 1999; Cope and Watts, 2000).

\section{European Commission approach to entrepreneurship education}

Entrepreneurship education is shaped by the changes in society and economy, by the advancements in the research but also it depends on international institutions taking a role in defining the educative policy and investing in developing and disseminating best practices. One of these institutions on the European landscape is European Commission.

European Commission understands that entrepreneurship education is much more than teaching how to set up and run a company. In one of its communications (2006) Commission states: Entrepreneurship refers to an individual's ability to turn ideas into action. It includes creativity, innovation and risk taking, as well as the ability to plan and manage projects in order to achieve objectives. This supports everyone in day-to-day life at home and in society, makes employees more aware of the context of their work and better able to seize opportunities, and provides a foundation for entrepreneurs establishing a social or commercial activity.

European Commission's understanding of entrepreneurship is broad and relates entrepreneurship education to strengthening the entrepreneurial attitudes, skills and knowledge, enabling to exploit business opportunities. The need for support for entrepreneurship education and its reinforcement on all levels of educations, that are: schools, vocational education institutions and higher education institutions, is highly stressed by European Commission (see: the Entrepreneurship 2020 Action Plan, the Rethinking Education Communication). Investing in education is treated as one of the highest return investments that Europe can make (European Commission, 2013, p. 1) and positive correlation between entrepreneurship and economic growth is highlighted (European Commission 2006). Being entrepreneurial is regarded as essential for business start-ups, any venture creations but also in working inside already existing companies and organizations, in all sectors, private, public and social sphere. Entrepreneurship education can take both formal and informal form but the European Commission recommends that entrepreneurial learning should be provided to all young people before they leave compulsory education. Interestingly, entrepreneurship education does not have to take form of a specific school subject, but it may have a form of a cross-curricular subject throughout the education. Therefore, it should not be isolated from other teaching programs. Also, it 
needs to include elements of following pedagogies: experiential learning, project-based learning, problem-based learning and learning by doing.

EU members are encouraged to include the entrepreneurial competences in their national curriculum. In fact, the need for a more advanced and accessible entrepreneurship education is fully recognized by national and regional authorities of all EU countries. There is growing awareness of the concept of an entrepreneurial university (Etzkowitz, 2004) and the necessity to enhance entrepreneurship education practices in order to stay competitive among other higher education institutions and to make the subject attractive for students. Adopting the broad definition of entrepreneurship enables universities to enhance their sustainable development towards entrepreneurial processes and activities.

\subsubsection{Pedagogies in entrepreneurship education}

\section{Evolution of entrepreneurship pedagogy}

General approach to entrepreneurship education and its constructivist flavour, supported by international organizations, is translated into teaching practices that is entrepreneurship pedagogies. When the evolutions of pedagogies in entrepreneurship education is discussed, Krueger (2007) identifies four types of pedagogies emerging in time:

- Teacher-centred,

- Teaching-centred,

- Learner-centred,

- Learning-centred.

Major assumptions and examples of tools for each of pedagogies are included in Table 1.3.

\begin{tabular}{|l|l|l|}
\hline \multicolumn{1}{|c|}{ Key focus of pedagogy } & \multicolumn{1}{|c|}{ Key assumption } & \multicolumn{1}{c|}{ Example of key tool } \\
\hline Teacher-centered & $\begin{array}{l}\text { Teacher transmits to passive } \\
\text { students }\end{array}$ & $\begin{array}{l}\text { Memorization (lectures } \\
\text { on entrepreneurial facts) }\end{array}$ \\
\hline Teaching-centered & $\begin{array}{l}\text { Recognizes learning as } \\
\text { a process }\end{array}$ & $\begin{array}{l}\text { Skills and Drills (e.g. writing } \\
\text { business plan) }\end{array}$ \\
\hline Learner-centered & $\begin{array}{l}\text { Learners have "ownership" of } \\
\text { learning }\end{array}$ & $\begin{array}{l}\text { Case studies (assessing } \\
\text { business plans) }\end{array}$ \\
\hline Learning-centered & $\begin{array}{l}\text { Learning is situated, students } \\
\text { and teachers alike }\end{array}$ & $\begin{array}{l}\text { Problem-based learning (e.g. } \\
\text { self-managed field projects) }\end{array}$ \\
\hline
\end{tabular}

Table 1.3. The evolution of pedagogy Source: Krueger (2007, p. 126). 
Taking the discipline development approach, Harrison and Leitch (1994) offer other views on the change of entrepreneurial pedagogies. They propose a three-stage model of the evolution of entrepreneurship education. Chronologically, the first stage related to the approach where entrepreneurship education was regarded as a part of management education. The second stage was a consequence of emerging entrepreneurship as a separate field and a need for entrepreneurial competences, which are different in small and large companies. Management and entrepreneurship education became separated. In the third stage, reconceptualization of entrepreneurship education as a field takes place. The interest in leadership and organizational structures provoked some grounds for the reintegration of management and entrepreneurship education.

\section{Teacher-centred versus learner-centred views of education}

The evolution of entrepreneurial pedagogies progresses from teacher-centred view to learner-oriented strategy. In entrepreneurship education this comes together with a conviction that content-oriented approach where knowledge is transmitted from the instructor to the learner is not appropriate to the uncertain and continuously changing environment of an aspiring entrepreneur. The comparison of teacher-centred and learner-centred views is included in Table 1.4.

\begin{tabular}{|l|l|}
\hline \multicolumn{1}{|c|}{ Teacher-Centred Paradigm } & \multicolumn{1}{c|}{ Learner-Centred Paradigm } \\
\hline $\begin{array}{l}\text { Knowledge is transmitted from professor to } \\
\text { students. }\end{array}$ & $\begin{array}{l}\text { Students construct knowledge through } \\
\text { gathering and synthesizing information and } \\
\text { integrating it with the general skills of inquiry } \\
\text { communication, critical thinking, problem } \\
\text { solving. }\end{array}$ \\
\hline Students passively receive information. & Students are actively involved. \\
\hline $\begin{array}{l}\text { Emphasis is on acquisition of knowledge } \\
\text { outside the context in which it will be used. }\end{array}$ & $\begin{array}{l}\text { Emphasis is on using and communicating } \\
\text { knowledge effectively to address enduring } \\
\text { and emerging issues and problems in real- } \\
\text { life contexts. }\end{array}$ \\
\hline $\begin{array}{l}\text { Instructor's role is to be the primary } \\
\text { information giver. }\end{array}$ & Instructor's role is to coach and facilitate. \\
\hline Teaching and assessing are separate. & Teaching and assessing are intertwined. \\
\hline Assessment is used to monitor learning. & $\begin{array}{l}\text { Assessment is used to promote and diagnose } \\
\text { learning. }\end{array}$ \\
\hline Emphasis is on right answers. & $\begin{array}{l}\text { Emphasis is on generating better questions } \\
\text { and learning from errors. }\end{array}$ \\
\hline
\end{tabular}




\begin{tabular}{|l|l|}
\hline \multicolumn{1}{|c|}{ Teacher-Centred Paradigm } & \multicolumn{1}{c|}{ Learner-Centred Paradigm } \\
\hline $\begin{array}{l}\text { Desired learning is assessed indirectly } \\
\text { through use of objectively scored tests. }\end{array}$ & $\begin{array}{l}\text { Desired learning is assessed directly through } \\
\text { papers, projects, performances, portfolios, } \\
\text { and the like. }\end{array}$ \\
\hline Focus is on a single discipline. & $\begin{array}{l}\text { Approach is compatible with interdisciplinary } \\
\text { investigation. }\end{array}$ \\
\hline Culture is competitive and individualistic. & $\begin{array}{l}\text { Culture is cooperative, collaborative, and } \\
\text { supportive. }\end{array}$ \\
\hline Only students are viewed as learners. & Instructors and students learn together. \\
\hline
\end{tabular}

Table 1.4. Comparison of teacher-centred and learner-centred paradigms Source: Hubba and Freed (2000).

\section{Entrepreneurship education pedagogies}

Contemporary entrepreneurship education pedagogies could be reduced to active and engaging pedagogy, which goes together with the development of action-bound theories in entrepreneurship field. Under this name there is a room for pedagogies used in entrepreneurship education like: action-based learning or learning by doing, experiential learning and problem-based learning. All these pedagogies link learning with doing and focus on behavioural nature of entrepreneurship. Their basic assumption is that actions enable learning. However, as Lackéus (2014) notices, despite their popularity, action-oriented approaches are hardly used in practice. This would mean, that probably action-oriented approaches are not recognized enough by the educators or there are some important challenges in implementing them.

Constructivist character and the transformative nature of the entrepreneurial learning process, room for autonomy and focus on experiencing make action oriented approach challenging to apply in practice. It takes form of experiential learning, problem solving, project-based learning, and creativity (Jones and English, 2004; Johannisson, 1991; Johannisson et al., 1998). However, it is demanding to have teaching interventions of this nature in the classroom. While stepping out of the classroom, the catalogue of teaching interventions becomes wider. Outside the classroom, students are able to collect lived, authentic experiences. Through creating relationships, they gather learning events and insights, learn how to be autonomous and independent but at the same time close to the society or community they belong to. Learners have to be responsible for their learning process and manage it to some extent by themselves. They are 
self-directed while making entrepreneurial choices and their entrepreneurial decisions.

The discussion presented in the prominent journals related to entrepreneurship education leads to the conclusion that successful entrepreneurship education requires action-based approach and that research needs to focus on uncovering the dynamics of entrepreneurial learning process being result of taking actions by the learners. The underlying idea of making this approach practical is that exposing learners to diverse experiences and enabling their transformation enhance entrepreneurial behaviour and thinking.

\section{$\rightarrow$ Action-based learning}

As Leitch and Harrison (1999, p. 92) define, action-based learning is learning by reflecting on the actions being taken in solving a real organizational problem with managers of similar position also experiencing challenging situations. It means learning by experiencing something and reflecting on it. Action is not only what happens to an individual, but also what this individual does with it by interpreting and reflecting. In the action-based approach to entrepreneurship education, the learning process is associated with "doing" (Fiet, 2000). Entrepreneurship means making venture creations happen; therefore educators through their teaching interventions should stimulate learners' behaviours. The actions of entrepreneurs do not happen in vacuum but are the results of some interactions with others. Following Kyrö (2008, p. 42), who writes: Proactive behaviour in complexity assumes that learning is simultaneously individual and social, relating to the dynamics between individual and collective human processes. She identifies two elements of entrepreneurial learning: an action-oriented proactive holistic attitude towards a complex and changing world and a holistic view of the human individual and social processes.

Action-based approach to entrepreneurship education corresponds to the logic of constructivism. As Löbler (2006) explains, constructivist approach takes place when learning is a self-governed on-going process where teaching supports learning thus the learner is an active producer and the teacher is an assistant, and activities are based on doing, thinking and talking together while having fun. From the constructivist point of view, entrepreneurship education should result in some change, which is supposed to occur in learners in order to make them more entrepreneurial. Constructivist approach is often combined with the concept of transformative learning (Mezirow, 1997; Mezirow et al., 2000) where in entrepreneurship education context transformation leads to more entrepreneurial thinking and behaviour. 


\section{$\checkmark$ Problem-based learning}

Under action-oriented pedagogy umbrella term, one of the strongest positions has problem-based learning concept. The concept is based on supporting students to find solutions to open-ended problems. These problems are usually articulated within cases or narratives taken from the real world and typical to the learners' field of studies. The solutions to the problems are not obvious and often create cognitive conflict in learners. In entrepreneurship education context, problem-based learning is believed to enhance entrepreneurial thinking. As Krueger (2007, p.132) explains: ... the particular value of problem-based learning $(P B L)$ in entrepreneurship pedagogy is that $P B L$ requires learners to move from answer-finding to question-creating, to take personal (cognitive) ownership of their projects. Faced with very high uncertainty, extreme time pressures and competing demands on their time and effort, problem-based learning mirrors what an entrepreneur faces on a daily basis. As students proceed, their reflections invariably lead them to that realization: the necessity for further improving their personal role identity as an entrepreneur.

Problem-based learning is grounded in critical and constructive thinking. It is an active type of learning, which takes place in a specific context (Barrows, 1996). Learners receive open-ended problems and strive for understanding the problem and providing some solutions. They take responsibility for their learning and are aware of learning process. Educators take rather a position of facilitator than disseminators. Team learning plays an important role in learning, which is often enhanced by interactions with experts in the field. The teaching interventions are less structured and less predefined.

$\checkmark$ Experiential learning in the context of entrepreneurship education will be discussed broadly in chapter three of the monograph.

\section{Entrepreneurship education as a method}

One of the most recent approaches to entrepreneurship education treats it as a method. Neck and Greene (2011) argue that the method of teaching is more important than its contents. They juxtapose teaching entrepreneurship as a process and a method (Table 1.5). For them, entrepreneurship education has to go beyond understanding, knowing, and talking. It has to be practice oriented and involve learners in using, applying, and acting. Neck and Greene offer alternative view on education where learning a method becomes more important than learning the contents. The method includes way of systematic thinking and acting. Suggested techniques embrace practices of starting businesses, serious games and simulations, design-based learning, and reflective practice. 


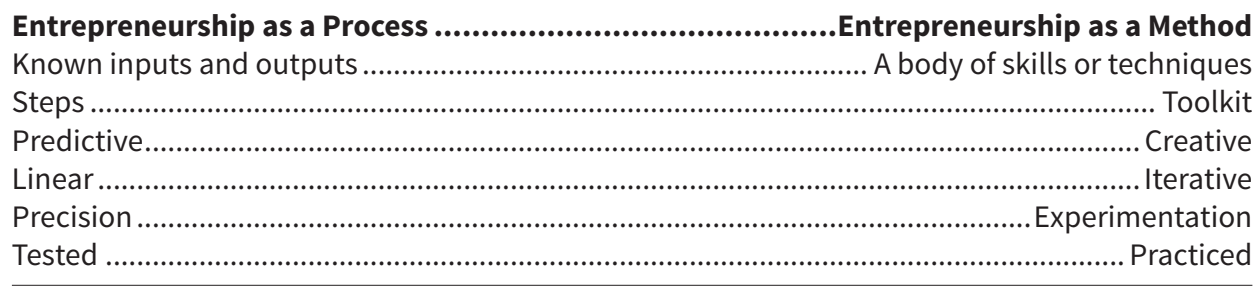

Table 1.5. Teaching entrepreneurship as a process and as a method Source: Neck and Greene (2011, p.62).

\subsubsection{Common problems in practice of teaching entrepreneurship}

After the initial period of recognition of entrepreneurship education and introducing it into university curricula, which mainly took place in last two decades, now more efforts are given to ensuring an access to and high quality of entrepreneurship education. The idea is to enable all students, regardless of their university background and level of studies, be exposed to entrepreneurship education. This goes together with moving entrepreneurship from an extra-curricular course to general courses. In turn, accessible and high quality entrepreneurship education generates more entrepreneurial society members, increases employment and encourages innovation and creativity. Students and graduates, who have experienced entrepreneurship education, are carriers of entrepreneurial identity throughout their lives. However, despite an unquestionable progress in implementing effective entrepreneurship education, some problems might be identified. Below problems are particularly adequate for environments that do not have much experience in entrepreneurship education.

General problems:

$\checkmark$ Limitations in understanding the role of entrepreneurship education are related to associating entrepreneurship only with the context of business, whereas entrepreneurship education means using knowledge, skills and competences in a vast range of contexts and situations. Moreover, entrepreneurship still happens to be perceived as a part of business or management education whereas it is a key competence for all students not only those studying business, management or economics. Interesting results might be achieved if students of different backgrounds, including arts, 
humanities, or engineering, form one team and work together on venture formation.

Separation of research and education. Entrepreneurship education is a specific academic discipline drawing from both fields of entrepreneurship and education. However, entrepreneurship teachers happen not to be researchers in the field. Lack of engagement in entrepreneurship education research and not following pedagogical advancements, result in substantially lower quality of entrepreneurship education.

Also, some university programs are not based on entrepreneurship research findings. For teachers, this means allocating their time to many research areas, which decreases the quality of their research and teaching. Some of the publications in this field are written in local languages and in national journals. There is a strong need to progress research for advancing entrepreneurship education, particularly in methodology.

$>$ Traditional understanding of the entrepreneurial learning process. The idea of entrepreneurship education is about creating commitment to learning, as well as acting and thinking in an entrepreneurial way. This needs a development of a strong students' learning culture. By immersing in an entrepreneurial culture, students gain numerous and extensive experiences through entrepreneurial processes. Learning process is centred around personal shift (in frames of references, points of views, assumptions, patterns of behaviour) and making meaning of the learners' lives (sense-making concept). In the context of entrepreneurship education, this means developing an entrepreneurial mind-set and creating or renewing self-perception of being an entrepreneur. The concept of entrepreneurial transformative learning is emerging in the field and has the potential to be developed together with more constructivist approach to entrepreneurship (Krueger, 2007; Krueger, 2009). They both focus on structuring an entrepreneurial learning process with its dynamics rather than on specific structures and both see the learner as the initiator of entrepreneurial process in a relational context. Entrepreneurship education is in need of permanent renewal. In some countries still, a rather transmission approach dominates in entrepreneurship education. Thus learning is mostly dependent on and governed by the teacher. In practice, it means providing traditional lectures where students' contribution is very passive and the learning outcomes are evaluated according to memorization skills. 
$\checkmark$ Missing components. What is often missing is an emphasis on entrepreneurship as a driver towards active citizenship and democratic empowerment. This approach to entrepreneurship cannot be found in many universities. Also social and sustainable entrepreneurship is not included or treated very marginally in entrepreneurship courses curricula. Inclusion of these themes helps to teach students that outcomes and impacts of their actions belong to whole community or society they live in. Entrepreneurship is connected to creation, innovation, creativeness, and problem solving. These are universal values, which contribute to sustainable socio-economic development of nations, are desired in society and ensure long-term integration and cooperation of regions.

In developing countries, where entrepreneurship education is not advanced and founds limited, the problems may also refer to:

$\checkmark$ Scarce and dispersed teaching resources. At some universities the problems with entrepreneurship education are the result of lack of a sufficient number of qualified teaching staff. Academics do not have much experience in teaching entrepreneurship as they usually were not trained in entrepreneurship and do not have many international experiences which could enrich their teaching practices. Very often entrepreneurship educators have research interests other than entrepreneurship and entrepreneurship education. They are obliged to give entrepreneurship courses to fulfil their teaching hours. In some countries, weak mobility of teaching staff (in and outside the country) often results in replication of obsolete teaching methods and lack of entrepreneurship research centres does not bring any advancements in entrepreneurship education.

$\checkmark$ Need of professional development program. Teaching staff does not receive appropriate training to deliver entrepreneurship education. In some environments there is no tradition of conducting regular research seminars with invited guests from outside the university or making career development plans with academic staff. As a consequence, teachers and researchers do not have many opportunities to enter inter- and cross-disciplinary collaborations with peers from other regions and countries. Research groups or consortia between different research and education institutions are not flourishing. 


\subsection{Learning process as a core of entrepreneurial processes and entrepreneurship education}

\subsubsection{The characteristics of entrepreneurial learning process}

\section{Process of learning and entrepreneurship}

The late 1980 os and 1990 os brought an interest in understanding entrepreneurship as a process. This new orientation was a consequence of starting to regard entrepreneurship more as a management field than the one deriving from economics. Entrepreneurship began to be understood as a creation of new ventures, organizations, goods or services and the process of emergence. The research efforts focused on reconstructing venture creation process that has been characterized as complex, multi-phased, multidimensional, evolutionary and comprising conceptualization and execution. More recently, the entrepreneurial process started to be identified with and related to learning process, both on individual and collective level (organizational learning, team learning). In this vein, learning exists within entrepreneurship (Corbett, 2005; Politis, 2005). This approach resulted in the concept of entrepreneurial learning and the idea that entrepreneurs learn to act and think in entrepreneurial way. In entrepreneurship context learning may be regarded an enacted practice of gaining and applying entrepreneurial knowledge and skills. As Higgins et al. (2013) notice, entrepreneurs are engaged in a process of questioning their ideas and assumptions, they look for alternative solutions by being involved in social interactions and the micro-practices of knowledge. Similarly, Rae and Carswell (2001, p. 221) define entrepreneurial learning as a problem solving process centered on the acquisition, storage and use of entrepreneurial knowledge in long term memory (Rae and Carswell, 2001, p. 221). It is composed of the intrinsic human processes of how people develop entrepreneurial capabilities and practices (Rae, 2000, p.145). Such an understanding of entrepreneurship education influenced both entrepreneurship and entrepreneurship education fields. However, entrepreneurship still has not been investigated enough from the perspective of learning process. Entrepreneurial learning has become a new area of study, deriving from the intersection of entrepreneurship and education. It became mainstreamed field in the first decade of 21st century, especially after the special issue on entrepreneurial learning and knowledge published by Entrepreneurship: theory \& practice journal in 2005. Some papers included in this issue indicated that entrepreneurial learning is experiential in its nature. Learning started to be understood as a process of changes in human behaviour and understanding of the world, being result of collecting experiences. 
The understanding of entrepreneurship as a learning process has some consequences. Taking entrepreneurial learning lenses, entrepreneurship is a never-ending process. It is a process of becoming entrepreneurial, which is facilitated by the number and quality of entrepreneurial experiences. It means accepting that entrepreneurship does not have clear borders. As Cope (2005, p. 374) writes: Rather than trying to define "who an entrepreneur is," it is argued that it is more productive to view entrepreneurship as a contextual process of "becoming". Also, assuming that entrepreneurship involves learning process leads to conclusion that both successes and failures are important in entrepreneurship, as both generate learning. It does not make sense, therefore, to research only successful entrepreneurs.

\section{Distinctiveness of entrepreneurial learning}

In entrepreneurship and entrepreneurship education context learning has at least double connotation. The learning process enables entrepreneurs to turn their ideas into business and develop them as entrepreneurs. However, it also means part of entrepreneurship education where learners through process of entrepreneurial learning become more entrepreneurial individuals or even aspiring entrepreneurs. The first meaning of entrepreneurial learning relates to entrepreneurs and it takes place throughout their professional lives; whereas the second relates to entrepreneurs to be or individuals who aspire to become more entrepreneurial. The first connotation of entrepreneurial learning belongs more to entrepreneurship field, whereas the second more to entrepreneurship education. In the first case entrepreneurial learning is part of entrepreneurial process and becomes a method to exploit high quality entrepreneurial opportunities. In this sense, entrepreneurship might be regarded as a learning process, which requires a theory of learning (Minniti and Baygrave, 2001). In the second case entrepreneurial learning is an aim per se, as its sense is to make learners more entrepreneurial. Although in each of these two cases the recipients are different, the process of entrepreneurial learning in both senses ends up with generating entrepreneurial knowledge and concerns developing entrepreneurial identity. In some way, and to some extent, entrepreneurial learning executed by entrepreneurs might be a general indicator for entrepreneurial learning realized through education. Instead, entrepreneurship education may facilitate any entrepreneurial processes. If the research finds an answer to the question how entrepreneurial learning takes place, it will allow to answer the next question on how to teach this process.

\section{Types of learning}

Corbett (2005), after Greeno et al. (1996), distinguishes and describes three types of learning: behavioural, cognitive and situative 
(see Table 1.6). The researcher considers experiential learning as both cognitive and situative as learners by using their cognitive abilities transform their experiences (which are situative) into new knowledge. Corbett (2005, p. 482) gives a convincing argument why behavioural learning is not adequate for entrepreneurship and even calls behavioural theories as antithesis of entrepreneurship: Behavioral theories may prove quite useful when an organization is trying to attain operational excellence in its processes or manufacturing. However, theories of this ilk reward those that follow the routine and status quo; these theories explain well the activities in organized and defined environments with clear goals, feedback, and reinforcement. This is the antithesis of entrepreneurship.

\begin{tabular}{|c|c|c|c|}
\hline & Behavioural learning & Cognitive learning & $\begin{array}{l}\text { Situative learning } \\
\text { (social learning) }\end{array}$ \\
\hline Task & $\begin{array}{l}\text { Behavioural learning } \\
\text { involves learning to } \\
\text { make associations and } \\
\text { learning new skills. }\end{array}$ & $\begin{array}{l}\text { Cognitive learning } \\
\text { involves the tasks of } \\
\text { reasoning, problem } \\
\text { solving, and planning. } \\
\text { It often involves } \\
\text { reorganization of } \\
\text { concepts already } \\
\text { in the individuals' } \\
\text { understanding. }\end{array}$ & $\begin{array}{l}\text { Situative learning } \\
\text { occurs through the } \\
\text { active participation } \\
\text { in group activities. } \\
\text { Learning is the } \\
\text { strengthening of those } \\
\text { practices through } \\
\text { interaction with others. }\end{array}$ \\
\hline Environment & $\begin{array}{l}\text { Behavioural learning } \\
\text { works best in an } \\
\text { environment that is } \\
\text { well organized and one } \\
\text { where there is a routine } \\
\text { to follow. }\end{array}$ & $\begin{array}{l}\text { Cognitive learning } \\
\text { works best in } \\
\text { an environment } \\
\text { that fosters an } \\
\text { understanding of } \\
\text { concepts and principles, } \\
\text { and one that makes } \\
\text { use of reasoning and } \\
\text { problem solving skills. }\end{array}$ & $\begin{array}{l}\text { Situative learning } \\
\text { occurs in an } \\
\text { environment when } \\
\text { individuals participate } \\
\text { with others in social/ } \\
\text { group settings to foster } \\
\text { confidence in their } \\
\text { learning. }\end{array}$ \\
\hline Note & $\begin{array}{l}\text { Behavioural learning } \\
\text { includes clear goals, } \\
\text { feedback, and } \\
\text { reinforcement. }\end{array}$ & $\begin{array}{l}\text { Cognitive learning } \\
\text { is an active process } \\
\text { of construction } \\
\text { rather than a passive } \\
\text { assimilation of } \\
\text { information or rote } \\
\text { memorization. Ability } \\
\text { grows out of intellectual } \\
\text { activity not absorption. }\end{array}$ & $\begin{array}{l}\text { Learning often occurs } \\
\text { from people of different } \\
\text { social or cultural } \\
\text { backgrounds. }\end{array}$ \\
\hline
\end{tabular}

Table 1.6. Three types of learning Source: Corbett (2005). 


\section{Entrepreneurial learning from the cognitive perspective}

Studies on entrepreneurial learning are closely connected with the development of cognitive approach in psychology. As Krueger (2003, p. 105) writes: Understanding entrepreneurial cognition is imperative to understanding the essence of entrepreneurship, how it emerges and evolves... Research into entrepreneurial cognition offers a way to bring the entrepreneur back into entrepreneurship. In similar vein, Corbett (2005) explains that: The cognitive body of research contributes to our understanding of entrepreneurship by helping to explain how each individual's mental makeup is related to his or her ability to identify and exploit an entrepreneurial opportunity. Other researchers sharing cognitive approach in their studies on entrepreneurships are for example Robert Baron, Connie Marie Gaglio, Jerome A. Katz, Ronald K. Mitchell or Lowell W. Busenitz.

From the cognitive perspective, an entrepreneur is an individual who makes decisions due to accumulated earlier knowledge and mental structures enabling its adequate usage while making judgments leading to exploiting entrepreneurial opportunities. The use of knowledge means putting acquired earlier information into purposeful action and mental structures include for example heuristics or expert scripts. In cognition approach the research interests lays in reconstructing the process by answering how an individual is able to acquire, process and use information in a way that results in venture creation and more enterprising self. In this sense, the basic question is how the entrepreneur constructs and uses the entrepreneurial knowledge. Taking into consideration strong opportunity focus in entrepreneurship, answering this question gives more understanding how individuals learn to see opportunities and make decisions to pursue them (Krueger, 2003).

Being aware of the achievements of cognitive psychology that investigates structures and cognitive processes enables better understanding of the individual entrepreneurial mechanisms. The means of receiving and perceiving the reality decide on the entrepreneurial action. Cognitive psychology is engaged in discovering how individuals get to know an environment and how they exploit the knowledge resulting from this exploration. Therefore, it describes cognitive mechanisms and the ways individuals discover environment. It characterizes mental processes of how an individual combines and uses information, and how this affects decision-making and consequently entrepreneurial activities.

The cognitive approach emphasizes individualism of entrepreneurial thinking process. It does not seek a collective portrait of personality 
of an entrepreneur. It looks for answers to the question on how entrepreneurs think and why they behave in certain ways (Mitchell et al., 2002). The cognitive approach helps to understand why the reactions of two people to the same event may vary. The entrepreneurial cognition is understood as knowledge structures which individuals use to evaluate or take decisions related to venture creations and their development (Mitchell et al. 2002, p. 97). This approach examines how entrepreneurs link seemingly unrelated information to produce new goods or provide new services.

\subsubsection{Entrepreneurial thinking theories}

The development of cognitive approach and focus on entrepreneurial learning brought an interest to the ways entrepreneurs think and take decisions. The special attention was given to entrepreneurial heuristics and entrepreneurial logic of thinking - bricolage and effectuation.

\section{Heuristics}

According to Baron (1998), what differentiates an entrepreneur from non-entrepreneur is a way of thinking. The entrepreneur uses heuristics, which are mental and subconscious mechanisms of making decisions. These simplified rules of inference allow him or her to make decisions faster and in a more effective way. A different way of thinking of entrepreneurs is not a result of differences in their traits, but rather is the consequence of functioning in situations characterized by a high degree of risk and uncertainties and also dealing with a huge amount of information.

Heuristics in the area of decision-making and judgments became an important issue of cognitive psychology. Individuals rely on mental scripts and heuristics to make sense out of reality (Berglund, 2005). In the context of entrepreneurship heuristics may be helpful in investigating the way entrepreneurial decisions are taken. They are especially informative in conditions of complexity of the reality in which rationality is not always a guiding principle, because the careful and logical attempts to understand the environment might prove non effective and efficient. Such an environment is a typical environment for entrepreneurial actions. The importance of heuristics for entrepreneurs is confirmed by empirical studies. For example, basing on models of irrational decision-making, Busenitz and Barney (1997) prove that entrepreneurs more often than managers use heuristics. 


\section{Effectuation}

The theory of effectuation describes a new logic of thinking and acting by entrepreneurs. It was created by Saras Sarasvathy to help to understand how experienced entrepreneurs make decisions. The theory offers an alternative perspective on the entrepreneurial process, in which the available resources define the purpose of the action, rather than are accumulated according to previously chosen goals. The theory paves the way for the concept of action-bound theory in entrepreneurship.

According to Sarasvathy (2008), there are two different approaches to taking actions, solving problems and making decisions, especially in an uncertain environment. The first one is effectuation and is based on the premise to the extent we can control the future, we do not need to predict it. The future is unpredictable yet controllable. Entrepreneurs create opportunities. They do not begin with a specific goal but with given means and seek to create new ends. The goal appears over time and depends on entrepreneurs' imagination and their relationships with others (Chandler et al., 2007). Entrepreneur is choosing between alternatives taking into consideration the affordability of experimentation and by creating alliances with future customers and suppliers. The second approach is causation and is based on the premise to the extent we can predict the future, we can control it. This approach is rooted in prediction as entrepreneurs start with an effect to be created. Entrepreneurs make rational choices. They evaluate alternatives and choose a solution most suitable for them that is generating the greatest profit. Decisions taken by them concern primarily the resources that can be used to make ventures happen.

From the point of view of entrepreneurship education it is very important to stress that effectuation is a way of thinking and kind of strategy that can be learned. It is pragmatic logic. Sarasvathy offers a method of overcoming the various stages of solving problems, stressing that educators are able to teach it and learners or entrepreneurs can learn it. The process starts by asking learners who they are, what they know and who they know, and then to determine the level of possible losses. At the time of taking entrepreneurial activities learners are encouraged to meet new people who may become shareholders which leads to the creation of new resources and new goals. This starts a new cycle, enriched with these resources, or goals. The result is a new company, products, or new markets. 


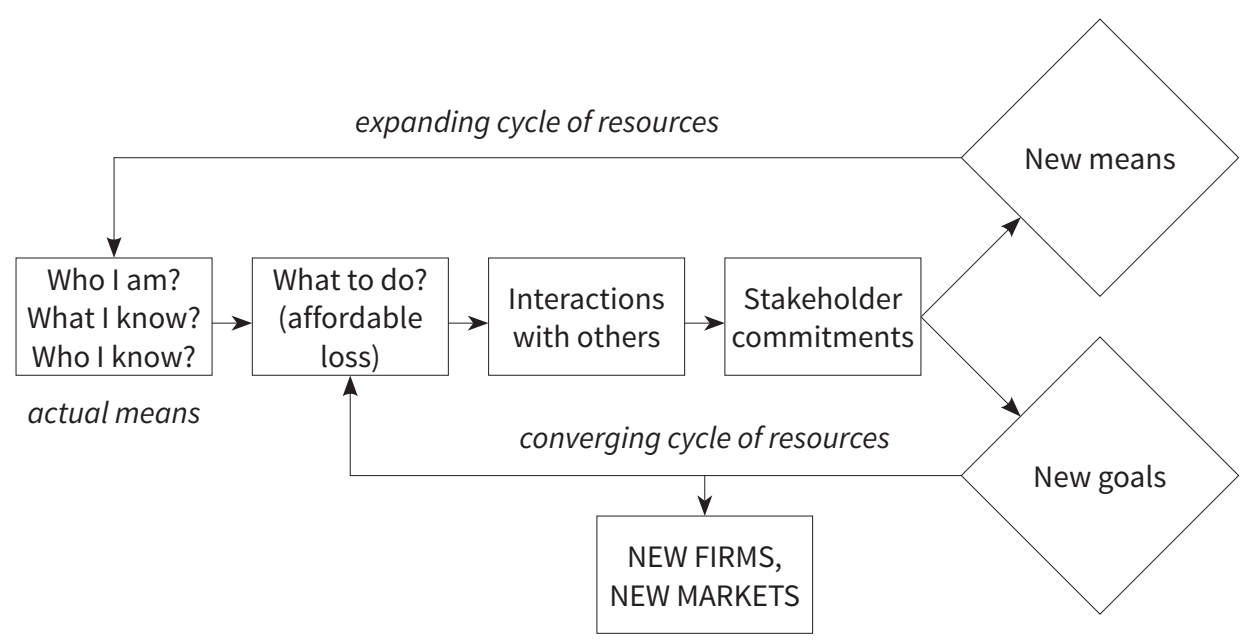

Figure 1.1. Effectuation logic Source: Sarasvathy and Dew (2005).

\section{Bricolage}

The logic of effectuation to some extent is similar to the entrepreneurial bricolage that is an entrepreneurial behaviour of creating something out of nothing or out of very limited resources. Entrepreneurs combine different resources they have at hand to meet their challenges (Baker and Nelson, 2005).

\subsection{Entrepreneurial intentions and opportunities in entrepreneurial learning process}

\section{Entrepreneurship education and entrepreneurial intentions}

The other perspective on entrepreneurial learning may be achieved if entrepreneurial intentions are taken into consideration. The aim of entrepreneurship education is then to induce or strengthen entrepreneurial intentions of learners, as well as to make these intentions more realistic (Krueger, 2009). Since entrepreneurial intentions are so strongly associated with the perception, that is subjectively perceived reality, it is possible to shape and even change them through education. 
Research on entrepreneurship should lead to implications, as its objective is to predict and support the entrepreneurial behaviour. In the context of entrepreneurial intentions, the task of entrepreneurship education is to incite or strengthen entrepreneurial intentions, as well as making them more realistic (Krueger, 2009). Since entrepreneurial intentions are so strongly associated with the perception, it is possible to influence them and even to change them through education.

In practice, there have been many studies trying to link entrepreneurial intentions with education. Moreover, education has also become one of the determinants affecting the level of entrepreneurial intentions. For example, Lena and Wong (2003) in their studies focused on the relationship between new business ventures and attitude to entrepreneurship education. After investigating 1,500 students they found that the more positive attitude towards entrepreneurship education, the more business ventures appear in the future. The study of Rasheed (2000) shows that students who have experienced education in entrepreneurship have a higher motivation to achieve their goals, a stronger sense of self-control, and a stronger sense of self-efficacy. Similarly, Kolvereid and Moen (1997) who studied students from Norwegian business schools emphasize the positive relationship between education in entrepreneurship and entrepreneurial attitude, both in the case of actual business behaviour and intentions. The study of Clark et al. (1984) brings similar results. Although most of the studies stress a positive relationship between entrepreneurship education focused on enhancing entrepreneurial intentions and plans for business start-ups, there are also some studies that indicate the opposite. For example, Oosterbeek et al. (2008) argue that entrepreneurship education programs have a negative impact on entrepreneurial competence and business plans. In case of entrepreneurship education also the cultural context is of great importance. Lee et al. (2005) indicate that in countries with poorly developed entrepreneurial culture, its influence is stronger than in countries in which culture can be regarded as mature.

Entrepreneurship education may affect the intentions directly or indirectly, by influencing the perceived feasibility and perceived willingness (Linan, 2004). It may be assumed therefore, that entrepreneurial intentions are affected by the broadly understood entrepreneurial knowledge. The collection of entrepreneurial knowledge may be the result of learning contents. It may also derive from accumulated experiences. 


\section{Entrepreneurship education and entrepreneurial opportunities}

The other perspective of entrepreneurial learning may be applied if entrepreneurial opportunities are discussed. Certainly there is no one type of entrepreneurial opportunity and one way of identifying them. The entrepreneurial opportunity concept is very capacious and ambiguous. However, the review of the literature on entrepreneurship confirms that opportunities are a key issue in entrepreneurship research and further work on their understanding is justified and desirable. Understanding opportunities and their identification should therefore be transposed to entrepreneurship education. The ideal situation seems to be able to educate how to identify, evaluate and exploit opportunities. This would increase the presence and effectiveness of the entrepreneurship in society and economy. The opportunity concept is in the area of interest of entrepreneurship education. However, the transposition of the opportunities to entrepreneurship education is still poor. This need is articulated by many authors. For example, Kirby (2007) notes that the development of entrepreneurship education requires the development of the competences to recognize opportunity. For Carrier (2007), identification of different types of opportunities is a basic entrepreneurial competence that should be taken into account at the beginning of entrepreneurial education.

There is no clear answer whether it is possible to learn competences necessary to perceive business opportunities. While De Tienne and Chandler (2004) recognize that it is feasible, the study of Saks and Gaglio (2002) indicates the opposite. In-depth interviews conducted by Saks and Gaglio with 14 well-known professors in entrepreneurship led to the conclusion that although learning business opportunites evaluation is possible, learning how to recognize or create them is rather difficult, if not impossible. Despite this fact, almost three quarters of respondents expressed the hope that students actually learn to identify potential business opportunities. Carrier (2005) argues that we should be more creative and put a stronger emphasis on the creation of a business, rather than assessing copied ideas.

The basic assumption in entrepreneurship education is that including individual competencies or skills to entrepreneurial opportunity processes is possible. The question is what kind of competencies should be strengthened through entrepreneurship education. The involvement of individual in entrepreneurial opportunity process may take the form of: systematic and rational searching, exploring the dynamics between cognitive properties of the individual and the outside world, or enacting opportunity. Differences in approaches to entrepreneurial opportunities encourage 
to reflect on the universality of methods and teaching tools. Since individuals are so different, the same stimuli does not work for all. Therefeore, the desired competencies can relate to identifying and formulating problems, making choices between alternatives, being alert to changes in the environment, possessing ability to reflect, and also experiencing the "real" situation in order to understand the mechanisms of own behaviour better (Kyrö et al., 2011).

Refering to the problem of entrepreneurial competence to the typology suggested by Kyrö et al. (2011), there are three types of approaches to opportunities: problem solving-oriented approach, cognitive approach and action-oriented approach.

Individuals with a problem-solving approach should be encouraged to be active and involved in tasks demanding seeking solutions and rational thinking. For this group of individuals, it is important to develop the ability of formulating the problem and following it until its solution. In entrepreneurship education, the most relevant issue seems to be the use of techniques of problem-based learning. A good idea also seems to be learning to write a business plan.

For individuals with cognitive approach to opportunities, interventions aimed at stimulating cognitive mechanisms prove to be the most effective. Awareness of cognitive processes, their potential and limitations, should increase the willingness and readiness of this group of individuals to explore opportunities. In education, the most supportive techniques might be mind mapping and concept mapping, as they help to understand and develop ideas as well as to identify relationships between them.

In the case of action-oriented approach, students should enhance their competences in the field of entrepreneurial opportunities by being exposed to teaching experiments. For them it would be recommended to create the conditions enabling them to participate in a real entrepreneurial process, during which they could implement their own ideas into life.

In order to strengthen the necessary competences, students should be offered a variety of teaching methods taking into consideration whether opportunities are sought, discovered or created. In case of opportunity seeking, learning is causal and learner uses the existing knowledge. He or she applies planning approach, based on the formulation of the problem, and then the consequent search for the solution. In the case of opportunity discovery, learning is active in nature and is based on experience. Knowledge is a result of assimilating information and adapting it to the existing one. In case of creating opportunities, learning process is similar to Sarasvathy's effectuation. Students are engaged in activities, and through their experiences they make further decisions. 
Entrepreneurial opportunities concept dominates in the modern approach to entrepreneurship and as a theoretical concept has a chance to contribute significantly to the progress in entrepreneurship as a research field. For Dutta and Crossan (2005) previous researches on entrepreneurial opportunities are too limited and still a lot remains to be discovered. There are, however, also warnings not to overuse the term. Short et al. (2010) warn that entrepreneurial opportunities should not become a concept that defines everything but does not mean anything and thus loses its meaning.

\subsection{The cognitive, conative and affective constructs in entrepreneurial learning}

Personality and intelligence of the learner consists of three constructs, next to cognitive, also affective and conative one. Koiranen (1999) in defining entrepreneurship refers to the mental constructs, defining it as a cognitive, affective and conative process striving to add value by creation and growth. The original concept of cognitive, affective and conative structure of the mind, determining the personality and intelligence of an individual, derives from the work of Snow et al. (1996).

As Kyrö et al. (2012) explains, conative structure is associated with motivation (desire to succeed), which directs individual's volition. The affective construct concerns the temperament and emotions, and also at a deeper level values and attitudes. Cognitive construct is connected with the processes associated with obtaining and processing information. It is associated with declarative knowledge (how to connect different concepts) and procedural knowledge (application of knowledge).

\section{Affection and entrepreneurship}

Recent research starts to illuminate that emotions play significant role in the opportunity process (Welpe et al., 2011; Foo 2011; Grichnik et al., 2010). All these studies are based on the assumption of interplay between cognition and affection. For example Hayton and Cholakova (2012) claim that affect and cognition are interwoven in an iterative process and through that process entrepreneurs feel, think, and finally act. Affective and cognitive processes come with the arousal of different parts of the brain (Cohen, 2005; Hayton and Cholakova, 2012) but as Baron indicates, their interaction is continuous (Baron, 2008). For Baron (2008) affection 
may influence cognition through its impact on perceptions of the external world, creativity, the tendency to engage in heuristic processing, memory, the cognitive strategies individuals use in coping with intense and persistent stress, interpretations of others' motives. None of the authors however, consider the role of conation in the interplay between affection and cognition.

The need for understanding the role of affection in entrepreneurial processes is strongly articulated by many authors, including Cardon et al. (2005, 2009). However, there is much confusion around affection and emotions concept in entrepreneurship literature. Cardon et al. (2012) regard affection as subjective concept concerning dispositional affect (personality that is more stable), specific emotion (intensive and short term one), and mood (low intensive but lasting, being result of some stimuli). They find emotion and affect semantically equal. Baron (2008) distinguishes between state affect and dispositional (trait) affect. The former is connected with changes in current moods as a result of external events; the latter refers to stable tendencies to experience specific affective reactions, both producing parallel effects in many situations. This corresponds more to Snow's et al. (1996) division of affection into temperament and emotion.

\section{Conation and entrepreneurship}

Entrepreneurship research, drawing for its conceptual understanding on cognitive psychology (Kickul et al., 2009; Palich and Bagby, 1995), often undermines the differences between conation and affection (as meta-analysis of Sitzman et al. (2010) well indicates) or manages to leave affection outside the actual conceptual discussion (Liu, Xu and Weitz, 2011). Motivation in entrepreneurship research is regarded as one of basic characteristics of entrepreneurs and investigated mainly in terms of push or pull factor (Vanevenhoven, 2013). What we know about motivation is that it may influence entrepreneurial process through risk taking, locus of control, self-efficacy, goal setting (Shane et al., 2003) and it usually goes with affection, as like Seo et al. (2004) state understandings of motivation fails if we do not consider human emotions. This interplay has been studied for example in regard of motivational effect of passion (Cardon, 2009) or in context of self-regulation providing linkage through which motivation and emotions integrate (Seo et al., 2004). Despite the fact that entrepreneurship might be regarded as an act of individual volition, the role of volition construct in entrepreneurial process remains unexplored, although the need has been already claimed, for example by Bygrave (2000, 2002). What we know is that motivation seems to influence the volition (Snow et al. 1996). 
Thus, it should be highlighted that not all streams of research follow the conceptual understanding of tripartite personality and intelligence. Most of these studies assume and concentrate only on the interplay between affection and cognition, ignoring conation, and more specifically the role of volition in entrepreneurial processes. Some research also does not differentiate enough between the constructs. For example, in their meta-analysis of the self-assessment of knowledge, Sitzman et al. (2010) regard learner motivation and self-efficacy as affective learning outcomes. This indicates that either affection is used as a synonym for conation or then it subsumes both conation and affection.

\section{Personality and intelligence constructs and learning process}

The discussed constructs are present during learning process. They are all valuable as they guide our willingness and interest to learn (Kyrö, 2008). However, they are not often studied and even if they are not studied simultaneously. Especially affection construct is ignored in learning models. Ruohotie and Koiranen (2000) claim that in entrepreneurial education, be it formally planned or taking place in everyday life, the key processes concern motivation and volition that is the conative aspects of learning. However, as already argued by Dewey (1951), emotions are essential factors in learning. Dewey saw man as a living being in interaction with the world and in a confrontation with things. This is how meanings, emotions and interests are born. Gibb likewise underlines how the affective aspects relating to our values and attitudes should take a more explicit place in learning practices (Gibb, 2002). Pittaway and Cope (2007) found that emotional exposure played a major role in creating an environment for effective entrepreneurial learning. For Feys et al. (2011) cognitive and affective processes are needed in self-regulation. Therefore Shrivastava (2010) calls for a more holistic pedagogy that integrates emotional and cognitive learning to be able to change human behaviour.

\section{The directions for future research}

When affection is embedded in all situations and each individual has his/her own temperament, this leads us to an assumption that there are individual differences in the interplay between cognitive, conative and affective aspects in the learning process. This follows a stream of research emphasizing students' differences in entrepreneurship education as identified by Bechard and Gregoire (2005) in their meta-analyses of entrepreneurship education research or by Kyrö et al. (2011) concerning students' different approaches to opportunity 
process. This assumption, too, gains empirical support from recent research by Kickul et al. (2009) on differential models of cognitive style on entrepreneurial self-efficacy and the new venture creation process. Thus we can assume that affective, conative and cognitive processes interact in the entrepreneurial learning process, yet there is little evidence of how this interplay takes place. 


\section{Chapter II \\ The foundations of \\ experience-based learning \\ and education}

Education is found in life-experience.

John Dewey (1946, p. 53).

\section{Introduction}

Experience is something that happens to individuals and, in vein of empiricism, is a source of some knowledge to individuals. This makes experience a desirable concept in education. However, seeing education from the experience-based perspective is rendered difficult, as the notion of experience is itself problematic and it is not a self-explanatory concept. Experience is both a philosophical and psychological construct but also everyday practice that happens to all people.

As a consequence, there are many perspectives the concept of experience may be investigated from, like: philosophical, aesthetic, political, cultural, social or historical. This chapter of the monograph provides a general overview of experience-based education and experiential learning from the perspective of philosophy, psychology, pedagogy and educational studies. The purpose is to revisit and synthetize the meaning of experience for learning processes, in order to relate it to entrepreneurship education in the next chapter.

The philosophical foundations of experience-based learning and education have been analysed from historical perspective in two time lines: from Ancient Greece up to $2 \mathrm{O}^{\text {th }}$ century and in $2 \mathrm{O}^{\text {th }}$ century that is mainly in form of American pragmatism and Dewey's concept of experience and experience-based education. The historic review starts from Plato and Aristotle. In the next centuries, experience started to appear in works of other philosophers: Locke, Rousseau, Hegel, Kant or Deleuze. However, until the late $2 \mathrm{o}^{\text {th }}$ century, experience was never in the center of interest of education. This has changed together with American 
pragmatism and progressive education movement in USA, especially after popularisation of the concept of experience-based education initiated by Dewey.

Experience appears also in psychology. The psychological foundations of experience-based learning and education are built on behaviouristic idea of learning from consequences (Thorndike, Skinner), cognitive development through experience (Piaget), cognitive load theory (Sweller), social psychology and experiential learning (Lewin), social learning theory (Bandura), self-regulated learning (Zimmerman). Taking into consideration pedagogy, the works of Freire and his concept of experience-based education have been revisited. Finally, the concept of experience may be found in contemporary education theories. In this chapter the particular attention is put on learning as a cycle and different learning styles (Kolb), action learning (Revans), transformative learning (Mezirow), humanistic approach to learning from experience (Malcolm) and modern constructivism.

The selection of referred philosophers, psychologists or education theorists is arbitrary. They were chosen based on the criterion of contribution to the development of experience-based education and their potential to enrich further discussion on experience-based entrepreneurship education.

\subsection{The philosophical foundations of experience-based learning and education}

\subsubsection{Philosophy of education and experience - historical review from Ancient Greece up to $20^{\text {th }}$ century}

The central role of education and learning in the development of humans as individuals and in the progress of societies does not have to be argued and justified. Some forms of teaching existed from the beginning of human kind and they were systematically formalized, institutionalized and broadly discussed in social, cultural, political, philosophical, economic and historical contexts. In general, there are two basic perspectives through which education may be perceived and analysed. The first one emphasizes the individual and focuses on human development that is intelligence and personality, knowledge, traits, skills and competences. The second sees education as a social process, therefore embeds it in a society or community frame of reference. Both 
perspectives acknowledge the connection between education/learning and life, either of an individual (for personal liberation, pursuing interests, establishing living and its maintenance) or a group (to ensure its continuity and progress). In this sense, life means a continuous learning process, which can be enhanced and enriched through education of any kind, be it formal or informal. In the process of educating the accumulated knowledge is transferred and disseminated between the society's members. Individuals learn though their own and others' experiences. The sense, outcome and value of all learning processes is knowledge creation and usage. Taking it for granted, the question is how to make this process a meaningful and useful passage for the individual and how through creating new knowledge, ensure development of the society? This fundamental question is guiding throughout chapter two and becomes a reference point in further discussions about entrepreneurship education.

The domain of philosophy of education is full of various ideas, concepts or approaches giving some clues how to answer this question. However, due to its abundance, it also lacks enough intellectual cohesion enabling to answer in one and an uncontroversial way. What might not be developed enough in philosophy of education are the rigors of work and the depth of scholarship (Phillips and Siegel, 2013). Majority of philosophers have asked numerous philosophical questions on education and learning. However, as they have represented different traditions and schools, and the field is being developed through the ages, the acknowledgement of what has been achieved so far is hard to reach. The difficulties are also connected with social changes taking place in parallel to the advancement of the domain, but which the domain needs to grasp. Philosophy of education cannot be developed without following society's progress and in separation from its intellectual, cultural and economic standing. The general impression about the field might be that everything has already been discussed and written about but at the same time that nothing is clear enough to provide guidelines how to teach to meet expected outcomes. The applied side of philosophy education still needs more attention and considerations.

Next to the enormous richness of philosophy of education, the challenge is also to accept that its borders are not tight enough. What may confuse is that next to philosophy of education there is also an enormous field of general education, and it is often hard to distinguish between the achievements of educational theorists and philosophers of education. Moreover, many socially engaged intellectuals and reformers, who are difficult to categorize to any of these two groups, also 
raised the problems of education. As Phillips and Siegel (2013) notice, the understanding of education was greatly influenced by developments of many intellectual trends, like for example: Marxism, psycho-analysis, existentialism, phenomenology, positivism, post-modernism, pragmatism, neo-liberalism, feminism, or analytic philosophy. The overall field of education is also very vast and mingled. When trying to make a systematic review of any educational concept, the solution is to swing between domains of education and philosophy of education and to choose threads according to preselected criteria and research needs. As it was argued in the Introduction of the monograph, the idea of this chapter is to learn about the role and the meaning of experience in education, not to systematize the field of philosophy of education or general education. Therefore, from the beginning the intention is to filter the domain of philosophy of education and select those philosophers and thoughts that directly tackled with or might be adapted into experience-based education and experiential learning.

Historically, the challenge of a sound education, its meaning, sense, occurrence, objectives and methods have been a topic of many philosophical debates. First philosophies of learning emerged in ancient Greece. It is assumed that one of the earliest philosophical discussions on education was initiated by Plato and included in his The Republic (especially Book III) 380 BC. In this great writing Plato distinguished two types of educations and two types of educational methods, one suitable for warrior guardians (more moral oriented, teaching obedience and courage, including music and gymnastics) and one for kings and philosophers (enhancing philosophical disposition and strengthening characters, including mathematics and dialectics). The Republic includes also the famous cave analogy, which is known as the Platonian theory of knowledge. The chained prisoners in the dark cave see only shadows of the objects behind them illuminated by fire. They are isolated from the real world, they cannot experience it and instead create their own one. Using Plato's words, The shadows of artifacts constitute the only reality people in this situation would recognize (515 $\mathrm{C} 1-2)$.

As humans, we cannot be similar to the prisoners and possess only very limited knowledge of the reality around us as by doing it, we make false assumptions about its sense and logic. Therefore, we need to try to gain an access to the reality by experiencing, reasoning and accumulating knowledge, that is by learning. Plato, being an idealist and rationalist, believed that knowledge about the world could be gained through self-reflection contemplation and own judgments. 
Aristotle who represented a very humanistic approach to education and propagated intellectual development of individuals also highlighted the importance of education and learning. He was distinguishing between two polar types of knowledge: theoretical (episteme) and experienced (empeira) one, although including also techne knowledge as an arch between these two and being understood as the knowledge gained through experiencing accompanied with reasoning. His famous division of knowledge to theoretical, practical and technical has had the long-standing consequences on understanding of differences between disciplines and brought the concept of experience into the light. Although Aristotle might be regarded as a father of "learning by doing" concept in education (as he believed in role of habits in learning), his understanding of experience (he used the term praxis which will be explained further in the monograph) was not limited to physical actions. He believed that the habits should be accompanied by reasoning thus proper attention and reflection.

Up to the end of $19^{\text {th }}$ century, only few great philosophers like: Locke, Rousseau, Hegel or Kant, gave broader attention to the issue of experience in education. However, none of them made experience a key concept around which more sophisticated theory was built.

During the Enlightenment, John Locke with his famous tabula rasa concept developed in the Essay Concerning Human Understanding (1690) was an advocate of great value of experiences in human life. In this essay (Book II, Chapter 1) Locke writes: Let us then suppose the mind to be, as we say, white paper, void of all characters, without any ideas: How comes it to be furnished? Whence comes it by that vast store which the busy and boundless fancy of man has painted on it with an almost endless variety? Whence has it all the materials of reason and knowledge? To this I answer, in one word, from EXPERIENCE. In that all our knowledge is founded; and from that it ultimately derives itself.

As he explains in Some Thoughts Concerning Education (1693), education has a great role in shaping humans. It fills "empty mind" with experiences that in turn form the mind. Locke believed that a child's mind is developed by experiences, however, mainly deriving from the outside world. Knowledge arises from accumulating experiences and questioning them. In this way, exposition to many various experiences ensures an individual development.

The $18^{\text {th }}$ century brought much more interest in philosophy of education and pedagogy. Jean-Jacques Rousseau in his pedagogic treatise Émile, ou De l'éducation (1762) included reflections on nature of education in the context of individual-society dimension and provided some instructions how to educate a child to be a good citizen. He 
created the principles of natural education (learning comes naturally with growth and development of a person) and described one of the first systems of education. He was distinguishing two types of education (giving to both essential role): public and individual one. He was also highlighting an important role of environment for education and stressing the individual character of learning and its dynamic character. Rousseau was clearly noticing the merits of experience and the need of individual reflection. According to him a child learns through experiencing, so the obligation of adults is to provide various experiences to him or her. Without accumulating experiences a child cannot grow and reach a higher intellectual level. In the treatise Rousseau writes: ... the real order of experience begins by setting up a light, and then shows the road by it, commencing with a regulated and digested, not a misplaced and vague course of experiment, and thence deducing axioms, and from these axioms new experiments. (p. 25).

Importantly, for Rousseau gaining experiences should not be a blind trial and error practice but a conscious and systematic process enabling a passage from one valuable experience to the next one.

In Germany later Enlightenment era brought Hegel's contribution to the domain of philosophy of education, although education was not of primary interest for this prominent thinker. His input to education was connected with the concept of Bildung, that is a concept of self-development of mind or spirit (Geist) that occurs through experience and is perceived as a social and historical process (Wood, 1998). For Hegel, experiences are processes rooted in conflicts through which individuals discover consciously their identity and selfhood (Wood, 1998) and learning is experiential in its nature. Education is connected with morality and ethics and is rather regarded as labour than a natural process of evolving (Lilge, 1974). Similar to Aristotle, Hegel believed that education makes humans ethical. However, he was noticing that although experiences give individuals a better understanding of the world, they never bring complete and perfect knowledge about it.

In $18^{\text {th }}$ century, which is often described as the age of pedagogy, another very influential philosopher shared his ideas about education. Immanuel Kant in his famous Über Pädagogik (1803/190o) stated the views on education and pedagogy. For him education foremost teaches character of a man and teaching morality is an important element of educating process. In all his writings Kant prioritizes knowledge. He refers knowledge to experience in a new way. In his Critique of Pure Reason (1781) he states: All our knowledge falls with the bounds of experience. However, although for Kant experience may be a source of 
knowledge, knowledge exists before experience. He argues that an idea is nothing other than the concept of a perfection which has not as yet been experienced (1900, Introduction). If the concepts and institutions would be the same as ideas about them, there would be no place for experience: experience would never have existed at all, if at the proper time, those institutions had been established in accordance with ideas. Kant asserts that experiences are determined and structured by minds. In this sense, experiences of humans have some common basic characteristics.

All these prominent personas of philosophy: Plato, Aristotle, Locke, Rousseau, Hegel, Kant included to some extent the concept of experience into their philosophies of education. Although they represent different times and philosophical traditions, even contradictory in their fundaments, they all see the value of experience and experiencing which is not merely reduced to acting but is realized through activating reason and thinking.

Following the chronological order, American pragmatists were next who dealt with the issue of education and experiences. Contrary to predecessors, for these philosophers the concept of experience became a central point of deliberation. The monograph gives priority to late $19^{\text {th }}$ main and $2 \mathrm{O}^{\text {th }}$ century contribution to the understanding of education as during this time experience concept has received central consideration. Therefore, in the next subchapter the attention is given to American pragmatism and its most prominent representative John Dewey.

The role of experience is also appreciated by the later neorealist philosopher Gilles Deleuze, for whom knowledge is a dynamic process of inquiry that is broadened by experiencing and practicing (Semetsky, 2009). Experiences equip individuals with capacities to affect and be affected (Semetsky, 2009). Moreover, experiences are public, not private. For the learning and education to be valuable and effective, experience needs to embed three criteria of critical, clinical, and creative (Semetsky, 2010).

Before moving to American pragmatism and the pragmatist conception of experience, one more issue should be noted. The relation between philosophy of education and the practice of teaching has not always been recognized. There are some attempts to categorize the teaching into five main streams, which are: perennialism, idealism, realism, experimentalism, and existentialism. The basic characteristics of all these streams are included in Table 2.1. However, these are teaching philosophies, not philosophies of education. These two should not be confused. 


\begin{tabular}{|c|c|c|c|c|c|}
\hline & $\begin{array}{l}\text { Perennial- } \\
\text { ism }\end{array}$ & Idealism & Realism & $\begin{array}{l}\text { Experimen- } \\
\text { talism }\end{array}$ & $\begin{array}{l}\text { Existential- } \\
\text { ism }\end{array}$ \\
\hline $\begin{array}{l}\text { Reality } \\
\text { (Ontology) }\end{array}$ & $\begin{array}{l}\text { A world of } \\
\text { reason and } \\
\text { God }\end{array}$ & $\begin{array}{l}\text { A world } \\
\text { of mind }\end{array}$ & $\begin{array}{l}\text { A world } \\
\text { of things }\end{array}$ & $\begin{array}{l}\text { A world } \\
\text { of experience }\end{array}$ & $\begin{array}{l}\text { A world of ex- } \\
\text { isting }\end{array}$ \\
\hline $\begin{array}{l}\text { Truth of } \\
\text { knowledge } \\
\text { - epistemol- } \\
\text { ogy }\end{array}$ & $\begin{array}{l}\text { Reason and } \\
\text { revelation }\end{array}$ & $\begin{array}{l}\text { Consistency } \\
\text { of ideas }\end{array}$ & $\begin{array}{l}\text { Correspond- } \\
\text { ence and } \\
\text { sensation }\end{array}$ & $\begin{array}{l}\text { What works, } \\
\text { what is }\end{array}$ & $\begin{array}{l}\text { Personal } \\
\text { subjective } \\
\text { choice }\end{array}$ \\
\hline $\begin{array}{l}\text { Goodness } \\
\text { (axiology) }\end{array}$ & Rationality & $\begin{array}{l}\text { Imitation of } \\
\text { ideal self, } \\
\text { person to be } \\
\text { emulated }\end{array}$ & $\begin{array}{l}\text { Laws of } \\
\text { nature }\end{array}$ & $\begin{array}{l}\text { The public } \\
\text { test }\end{array}$ & Freedom \\
\hline $\begin{array}{l}\text { Teaching } \\
\text { reality }\end{array}$ & $\begin{array}{l}\text { Disciplinary } \\
\text { subjects and } \\
\text { doctrine }\end{array}$ & $\begin{array}{l}\text { Subject of } \\
\text { the mind } \\
\text { - literary, } \\
\text { philosophi- } \\
\text { cal, religious }\end{array}$ & $\begin{array}{l}\text { Subjects } \\
\text { of physi- } \\
\text { cal world } \\
\text { - math, sci- } \\
\text { ence }\end{array}$ & $\begin{array}{l}\text { Subject mat- } \\
\text { ter of social } \\
\text { experience } \\
\text { - social stud- } \\
\text { ies }\end{array}$ & $\begin{array}{l}\text { Subject mat- } \\
\text { ter of choice } \\
\text { - art, ethics, } \\
\text { philosophy }\end{array}$ \\
\hline $\begin{array}{l}\text { Teaching } \\
\text { truth }\end{array}$ & $\begin{array}{l}\text { Discipline of } \\
\text { the mind via } \\
\text { drill }\end{array}$ & $\begin{array}{l}\text { Teaching } \\
\text { ideas via } \\
\text { lecture, dis- } \\
\text { cussions }\end{array}$ & $\begin{array}{l}\text { Teaching for } \\
\text { mastery of } \\
\text { information } \\
\text { - demon- } \\
\text { strate, recite }\end{array}$ & $\begin{array}{l}\text { Problem } \\
\text { solving, } \\
\text { project } \\
\text { method }\end{array}$ & $\begin{array}{l}\text { Arousing } \\
\text { personal } \\
\text { responses } \\
\text { - questioning }\end{array}$ \\
\hline $\begin{array}{l}\text { Teaching } \\
\text { goodness } \\
\text { (values) }\end{array}$ & $\begin{array}{l}\text { Disciplining } \\
\text { behaviour } \\
\text { (to reason) }\end{array}$ & $\begin{array}{l}\text { Imitating } \\
\text { heroes } \\
\text { and other } \\
\text { exemplars }\end{array}$ & $\begin{array}{l}\text { Training in } \\
\text { rules of con- } \\
\text { duct }\end{array}$ & $\begin{array}{l}\text { Making } \\
\text { group deci- } \\
\text { sions in light } \\
\text { of conse- } \\
\text { quences }\end{array}$ & $\begin{array}{l}\text { Awakening } \\
\text { self to re- } \\
\text { sponsibility }\end{array}$ \\
\hline $\begin{array}{l}\text { Why schools } \\
\text { exist }\end{array}$ & $\begin{array}{l}\text { To reveal } \\
\text { reason and } \\
\text { God's will }\end{array}$ & $\begin{array}{l}\text { To sharpen } \\
\text { the mind and } \\
\text { intellectual } \\
\text { processes }\end{array}$ & $\begin{array}{l}\text { To reveal the } \\
\text { order of the } \\
\text { world and } \\
\text { universe }\end{array}$ & $\begin{array}{l}\text { To discover } \\
\text { and expand } \\
\text { the society } \\
\text { we live in to } \\
\text { share experi- } \\
\text { ences }\end{array}$ & $\begin{array}{l}\text { To aid learn- } \\
\text { er to know } \\
\text { themselves } \\
\text { and their } \\
\text { place in so- } \\
\text { ciety }\end{array}$ \\
\hline $\begin{array}{l}\text { What should } \\
\text { be taught }\end{array}$ & $\begin{array}{l}\text { Eternal } \\
\text { truths }\end{array}$ & $\begin{array}{l}\text { Wisdom of } \\
\text { the ages }\end{array}$ & $\begin{array}{l}\text { Laws of phys- } \\
\text { ical reality }\end{array}$ & $\begin{array}{l}\text { Group inquiry } \\
\text { into social } \\
\text { problems and } \\
\text { social scienc- } \\
\text { es, method } \\
\text { and subject } \\
\text { together }\end{array}$ & $\begin{array}{l}\text { Unregiment- } \\
\text { ed topic } \\
\text { areas }\end{array}$ \\
\hline $\begin{array}{l}\text { Role of the } \\
\text { teacher }\end{array}$ & $\begin{array}{l}\text { Interprets, } \\
\text { tells }\end{array}$ & $\begin{array}{l}\text { Reports, } \\
\text { person to be } \\
\text { emulated }\end{array}$ & $\begin{array}{l}\text { Displays, } \\
\text { imparts } \\
\text { knowledge }\end{array}$ & $\begin{array}{l}\text { Aids, } \\
\text { consultant }\end{array}$ & $\begin{array}{l}\text { Questions, } \\
\text { assists stu- } \\
\text { dent in per- } \\
\text { sonal journey }\end{array}$ \\
\hline
\end{tabular}




\begin{tabular}{|l|l|l|l|l|l|}
\cline { 2 - 6 } \multicolumn{1}{c|}{} & $\begin{array}{c}\text { Perennial- } \\
\text { ism }\end{array}$ & Idealism & Realism & $\begin{array}{l}\text { Experimen- } \\
\text { talism }\end{array}$ & $\begin{array}{l}\text { Existential- } \\
\text { ism }\end{array}$ \\
\hline $\begin{array}{l}\text { Role of the } \\
\text { student }\end{array}$ & $\begin{array}{l}\text { Passive re- } \\
\text { ception }\end{array}$ & $\begin{array}{l}\text { Receives, } \\
\text { memorizes }\end{array}$ & $\begin{array}{l}\text { Manipulates, } \\
\text { passive par- } \\
\text { ticipation }\end{array}$ & $\begin{array}{l}\text { Active par- } \\
\text { ticipation, } \\
\text { contributes }\end{array}$ & $\begin{array}{l}\text { Determines } \\
\text { own rule }\end{array}$ \\
\hline $\begin{array}{l}\text { School's } \\
\text { attitude to- } \\
\text { ward change }\end{array}$ & $\begin{array}{l}\text { Truth is eter- } \\
\text { nal, no real } \\
\text { change }\end{array}$ & $\begin{array}{l}\text { Truth to be } \\
\text { preserved, } \\
\text { antichange }\end{array}$ & $\begin{array}{l}\text { Always com- } \\
\text { ing toward } \\
\text { perfection, } \\
\text { orderly } \\
\text { change }\end{array}$ & $\begin{array}{l}\text { Change is } \\
\text { ever-present, } \\
\text { process }\end{array}$ & $\begin{array}{l}\text { Change is } \\
\text { necessary at } \\
\text { all times }\end{array}$ \\
\hline
\end{tabular}

Table 2.1. Five basic teaching philosophies Source: Van Cleve and Young (1976).

\subsection{2. $20^{\text {th }}$ century: American pragmatism and Dewey's concept of experience and experience-based education}

Pragmatism was a philosophical movement initiated in USA around the year 1870. The most characteristic feature of this tradition is a strong practice orientation and striving for truth by a method of thinking that clarifies concepts and hypotheses (through scientific inquiry). Pragmatism is then both a theory of truth and a method to reach it.

Pragmatism, also known under the name of instrumentalism, is connected with activity. Ideas are born out of human actions (being active) and individuals learn by doing. Practice and the utility of the consequences are criteria for truth. The truth is action, as it has to be checked for practical consequences in order to be valuable. The ideas are true as long as they bring some value to our lives. One of the first writing on pragmatism was an article of Charles Sanders Peirce titled How to Make Our Ideas Clear (1878). The basic and most famous explanation of the novelty of the approach and its logic is included in a series of lectures on pragmatism Pragmatism: A New Name for an Old way of Thinking published by William James in 1907. James equipped pragmatism with a special mission to reconcile previous contrasting philosophies of tough empiricists basing on facts and dogmatic idealists believing in human values. In this sense, pragmatism is a method that allows perceiving science, morality and religion as not competing ones. Free will and determinism do not have to bring opposing practical consequences (Hookway, 2013). Clarifications of concepts and hypothesis take place by determining their practical consequences. Pragmatism turns down the dualism of epistemology and metaphysics to accept more naturalistic view of knowledge. This knowledge 
derives from an active interaction and adjustment between organisms and their environment. The reality has to be experienced by the learner.

In this light, it is clear that what is distinctive for the pragmatism is the conception of experience. Referring pragmatic concept of experience to education, the essence of experiential education has its intellectual roots in progressive educational movement in USA. Pragmatism and a pragmatic approach to education were developed by John Dewey, regarded as one of the most important philosophers in modern history of USA. After the 1930 s pragmatism has started to be ousted by analytical philosophy but it came back to the scene in the 7os and was further developed by Richard Rorty or Hilary Putnam and received back a lot of recognition and appreciation (Hookway, 2013).

\section{Experience and education - John Dewey}

Grounding experiential education in pragmatism entitles to refer to its most seminal representative - John Dewey (1859-1952), one of the most leading figures who shaped the philosophy of pragmatism and instrumentalism, and one of the founders of functional psychology. However, Dewey also, if not above all, provided one of the most compelling and powerful contributions to the development of experience-based education. Dewey very ably matched pragmatism with education and the theory with practice. He developed the concept or the method of pragmatism and incorporated it to education. He believed in the relationship between the cycle of life experiences and the processes of learning. By initiating the progressive education tradition he influenced pedagogy in the $20^{\text {th }}$ century all over the world. His theory of knowledge based on the concept of experiential learning changed how contemporary education is understood and provided.

\section{Progressive education movement}

Progressive educational movement started in USA at the end of $19^{\text {th }}$ century. The term progressive was used in order to differentiate it from the curricula of the $19^{\text {th }}$ century and earlier, which in consequence has started to be regarded as traditional. The movement resulted both in developing the philosophy of experience-based education and introducing actual education reforms. From the outset, progressive education was connected with the ideas of freedom, human development, active participation and democratic society. It was a coherent part of the broad catalogue of changes, which started to take place in order to reconstruct American society at the end of $19^{\text {th }}$ century and to strive for modernity and progress promised by upcoming $2 \mathrm{O}^{\text {th }}$ century. Progressive educators stressed the role of individuality and autonomy of a person, with their own traits, abilities, 
capabilities, skills and ambitions. An interest moved towards individuals' critical but socially engaged intelligence used in taking actions. The cult of individuality, acceptance for differences and consideration of personal characteristics and motives are central to progressive education. However, they need to be accompanied with socially engaged intelligence, developed through exposure to experiences and critical thinking.

For progressive educators learning is a never-ending process, which starts from current experience and leads to new ones. The process is very individual and learner-centred, however at the same time, it is always interrelated with a group (understood at different levels, as a team, community, society), thus is cooperative and collaborative in nature. Learning leads to personal development but also to democratization of society and its growth.

The main claims of progressive education includes the need for:

$\checkmark$ Broad understanding of education as responsible for intellectual and moral development of a learner,

$>$ Attention to learning by doing and "hands on" experiences,

D Active implementation of a purposeful and reflective learning,

$\checkmark$ Community-oriented and engaged citizenship approach to learning,

$\checkmark$ Support for human freedom and emancipation,

$\checkmark$ Enhancing human development in all aspects, also emotional and artistic,

$\checkmark$ Appreciation for diversity and individuality in learning, in opposition to universal and mass learning,

$\checkmark$ Developing intrinsic motivation of learners,

$\rightarrow$ Low standardization of education.

One of the ways to characterise progressive education is to contrast it with a traditional one. When comparing these two traditions of education Dewey (1946, p. 83) made a note: Traditional education tended to ignore the importance of personal impulse and desire as moving springs. But this is no reason why progressive education should identify impulse and desire with purpose and thereby pass lightly over the need for careful observation, for wide range of information, and for judgment if students are to share in the formation of the purposes which activate them.

The important difference between traditional and progressive education is in their time orientation. The progressive education is more oriented on solving actual problems of society whereas traditional education more focuses on the achievements and cultural heritage of previous generations. The first considers the present as a benchmark, whereas the second one tracks back without referring much to the contemporary context. The progressive approach assumes that the reality and all its elements constantly change; therefore the education needs to be dynamic and flexible 
enough to acquaint with the changing world and make the most of opportunities emerging in present life. Only relating to present issues and problems brings interests of learners. They may personally refer and react to the gained knowledge and make sense of it by applying in their lives. Some more differences between pedagogy of traditional and progressive education are included in table 2.2.

\begin{tabular}{|l|l|}
\hline Traditional education & Progressive education \\
\hline Imposition from above & Expression and cultivation of individuality \\
\hline External discipline & Free activity \\
\hline $\begin{array}{l}\text { Learning from textbooks and teachers } \\
\text { (instructors) }\end{array}$ & Learning through experience, varied sources \\
\hline $\begin{array}{l}\text { Acquiring isolated skills and techniques by } \\
\text { drill }\end{array}$ & Acquiring skills as means of attaining ends \\
\hline $\begin{array}{l}\text { Preparation for future } \\
\text { Following achievements and heritage of past } \\
\text { generations }\end{array}$ & $\begin{array}{l}\text { Making the most of the opportunities of } \\
\text { present life }\end{array}$ \\
\hline Static aims and materials & Acquaintance with a changing world \\
\hline
\end{tabular}

Table 2.2. Traditional versus progressive education Source: adapted from Dewey (1946).

What is not that common for a doctrine, the progressive education was put into practice with success. In 1919 the Progressive Education Association was founded with a very ambitious plan to reform school system of the time in USA. For the purpose of being close to practice of progressive education, its leading propagator John Dewey opened the laboratory school in 1896 next to the University of Chicago where he was affiliated on that time. The school was regarded as a scientific "laboratory" where educational innovations and experiments took place, which aimed at starting the revolution in American education system.

Despite many years having passed, the influence of the progressive education movement is still present and fundamental for the contemporary American and worldwide education. Even if not existing in its original and radical form, the pragmatic approach and experience orientation in learning remained a regular element of education.

\section{The prominent role of individual and experience}

The father of progressive educational movement, John Dewey was not only an exceptional educational theorist and reformer, but also great philosopher and psychologist. Deep and numerous discussions on the 
issues of education and experience might be found in most of his writings, among which the most influential are (in a chronological order): My Pedagogic Creed (1897), The School and Society (1900), The Child and the Curriculum (1902), Democracy and Education (1916) and Experience and Education (1946).

For Dewey, both learning and experiencing are life processes connected with human development. He understands experience as an experiment and education as a continuous process of active growing through experiencing. The role of education is to equip the learner with valuable experiences and by doing it enhancing his progressive intellectual growth. The process of an active growing is possible only through collecting meaningful experiences. For Dewey education is a development within, by, and for experience (Dewey, 1946, p. 17). The process starts with finding the material for learning within experience, which is followed by progressive development of previous experiences in order to achieve a fuller and richer and also more organized form, a form that gradually approximates that in which subject-matter is presented to the skilled, mature person (1946, p. 87). Learning is a process of constructing and reconstructing experiences. Education facilitates this process and enables linking theory and practice. Linking education and experiences, Dewey (1946, p. 21) argued that a coherent theory of experience, affording positive direction to selection and organization of appropriate educational methods and materials, is required by the attempt to give new direction to the work of the schools.

Education is a continuous experiment and educative process means growing. However, "growth" per se is not enough. The specification of the direction in which growth takes place and the end towards which it tends to is needed. Dewey makes educators responsible for indicating the direction of learners' growth. He (1946, p. 32) clearly writes that it is the business of the educator to see in what direction an experience is heading.

Dewey combined education and learning processes with social and psychological life. According to him, experiencing does not have to be solely cognitive exercise but an intellectual capacity for a self-development of a learner. Experiences depend on reality and its perception by the learner. Humans interact with the world. Experiences appear as an outcome of interactions between learner, his environment, available resources and impulses. As Dewey (1946, p. 34) writes: Experience does not occur in a vacuum. There are sources outside an individual which give rise to experience.

However, at the same time all genuine experiences change the environment. Change is omnipresent and has to be accepted and coped with. Dewey recognized two sides of experience: active and passive one. Experiences depend on reality but also have their active side which changes 
in some degree the objective conditions under which experiences are had (Dewey, 1946, p. 34).

However, although both sides appear together in one experience, they do not need to be analysed in separation.

Experience does not "go" exclusively to the individual's mind but is shaped by previous experiences. The experience goes on inside an individual to influence the formation of attitudes and purposes (Dewey, 1946). Experiences have to be of personal interest of learners. Learners should feel a natural passion about them and follow unforced engagement. However, at the same time every experience lives on in further experiences. The essence of experience-based education is to select the kind of present experiences that live fruitfully and creatively in subsequent experiences (Dewey, 1946, p. 17).

From the learning perspective, experiences should not be random or accidental. They should include a systematic inquiry or problem solving as these practices enable meaningful learning. Therefore, Dewey proposes a concept of intelligent inquiry, where trial and error method does not cause learning, but where intelligent problem solving is a result of working with means-consequences. What is crucial in experience is its consequences, so what learners take from the learning process. This "take away" is a result of intelligently processed experience. Importantly, Dewey regards education as the scientific method of inquiry, which enables to study reality and broadens scope and contents of experiences. He strongly believes in freedom of intelligence and power of thought: The only freedom that is of enduring importance is freedom of intelligence, that is to say, freedom of observation and of judgment exercised in behalf of purposes that are intrinsically worth while... this external and physical side of activity cannot be separated from the internal side of activity; from freedom of thought, desire, and purpose (Dewey, 1946, p. 69).

Although Dewey puts the learner in the centre of the learning process, he links individuals with a society. In order to achieve that, the educational environment is needed. However, there has to be integration between the learner and what is being learned. Experience has a transactional character. It is always a result of transaction taking place between an individual and what, at the time, constitutes his environment, whether the latter consists of persons with whom he is talking about some topic or event, the subject talked about being also a part of the situation (Dewey, 1946, p. 41).

\section{The quality of experience}

For Dewey, not all experiences have the same value. Dewey (1946, p. 13) writes: Experience and education cannot be directly equated to each other. Some experiences might be mis-educative. Any experience 
is mis-educative that has the effect of arresting or distorting the growth of further experience

There are experiences that are defective and not linked with future experiences and those valuable which are present in subsequent experiences. The most valuable experiences are those that are not only connected with future experiences, but also are shared, thus communicable and useful in solving social problems.

Dewey provides some principles leading to the theory of education based on experience. He distinguishes two basic criteria of discrimination between experiences that are educative and those that are not. These two principles for interpreting the quality of experience in its educational function and power are:

- Principle of continuity or experiential continuum, as for Dewey there is a continuity in experiencing;

- Principle of interaction, which he explains in the following words: It assigns equal rights to both factors in experience - objective and internal conditions. Any normal experience is interplay of these two sets of conditions. Taken together, or in their interaction, they form what we call a situation.

These two principles are not separate from each other but they intercept and are united. They are the longitudinal and lateral aspects of experience (Dewey, 1946, p. 42).

\section{Continuity and interaction of experiences}

Dewey's experience is not only progressive but also continuous. Experiences should serve as an aim of future problem solving and application. For Dewey experiences are the moving force. They help to avoid difficult situations in future by forming a habit of learning from experience and enhancing learner's intelligence. Experiences interact among themselves but also influence and shape the objective conditions under which future experiences are gained. Likewise, they modify the experiencing individual (1946, p. 26-27): Every experience enacted and undergone modifies the one who acts and undergoes, while this modification affects, whether we wish it or not the quality of subsequent experiences.

Just habits of gaining experiences are not enough as they are thoughtless actions. They need to be followed by thoughts, thus intellectual part of a human nature has to be activated. Dewey advises to stop blindly bowing impulses and desires but allow inhibition through reflections and judgments. For the philosopher, thinking is the method of inquiry and intelligent learning (Dewey, 1916). Interpreting further Dewey, there are no two heterogenetic elements - action and thought but one, that is experience. The distinction between reflection and action only has a functional or 
instrumental character, within broadly understood experience. Similarly, Dewey claimed that theory and practice are united. Theory should be applicable to be a good one.

\section{Education as a contribution to society}

Dewey combines knowledge with experiences and education with social democracy. He sees education as an individual, collective and social process bringing knowledge to society. Experience is an individual's reaction to situation but collecting experiences also regulates social processes and should be useful in a broader sense for communities. Strong individuals are independent, realize their ambitions and think critically but also need to cooperate with other individuals in society and community. The objectives of education cannot be isolated from society and communities and should prepare learners to function and participate actively in social life and citizenship. Education prepares for social changes and goes much beyond actual society. The sense of experience is linked with the society's or community's identity. It should serve the society as, according to Dewey, all experiences are ultimately social. It should involve contact and communication, and prepare for responsible citizenship. Sharing experiences and being able to communicate them well becomes an important competence of individuals. Moreover, an individual is able to construct and reconstruct society he or she exists in by applying systematic and thoughtful experiencing and education.

The role of education is to support individuals to fulfil their own potential through which they may contribute to society. Combining the individual and social aspect of experiencing, education is a regulation of the process of coming to share in the social consciousness; and that the adjustment of individual activity on the basis of this social consciousness is the only sure method of social reconstruction (Dewey, 1897, para. 60).

\section{The role of the educator}

According to Dewey, the difference between the learner and teacher is that the teacher already knows the content of teaching intervention. He notices that experiences of young learners and those who produce learning materials are usually very different. Books, apparatus and equipment represent the products of the more mature experience of elders. Therefore, educators' attention should be put on learner's response and perception of provided content, not the content per se. Teachers should be interested and aware of the learners' concerns about learning and take more long-term perspectives on the process and outcomes of learning. The educator, comparing to representatives of other professions is obliged to have a long look ahead (Dewey, 1946). This long-term perspective is 
also needed to facilitate the conditions and environment the learning takes place in. The surroundings of the learner should support him or her to gain valuable experiences: A primary responsibility of educators is that they not only be aware of the general principle of the shaping of actual experience by environing conditions, but they also recognize in the concrete what surroundings are conducive to having experiences that lead to growth (Dewey, 1946, p. 35).

Learning model proposed by Dewey might be called a learner-centred. The role of the educator is to be on the alert to see what attitudes and habitual tendencies are being created (1946, p. 33). Educator should be able to judge what attitudes are actually conducive to continued growth and what are detrimental (1946, p. 33). He also has to represent deep understanding and show sympathy towards the learner as this gives an idea of what is happening in the learner's mind along learning process (Dewey, 1946, p. 33).

Dewey's philosophy of experience and experience-based education was an inspiration for many other educators, philosophers and psychologists. They also changed the education system in USA and other parts of the world. Up to today there are many continuers of Dewey's views on education. The ones, which become part of the history of education, are for example Dewey's student and successor William Kilpatrick or Maria Montessori.

\subsection{The psychological foundations of experience-based learning and education}

Psychologists, especially in the stream of cognitive and behavioural psychology, also broadly discuss the problem of education and learning. In context of learning, behavioural psychology is interested in the results of learning on individuals' behaviour (particularly its changes), much less on their thoughts or observations, as they are too subjective. Learning is achieved through experiencing and experimenting, and behaviours are acquired through conditioning, which in its classical form is understood as an association between an environmental and a naturally occurring stimulus. Cognitive psychology tends to stress importance of mental processes, internal states as thinking and reflecting. The attention is given to the human brain, which is responsible for collecting data, storing them, processing and interpreting. Both behavioural and cognitive streams enrich understanding of experience and learning through experiencing. 
Like in the previous philosophical discussions, the issue of experience is present in many intellectual movements and doctrines of psychology. One of the most prominent representatives in this field are: Edward Thorndike, Burrhus Frederic Skinner, Jean Piaget, Kurt Lewin, Albert Bandura, Berry Zimmerman. They all discuss the issue and significance of experience in their discourses. Interestingly, some of their findings come from observing and making experiments on children or animals, and later on translating into adult learning practice.

\subsubsection{Behaviouristic idea of learning from consequences}

\section{Edward Thorndike, Burrrhus Frederic Skinner and their behaviouristic idea of learning from consequences}

Edward Thorndike (1874-1949) was a famous American psychologist, especially recognized for his learning theory and development of operant conditioning (instrumental learning). He is considered to be one the first researchers who applied psychology to the area of learning. His main works include: Animal intelligence: An experimental study of the associative processes in animals (1898), Educational Psychology (1903), Introduction to the Theory of Mental and Social Measurements (1904), The Elements of Psychology (1905) or The Fundamentals of Learning (1932).

Thorndike is an author of famous in psychology Law of effect, the law which states that if the behaviour is accompanied by pleasant consequences, it is more probable to be repeated and it will not be continued if unpleasant effects are noticed. Thorndike (1898) came to this conclusion by studying animals behaviour, predominantly cats (but also dogs, monkeys and others). He used to observe cats trying to escape from cages ("puzzle boxes") in two situations, one in which they knew and one in which they did not now about food outside the cage. Animals using trial and error method were choosing the way to get out of the cage. However, the learning process was more effective if the animals knew about the reward.

Particularly relevant for the logic of this monograph is Thorndike's approach towards learning from the consequences, i.e. through experiencing. Cats tried to escape from cages by trying different ways and methods, often making mistakes and repeating the previously taken paths. This is, according to Thorndike, the way in which also humans learn, first trying blindly (by trial and error) different options but then systematically learning with experiences. If the results of the taken behaviour are desirable, the learning process runs more effectively. Individuals learn by making 
connections between behaviour and its consequences. They continue their behaviour depending whether its result was positive or negative for them. Some consequences reinforce behaviour whereas others weaken them, and individuals are able to change their actions in light of anticipated consequences. Thorndike illustrated his observations with the curve of learning, which in light of his many observations proved to be true for many species. The learning curve shows that to complete a particular behaviour more time is needed at the beginning, but while practicing time shortens up to its minimum.

What is also important in Thorndike's theory of learning is the role he designates to motivation that is influenced by previous events and experiences. The learning can be effective only if it is purposeful and the learner knows its sense and meaning. For learning practice to be successful learners should be able to make connections (associations) between what is learned and what they have experienced.

Thorndike's theory is very mechanistic and behavioural. It puts emphasis on the stimuli-response effect. The trial and error method is difficult to accept in more advanced learning theories. However, it gives also a good grounding for appreciation of experience in learning process and understanding it as a gradual and incremental process. The theory of Thorndike influenced understanding of learning from psychological perspective. It was further developed and popularized by many others, among them a famous American psychologist and behaviourist Burrhus Frederic Skinner (1904-1990).

Burrhus Frederic Skinner is often recognized as one of the most celebrated American psychologists and a great promoter of a practical approach to psychology. He is particularly appreciated by enriching theory of psychology with radical behaviourism and by publicizing experimental psychology. Currently, he is especially recognized due to developing operant conditioning, which was built upon classical conditioning, but dealing with voluntary behaviour. He made an impact on learning theory and practice. His views on education are introduced in The Technology of Teaching (1968). Skinner was agreeing with Thorndike that the behaviour that is being reinforced is more probable to continue, and believed in power of consequences in explaining behaviours. Skinner's theories were based on supposition of an influence of an environment on the behaviour. To change the behaviour one has to change the environment he or she is in. The role of education is to improving the stimuli from outside to enhance learning process.

Although the behaviouristic theories are not that dominant anymore in the field of education, their influence on the development of psychology of learning cannot be denied. 


\subsubsection{Cognitive development through experiences}

\section{Jean Piaget and cognitive development through experiences}

The idea of learning as a part of developmental psychology, that is in general terms the study of the process of human changing, was promoted by Swiss psychologist Jean Piaget (1896-1980). Piaget put focus on human cognitive development and tried to understand the nature of knowledge. For this psychologist, intellectual development is possible through experience and experiencing. Learners construct their own understandings of what is around them and by collecting experiences (which correct their understanding of reality) adjust their views. Piaget was interested in reconstructing the process of knowledge growing, being the result of experiencing, learning by doing and reflecting. Knowledge is created and internalized, and experiences help to build mental schemes and are important factors of human development.

Piaget's understanding of learning process is considered as constructivist one. His research belongs to cognitive constructivism stream. Individuals create cognitive structures (mental representations) as the result of some stimuli from outside (environment). Cognitive development is the result of both biological processes and environmental experiences.

Piaget's focus was mainly put on children learning. The child is creating its own mental construction of the world on the basis of accumulated experiences, by experiencing it. Cognitive development is achieved through different stages, each with its own specifics. During these stages, a child creates cognitive schemas enabling its intellectual development. Intellectual development of a child differs from an adult because they are thinking in a different way. Children learn and develop through cumulating experiences that can be understood by previous experiences. They learn through assimilation and accommodation. The cognitive development of a child takes place in four stages:

1. Sensorimotor stage that takes place between $\mathrm{o}$ and $2^{\text {nd }}$ year,

2. Preoperational stage that takes between 2 nd and $7^{\text {th }}$ year,

3. Concrete operational stage that takes place between $7^{\text {th }}$ and $11^{\text {th }}$ year, 4. Formal operational stage that takes place over $11^{\text {th }}$ year.

During the sensorimotor stage of development children are getting to know the world through sensory experiences and objects around. They start to communicate with others and notice the influence on their movements. In the next stage, preoperational one, children follow and imitate adults' behaviour (they pretend play). Children behave in an 
egocentric way, limit themselves to one (own) perspective and do not consider others much. They consciously start to use language to communicate. In concrete operational stage children start to think in more logical and individual way, although they still have problems with more abstract issues. In the last stage, children start to notice more perspectives of one problem and think in a more abstract and theoretical way. They become adults and they learn like adults.

Although Piaget concentrated on learning process among children, his influence on understanding of learning process cannot be neglected. In broader sense, Piaget's theories indicate that learning process should be adequate to the stage of the development of learners and experiences they accumulated so far. In the light of Piaget's views, it is also important to consider not only the results of the learning but the whole process leading to the results, that is its mechanism, course, nature and determinants.

\subsubsection{Cognitive load theory}

Cognitive load theory (CLT) has been developed within cognitive psychology by John Sweller in the late 1980s (Sweller, 1988; Sweller, 1991; Sweller 1994). The idea of the theory was to be able to create learning contents in a way that they provide information at a pace and level understandable by the learner (that are able to be absorbed by learner's mental capacity). The theory has instructional character. It rests on the division of memory into: sensory memory, working memory (short term memory) and long-term memory. The process of processing information involves long and short-term memory. Learners are only conscious of the information being kept and processed in working memory and rather not conscious of information gathered by long-term memory. There are two basic assumptions regarding human memory around which CLT is built on. The first one states that learners have a limited capacity of working memory when processing new information. The second one is that learners have unlimited long-term memory. In practice the theory promises that learning might be less effective if learning materials block learners' working memory, and more effective if long-term memory is activated. Taking this under consideration, the learning process needs a change in the schematic structures of long-term memory. Information is kept in long-term memory due to the schemas that is mental structures enabling organizing knowledge. Although schemas are stored in long-term memory, they are constructed in working memory. 
Sweller (1998) introduces three sources of cognitive load (mental processing power):

- intrinsic, related to complexity of concepts,

- extraneous, related to instructional design,

- germane, related to the effort involved in the processing and constructing schemas;

Extraneous and germane cognitive load may be influenced by instructional guidance. The idea is to reduce extraneous cognitive load and encourage processes associated with germane cognitive load. Impropriate and too complex learning materials may lead to cognitive overload.

Relating cognitive load theory to the discussion on experience, to some extent the effectiveness of an instructional guidance depends on the learner's experience in the field that is taught (Kalyuga et al., 2003). Not experienced learners do not have appropriate schemas and require more precise instructions, whereas in the case of less experienced ones too much instructions may lead to cognitive overload. This leads to the conclusion that instructions are more effective for novices and may even have negative outcome for learning of experienced learners. This idea is known as the expertise reversal effect (Kalyuga et al., 2003).

\subsubsection{Social psychology and experiential learning}

\section{Kurt Lewin's idea of social experiences}

Kurt Lewin (1890-1947) was a German-American social and organizational psychologist who appreciated a lot of experiential learning, but is also well recognized in psychology for developing action research, field theory and the concept of group dynamics. In Lewin's field theory human behaviour is the function of both the person and the environment:

$$
B=f(P, E)
$$

Individuals' behaviour depends both on personal characteristics and their social situation. By stating that Lewin stood against the famous dispute in education called nature versus nurture. Lewin claimed that only nature (inborn qualities) or only nurture (the way experiences form individuals) could not explain individuals' behaviours. They are both needed to shape an individual. 
Inspired by the Gestalt psychology, Lewin devoted a lot of attention to perception and social experience. Learning for him means perceiving. It is based on insights (which are perceptual processes) but also structuring and restructuring the perceived areas (Wolman, 2012). Learning and behaviours of individuals depend on both the persons and the environment in which they execute the behaviour or where the learning takes place. The environment can be described through social and psychological parameters. Individuals and their ideas cannot be understood without social and psychological context. First-hand experiences do not give the most accurate understanding of reality. The link between the image of other individuals (within the group) and stereotype existing within this group needs also to be made.

\subsubsection{Social learning theory}

\section{Albert Bandura and vicarious experiences}

Another illustration of learning process, noticing the role of experiences, is provided by social learning theory. Social learning theory advocates that behaviour is learned from the environment through observing the actions of others, i.e. observational learning. The theory was created by the Canadian psychologist - Albert Bandura (born in 1925). The researcher is particularly recognized in entrepreneurship field for his construct of self-efficacy, being regarded as a basic entrepreneurial capability (see Bandura, 1977, 1982, 1986, 1989, but also for example De Noble et al., 1999 or Boyd et Vozikis, 1994).

According to Bandura (1977), human behaviour is learned observationally through modelling. Individuals develop and learn through experiencing. They observe others (so called models), process information and form ideas how behaviours are performed. Further on, the coded information leads to further actions and imitations. As well as observing others, individuals can learn from direct experience, direct instructions or observing consequences of the behaviour. In case of direct experience or observation the learner has to do with "live model", i.e. actual demonstration of the behaviour. If the learner receives detailed description how to behave, it takes form of "verbal instruction". Finally, the learning process can be activated by symbolic stimuli occurring by means of the media. Regardless of the stimuli, observed behaviour can lead to strengthening or weakening the learner's performance of the particular behaviour or to learning new patterns of behaviour.

In light of Bandura's views, individuals learn and change by vicarious experiences that are experiences based on observing other 
individuals' behaviours and their consequences for them. They are the equivalent source of knowledge and understanding of relationships as direct experiences, but they enable to learn faster. Bandura (1989, p. 32) explains the significance of vicarious experiences in following words: What gives significance to vicarious influence is that observers can acquire lasting attitudes, emotional reactions, and behavioral proclivities toward persons, places, or things that have been associated with the model's emotional experiences.

Social learning theory is regarded as an example of cognitive approach to learning that includes its social context. In fact, it integrates behavioural and cognitive theories of learning to provide one more general model. It bridges behavioural and cognitive approaches. According to Bandura (1989b) human behaviour should not be explained through one-sided determinism. Instead, he proposes that behaviour and learning is influenced by three types of interactive determinants:

- Cognitive (like knowledge or attitudes),

- Behavioural (like skills or self-efficacy),

- Environmental (like other individuals or social norms).

The learning process is not built of particular stages but it is a result of continuous and bidirectional interactions between individuals, models and environment. The strength of each determinant may change in particular situation and time. They also do not have to appear simultaneously. Bandura's understanding of social learning, named triadic reciprocal causation model, is illustrated on Figure 2.1.

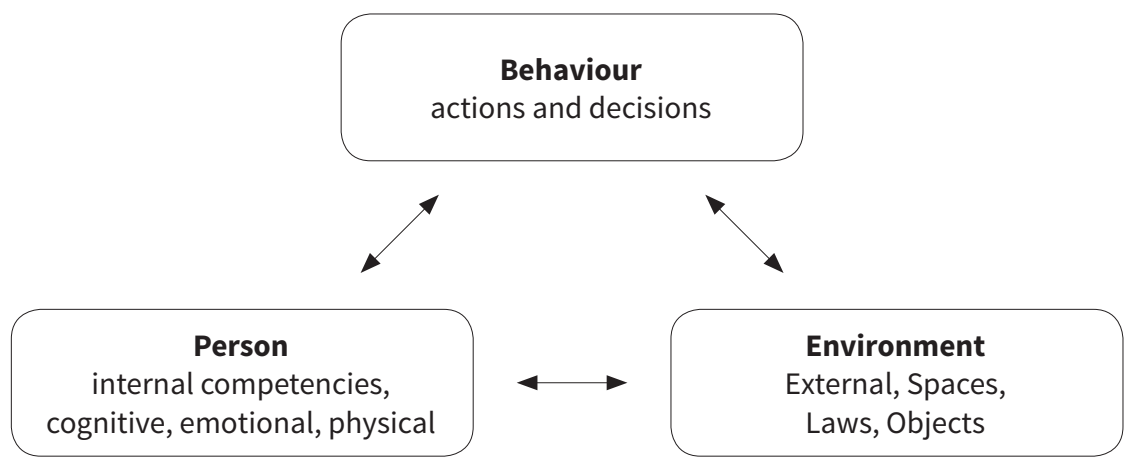

Figure 2.1. Bandura's triadic reciprocal causation model Source: Bandura (1977).

Taking cognitive perspective, observational learning is not taking place without cognitive processes (mental states). The observational 
learning and modelling process happen when four elements are present: attention, retention, reproduction and motivation. First, the learner has to pay attention to the model and his behaviour. He or she has to be able to retain the behaviour in memory and being able to repeat it (imitate).

From behavioural perspective, all behaviours receive some responses; either reinforcement or punishment, both might be internal and external type. Individuals tend to model and adopt the particular behaviour if in consequence it leads to some outcomes that they value. Behaviour is learned from environment. Environmental factors take form of others, situations, roles and relationships. As Bandura (1989, p.3) states: Human expectations, beliefs, emotional bents and cognitive competencies are developed and modified by social influences that convey information and activate emotional reactions through modeling, instruction and social persuasion.

Interestingly, individuals have both passive and active role in learning process. They are both products and producers of their environment (Bandura, 1989).

\subsubsection{Self-regulated learning}

A concept of self-regulation also gives some insights about the learning process. Self-regulated learning derives from social cognitive theory and was developed by American educational psychologist Barry Zimmerman (1990, 1994, 1995, 2000, 2001, 2002, 2008). In light of Zimmerman's works, to be effective, the learning process needs self-regulation. Self-regulated learning is based on the concepts of learner's metacognition and motivation. It is a self-directed process in which learners take control and responsibility for their own learning. He or she sets the goal for the learning, develops the strategy to achieve it and pursue its completion. Self-regulated learning is a group of behaviours. Learning is a planned process regarded as essential to achieve success.

An important aspect of self-regulated learning is transformation. Change accompanies learning process. During self-regulated learning, learners transform their mental abilities into skills. The transformation considers cognitive, behavioural and motivational aspects.

Self-regulated learners are metacognitively, motivationally, and behaviorally active participants in their own learning (Zimmerman, 1990, p. 4). They engage and organize all elements of their intelligence and personality: cognition, conation and affection. Learners have an ability 
to understand their social and learning environment. They feel responsible for their learning experiences. Personal initiative in learning makes individuals active and autonomous learners. They are aware whether they possess knowledge and skills or not (Zimmerman, 1990). They consciously and purposefully select the learning contents. Regulated learning happens to all learners but with different degree. As Zimmerman (1990, p. 5) notices: Undoubtedly, all learners use regulatory processes to some degree, but self-regulated learners are distinguished by (a) their awareness of strategic relations between regulatory processes or responses and learning outcomes and (b) their use of these strategies to achieve their academic goals.

A crucial element of self-regulation learning is motivation. In self-regulated learning, learning and motivation are understood as interdependent processes that cannot be separated from each other. The motivation of self-regulated learners makes them influence their learning environments in order to correspond to their needs (Kolovelonis et al., 2011). They approach teachers or instructors more often, ask questions, look for extra sources of knowledge.

An important characteristic of self-regulated learning is what Zimmerman (1989), after Carver and Scheier (1981), calls "self-oriented" feedback loop. Information is processed through three types of loops: personal, behavioural and environmental. Zimmerman proposes cyclical model of self-regulated learning (Figure 2.2). The stages include forethought phase (task motivation, self-motivation beliefs), performance phase (self-control, self-observation), self-reflection phase (self-judgment, self-reaction). The process starts with setting the goal and mapping out essential task to attain it. Learners are guided by the vision of outcomes and are in general positive about the results. They chose the strategy enabling them to be effective. The performance phase means actual learning. Learner observes the results and control the process to optimize learning process. Self-regulation also includes self-reflection. This phase takes place after the completion of learning. It serves self-judgments as a learner (whether learning experience was positive or negative and why). It also includes self-reaction that is reaction to self-judgment. Motivation for future learning endeavours is built. Learners take into consideration and are influenced by their previous learning experiences to proceed to the next ones (Zimmerman, 2011).

Although Zimmerman does not focus directly on experiences per se, students chose their self-regulated learning strategies in light of their prior experience and the concept is based on a strong link between performing and reflecting, which is the essence of experiencing. 


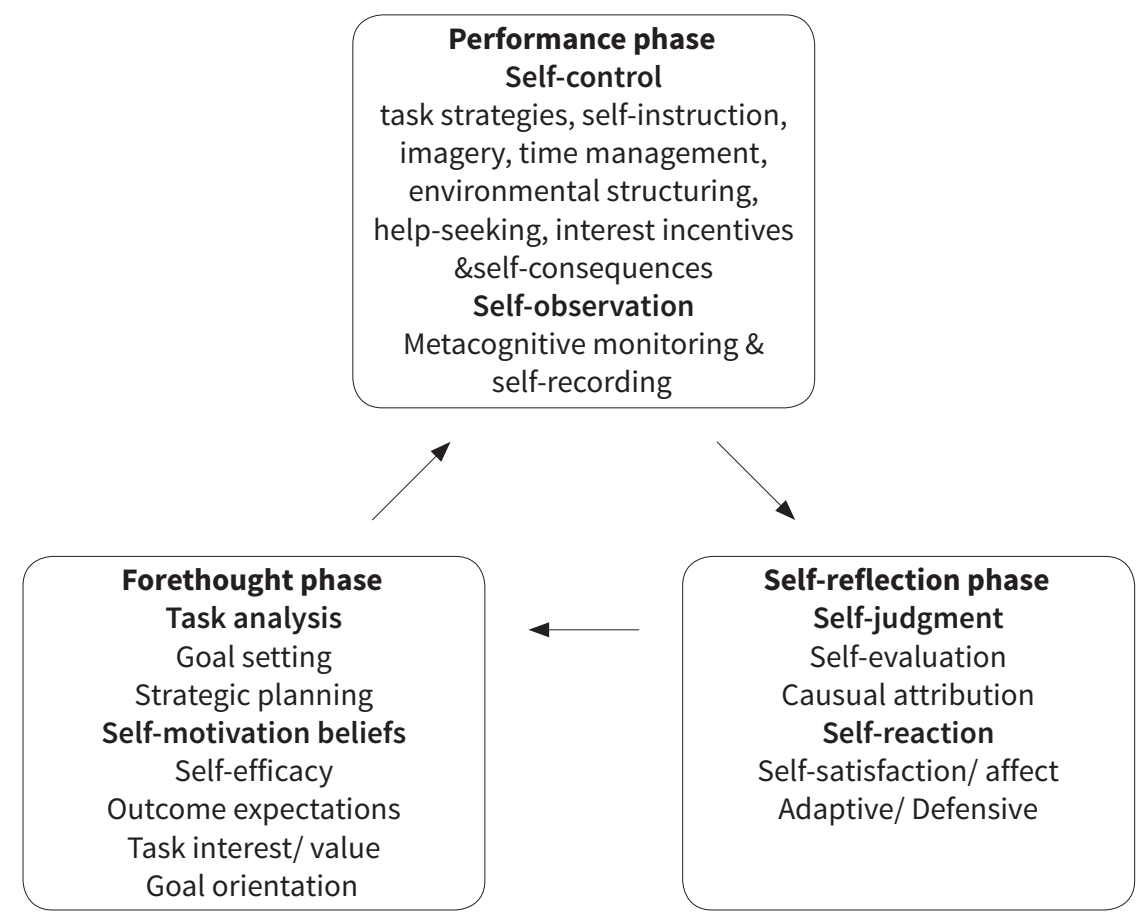

Figure 2.2. Process of self-regulated learning Source: Zimmerman and Moylan, 2009.

\subsection{Pedagogy of experience}

Understanding experience may be also enriched by studying pedagogy. The most famous and influential person in experience-based pedagogy is Paulo Freire (1921-1997), a Brazilian educationalist and philosopher who developed a critical pedagogy concept and was stressing the liberating power of education. Similarly to Dewey, Freire continued the topic of progressive educational practices. To some extent his views are similar to Dewey's ones, although they were raised in completely different environment, the researchers did not meet, and Freire never directly referred to Dewey in his writings. Sometimes Freire is even called "the Latin John Dewey" (Aronowitz, 1993). However, they both share perspective on the core interest of this monograph - experiential learning, both believed in power of active and conscious citizenship (or belonging to community), 
strength of critical thinking and the sense of social change through education. They also both were socially engaged intellectuals who were advocates of lived experiences as a mechanism for learning. What was new in Freire's approach was to include political flavour into the educational debate. His dominating motive was to help the poorer, "the oppressed", to come out of their situation and overcome social problems. In his view, education should be followed by political action.

Freire's philosophy on education and pedagogy are embedded in many writings, like Pedagogy of the Oppressed (1970), Pedagogy of Freedom (1970), Cultural action for freedom (1970), Education for critical consciousness (1973), Education, the practice of freedom (1976), The politics of education: culture, power, and liberation (1985), Pedagogy of freedom: ethics, democracy and civic courage (1998), Teachers as cultural workers: letters to those who dare teach (1998).

Freire was criticizing what he called "banking" education which he regarded as oppressing. In this model of education learners are passive and receive ready "deposits" of knowledge, which they need to keep by memorizing. In Teachers as cultural workers: letters to those who dare teach Freire writes: I have said so many times, teaching cannot be a process of transference of knowledge from the one teaching to the learner. This is the mechanical transference from which results machinelike memorization, which I have already criticized. Critical study correlates with teaching that is equally critical, which necessarily demands a critical way of comprehending and of realizing the reading of the word and that of the world, the reading of text and of context (Freire, 1998, p. 22).

For Freire knowledge is a social construct and there is no final act of knowing (Breunig, 2005). It is shaped through social interaction between the members of a community. He believed that education should be built on dialogical problematization but also activism. Education should lead to some action, to the empowerment of the oppressed and the poor. Both teachers and students are agents of social change (Breunig, 2005). To Freire, education does not happen merely in the classroom but lasts in all other aspects of the learners' life and is political.

For understanding Freire's pedagogy three categories seem to be crucial: conscientization, praxis and dialogue. Conscientization is the process of developing a critical consciousness and awareness of social reality through reflections and actions in order to be able to transform this reality. Learners critically think and evaluate their situations and their experiences taking into consideration a social context they belong to. Consientization next leads to praxis that is informed actions. Being aware of one-self and knowing the situation and context provoke 
new actions. There is a continuous cycle of actions and reflections leading to next actions and reflections, all giving rise to change of world. Only through thoughtful actions social changes and progress may be achieved. In this sense Freire was an advocate for transformative capacity of education. Freire is also known to promote dialogue in learning. The dialogue means both dialogue between teacher and learner, between learners themselves, between formal and informal education, between action and thought, between theory and practice.

In this monograph the attention is given to praxis concept. Freire is not the one who invented this term but he brought it to education. To understand praxis, it is first necessary to move back to ancient Greece. Praxis is usually considered through the lenses of synthesis and interrelation of theory and practice. It appears in the discussion initiated by Aristotle, who contrasted three basic activities of man: theoria (truth-oriented), poiesis (production-oriented) and praxis (action-oriented). Hence, praxis is not as simple as practice. In ancient Greece praxis concerned doing or acting, however not in a way of executing physical work. It meant acting appropriately, thus truly and justly in a social-political situation (Carr and Kemmis, 1986). The Greeks associated praxis with ethical actions. They distinguished between actions which are directed towards making something (poietike or poiesis), and making something well (praxis) (Blenkin et al., 1992). Carr and Kemmis (1986, p. 33) defined praxis and separated it from poietike: Praxis is distinguished from poietike because it is informed action which, by reflection on its character and consequences, reflexively changes the 'knowledge-base' which informs it. Where poietike is 'making-action', praxis is 'doing-action'.

Therefore, praxis is more creative, dialogic and sense-oriented. It is guided by a moral disposition to act truly and justly, called by the Greeks phronesis (Carr and Kemmis, 1986). Phronesis is a practical wisdom that is rooted in experience and enables to choose appropriate course of action (Blenkin et al., 1992). It makes people act rightly according to their understanding of reality and leads to better life. Interestingly, similar dualistic view of experience exists up to today in some languages.

Much later the concept of praxis started to appear in works of great philosophers, like Marx, Hegel or Gadamer. Hegel was not in favour of splitting theory and practice and perceived human existence as process of moving. He was interested in the dilemma how the subjective freedom of a person can orientate itself as a mediated relation at a certain historical moment to a historically determined state. For Marx praxis was a very critical activity and more revolution oriented. The concept of 
praxis appeared to be central to his philosophical vision of transforming the world through revolution. Gadamer concentrated on dialogic specifics of praxis by perceiving it as a path to a better understanding of reality. This dialogue (called also hermeneutic circle) is according to him achieved by linking the general (history and tradition) and individual experiences.

For Freire praxis is a way to support the uneducated in emancipating themselves. He (1970, p. 13) explains praxis through the process of learning: The act of knowing involves a dialectical movement that goes from action to reflection and from reflection upon action to a new action. For the learner to know what he did not know before, he must engage in an authentic process of abstraction by means of which he can reflect on the action-object whole, or, more generally, on forms of orientation in the world.

Action and reflection are two sides of the same phenomenon. Action without reflection is just activism and reflection without action is just verbalism (Freire, 1998). Thus, similarly as the Aristotle distinguished praxis from poiesis, Freire distinguished praxis from activism and verbalism. Verbalism is an empty word, "blah", word without action, and transformation cannot happen with action. Transformation is also impossible with just activism, because without reflection, there can be no commitment to transformation, it is an empty action. Only with both action and reflection praxis is achieved, which enables transformation to take place.

Freire (1970, p. 50) also highlights dialectical character of the relation between subjectivity and objectivity: ... one cannot conceive of objectivity without subjectivity. Neither can exist without the other, nor can they be dichotomized. The separation of objectivity from subjectivity, the denial of the latter when analyzing reality or acting upon it, is objectivism. On the other hand, the denial of objectivity in analysis or action, resulting in a subjectivism which leads to solipsistic positions, denies action itself by denying objective reality. Neither objectivism nor subjectivism, nor yet psychologism is propounded here, but rather subjectivity and objectivity in constant dialectical relationship.

Taking the advantage of understanding praxis in philosophical pedagogy of Paulo Freire, it is possible to synthetize that praxis is a human action and a word "human" makes it not just a mechanical act but add thoughtful orientation. In praxis material and ideal worlds meet and co-exist together. As Carr and Kemmis (1986) notice, praxis involves dialectical thinking. It is an open and questioning form of thinking which demands reflection back and forth between elements like: part and whole, knowledge and action, process and product, subject 
and object, being and becoming, rhetoric and reality, or structure and junction. Translating it into education practice, the epicentre of praxis is action but for the learning to happen it has to be accompanied with reflection. Action and reflection cannot be polarized but investigated for their unity, mutual constitutiveness and interaction. This suggests that entrepreneurship education focused on better understanding of learning process should position praxis, understood as some continuum between action and reflection, as a primary concept to explore.

\subsection{The concept of experience in contemporary education theories}

The 198 os brought a view of cyclical process of experiential learning. In this decade concepts like action learning or transformative learning were popularized among scholars and entered into teaching practices. They changed the understanding of the learning process, its objectives, frames and techniques. The emerging learning theories focused on understanding better how adult individuals learn. They were related to a more active approach in educating than before. By being teacher-centred the pedagogy moved its interests towards learners and learning process. Knowledge started to be constructed by the learner and the research interest focused more on the cognitive processes while learning.

This chapter includes selected theories from a large catalogue of what has been achieved in education in $20^{\text {th }}$ century. Again, they were chosen taking into consideration whether they are meaningful for understanding the growing role of experience in education.

\subsubsection{Action learning}

Action learning is usually associated with modern education. The concept is a result of the conviction that new knowledge and progress derive from practice and experience, rather than from already existing knowledge. Such an understanding of learning reflects professional background and life story of its founder, Reginald "Reg" Revans (1907-2003), a British astrophysicist and professor of management but also a management consultant and practitioner. Revans developed his 
concept by supporting managers in coal mines, hospitals and many different industries, but also observing work of Nobel prize winners at the University of Cambridge. His professional life was full of interesting turns but always connected with the practice of doing something. This approach gave the grounding for the theory.

The objective of action learning is not only learning as such but also bringing the change that is aimed at resulting in improved actions and better outcomes in the future. Using Revans' (2011, p. 12) words action learning should be used to make a useful progress, not to resolve puzzles (p. 24). The change is brought through learning, which is mutual, dialogical, strategic and purposeful.

Action learning is an educative process that involves doing. For the action learning to occur, firstly the problem has to be realized by a group of individuals, called by Revans the action learning set. Next, the solution for this problem has to be sought and, through interaction with others and/or environment, some steps have to be taken to approach it. The problem has to be real, important and quite complex and should lead to real and valuable actions. It has to be relevant to the situation and connected to individuals who solve it. Action learning does not stop at this stage. The process cannot be ended without the follow-up of the problem solution and further learning from its outcomes. It includes the reflective analysis of the results and the ways to achieve it. An important element of action learning is that the participants realize their own deficiencies and gaps in knowledge and try to overcome them.

The cycle of action learning is quite simple. It is a step-by-step approach. However, two issues need to be stressed. Firstly, the solutions for the problem come from the previous experience of the person(s), ability of critical thinking and reflecting, analytical skills and logical thinking. What is interesting, experiences cannot be evaluated as wrong or good ones, they are beyond any assessment. Secondly, action learning can take place if the individuals involved take responsibility for the results of problem solving. Therefore, two key issues of this monograph, experience and responsibility, meet in action learning concept and allow for the renewal of learning. Action learning needs a problem, some accumulated experience to solve it and responsibility for the results and for the further learning. Developing the answers for the problem means also development of a person. Giving responsibility brings more commitment to the problem and to the learning, and giving autonomy for seeking the solution results in more creativity.

To describe action learning, Revans developed the formula: 


$$
\mathrm{L}=\mathrm{P}+\mathrm{Q}
$$

where:

$\mathrm{L}$ - stands for Learning,

$\mathrm{P}$ - stands for Programing (programmed knowledge which is more traditional knowledge),

Q - stands for reflective questioning to create insight.

This formula means that for the action learning to take place, the traditional, programmed (usually expert, specialist) knowledge has to be accumulated and then related to the problem through questioning. In other words, programmed knowledge is what is known and questioning brings what should be known. Therefore, problem solving is based on questioning and relating to previous experiences. Questions enable to tackle the nature of the problem and lead to its solution. Questioning is a result of insights and reflections. Both questioning and programming have to be balanced during learning in order to avoid a discouragement or an overload.

Action learning creates environment for the personal development. Participants are not only interested in techniques of achieving the solution but are eager to understand the problem and themselves as learners and individuals. They are conscious of the learning process, its meaning and value. In achieving results more important than the expertise is the practice of doing and reflecting. Action and reflection are the core attributes of action learning.

As the result of the action learning the problem is solved, some renewal, reform or transformation takes place. Opportunities get exploited successfully. Action learning has numerous benefits for the learners. It develops many skills of the learners, the dissemination of knowledge and experience is guaranteed and learning culture is built and continued. Learning concerns both individual learning and, due to its dialogical nature, also group learning. Revans stresses the importance of relationships between individuals. According to him learning means changing self, changing others (by advising) and changing the external world (by deciding and taking actions). This also may be understood as influencing upon self, upon peers and the world (Revans, 2011).

Interestingly, Revans's works are much more related to business practice than to managerial education. He himself also mostly treated action learning as a method or program for business development and improvement, not a theory. Nowadays, action learning is mostly discussed in the context of organizations as a powerful tool to solve problems of organizations or to create leadership. In entrepreneurship research action theory was not used much. Some few examples include Jones and Holt (2008) 
or Taylor and Thorpe (2004). The literature on action approach in entrepreneurship education is not rich. One of the reasons why action-based entrepreneurship is not broadly implemented at higher education institutions is not the lack of trust in this type of education among scholars but rather lack of funds to finance this usually outside the classroom, extra-curricular activities.

\subsubsection{Transformative learning and critical reflection}

The role and need for transformation in learning was already raised by Paulo Freire and provided grounding for his concept of conscientization. The reasoning behind this view was that knowledge and learning equip learners with more power of freedom enabling to make meaningful changes in their lives. Therefore Freire focused mainly on social transformations and their impact. However, the most influential theory devoted to transformative learning belongs to Jack Mezirow (1923-2014), an American sociologist and educational theorist. He created comprehensive and coherent theory how transformative learning takes place and how it changes the learner. Many of his views came from the extensive studies he conducted on women who decided to continue education after longer breaks. Mezirow also greatly contributed to the understanding of the role of experience in adult learning.

Mezirow understands transformative learning as a cognitive and developmental process of giving meaning of one's experience. The idea of transformative learning is connected with a great autonomy of thinking processes of the learner. It is a learner-focused learning theory. The result of the transformative process is learner's new or revised interpretation of gained experiences (Mezirow, 1996). In this vein, Mezirow defines learning as the process of making a new or revised interpretation of the meaning of an experience, which guides subsequent understanding, appreciation, and action (Mezirow, 1990, p. 1). Mezirow believes in rational transformation (Taylor, 1998) and has little concern for emotions or intuition. ${ }^{1}$ The learner rationally assesses the world and its own position in this world.

Transformation is based on a conscious and meaningful change, which Mezirow (1978) calls structural. The meaning structures the change. The

1 Mezirow's assumption about the rationality in transformative learning was later on criticized and proposed to be replaced by emotions. 
change is usually provoked by some strong reactions to experiences (for example a disorienting event or crisis); rarely does it just come from accumulation of experiences. The reactions are strong enough for learners to start using different frames of references, values or beliefs than before. The learner's view of world changes as well as his or her relationships and interactions with environment. The learner needs to try out new roles and adapt to new perspectives. This calls also for integration back to community or society.

Mezirow matches transformative learning with critical reflection and experiences. He explains it in following words (1990, p. 14): Perspective transformation is the process of becoming critically aware of how and why our presuppositions have come to constrain the way we perceive, understand, and feel about our world; of reformulating these assumptions to permit a more inclusive, discriminating, permeable and integrative perspective; and of making decisions or otherwise acting on these new understandings. More inclusive, discriminating permeable and integrative perspectives are superior perspectives that adults choose if they can because they are motivated to better understand the meaning of their experience.

Perspective transformation is possible only if the learner is critically aware of his understanding of the world and own position in this world. Transformative learning cannot take place without experiences. However, they are only important if the learner understands it and if it leads him to his own interpretations, views and opinions. In transformative learning matters how experiences are (re)formulated. As Taylor (1998, p. 52) sums up: Fostering transformative learning is not just about making sense of experience through dialogue; it also involves creating experiences that can help facilitate understanding among the participants involved.

Transformative learning includes reflection and analytical skills. Insightful reflection enables transformation, as experience followed by reflection leads to the change. Analytical skills allow rational thinking, which is a catalyst for transformation and allow communicating about the change.

According to Mezirow (1978), there are ten phases of transformative process:

Phase 1. A disorienting dilemma

Phase 2. A self-examination with feelings of guilt or shame

Phase 3. A critical assessment of epistemic, sociocultural, or psychic assumptions

Phase 4. Recognition that one's discontent and the process of transformation are shared and that others have negotiated a similar change

Phase 5. Exploration of options for new roles, relationships, and actions 
Phase 6. Planning of a course of action

Phase 7. Acquisition of knowledge and skills for implementing one's plans Phase 8. Provisional trying of new roles

Phase 9. Building of competence and self-confidence in new roles and relationships

Phase 10. A reintegration into one's life on the basis of conditions dictated by one's perspective.

The process starts with a problem that must be solved by choosing best solution (phase 1). The problem comes from experience and either has to fortify the current understanding of the issue or leads to its revision and reformulation. The learner critically assesses all aspects of the problem (phase 2 and 3 ) and by employing rational way of thinking (phase 4-5) plans actions and resources needed to execute them (phases 6-9). The process ends with integrating what has been achieved within the process.

Transformative learning represents constructivist and developmental view on learning. Crucial elements of transformative learning theory are meaning structures, which are defined by Mezirow as broad sets of predispositions resulting from psycho-cultural assumptions which determine the horizons of our expectations (Mezirow, 1991). Transformation is a cognitive process. The theory is also grounded in the nature of human communication (Taylor, 1998), not instructional learning. Transformative learning is a communicative learning, which means that learning is involved in understanding experiences (Taylor, 1998).

Transformative learning is not a universal type of learning. It requires an experienced teacher who creates environment for transformative learning and a learner with experiences and ability to reflect on them. Mezirow (1991) pays attention both to the role of learner and teachers/ instructors in the process of transformative learning. He suggests that teachers should create adequate conditions, giving learners a sense of safety, openness and trust to make communication possible. Learners should be able to follow freely their individuality, be autonomous but at the same time participative. The practices should encourage reflectivity, critical thinking and support analytical skills.

Mezirow's main contribution to the field of education was an introduction of the concept of transformative learning lean on experiences, critical reflection and rationality. However, he also contributed to the field by introducing two different types of knowledge: programmed knowledge and questioning (Revans, 1983). Mezirow (1985) distinguished three types of learning: instrumental, dialogical and self-reflective. 


\subsubsection{Learning as a cycle and different learning styles}

\section{David Kolb and experiential learning model and different learning styles}

Discussions on adults learning should not take place without mentioning great American educational theorist David Kolb (born 1939) whose contribution to experiential learning cannot be overemphasized. He is particular famous for his Experiential Learning Model (ELM) and learning style inventory.

According to Kolb (1984), much influenced by before mentioned learning models of Dewey, Piaget and Lewin, learning means transforming experiences into knowledge. In this transformation the particular role plays the practice of reflecting on experiences. As Boreham (1987, p. 89) noted, for Kolb the term 'learning from experience' really means learning from reflection on experience. For Kolb experiential learning is not an alternative to behavioural or cognitive theories of learning but rather, as he notes (Kolb, 1984, p. 21) a holistic integrative perspective on learning that combines experience, perception, cognition, and knowledge. All learning involves experience. Learning is seen as an emergent process of creating knowledge but also a holistic process of adaptation to the world. Kolb focuses on process-oriented character of learning, rather its dynamics than its static contents or outcomes. For him learning is a never-ending process, as the lack of possibility to modify our understanding of the world in light of gained experience is contrary to the sense of learning. He explains: When viewed from the perspective of experiential learning, the tendency to define learning in terms of outcomes can become a definition of non-learning, in the process sense that the failure to modify ideas and habits as a result of experience is maladaptive (Kolb, 1984, p. 26).

The starting point for Kolb (1984) was noticing similarities between the models of learning proposed by Lewin, Dewey and Piaget, which resulted later in six propositions about experiential learning. These propositions are following:

- Learning is best conceived as a process, not in terms of outcomes - Ideas are not stable elements of thought but they are always shaped and re-shaped through experience, therefore two thoughts cannot be the same as they are always influenced by experience. The outcomes of learning are only historic record, not knowledge to use in future.

- Learning is a continuous process grounded in experience - Consciousness is continuous and so are experiences. In consequence, knowledge is consequently and continuously created through 
experiences. It means that, quoting Kolb (1984, p.38), all learning is relearning and that everyone enters learning situation with more or less articulate ideas about the topic at hand. Education means not only providing new ideas and concepts but also modifying existing ones.

- The process of learning requires the resolution of conflicts between dialectically opposed modes of adaptation to the world - Learning is based on conflicts and requires polar abilities. Kolb distinguished two dimensions of the learning process. The first dimension is continuum between experiencing concrete events and abstract conceptualisation. The second one is situated between active experimentation and reflective observation. This means that the learner moves in varying degrees from actor to observer, and from specific involvement to general analytic detachment (Kolb, 1984, p. 31).

- Learning is a holistic process of adaptation to the World - Learning is perceived as a process of adaption of individuals to the conditions of both physical and social environment. It is a refined and scientific method of adapting to the world. Learning is holistic, as it does not belong solely to cognition or perception. It refers to human intellect, emotions, senses and behaving. Learning happens in all possible situations and settings and by no means it is only related to school or in-class practice.

- Learning involves transaction between the person and the environment - Transactions taking place between the learner and the environment reflect the double meaning of the word "experience". Experiences are individual and subjective; they refer to internal state of the person. But they are also objective and environmental. Experiences are active and change the to some extent conditions of the environment they come from.

- Learning is a process of creating knowledge - Knowledge is the result of the transaction between objective and social knowledge (earlier accumulated by experience), and personal knowledge gained through individual experiences. Knowledge is produced as a result of transaction between objective and subjective experiences. Being the consequence of grasping and transforming experiences, it is constantly created and recreated by learners.

Kolb's core contribution into learning theories is Experiential Learning Model (ELM). The theory is based on the dual dialectics of action and reflection, and experience and abstraction (Kolb and Kolb, 2008). Learners learn through experiencing, reflecting, abstracting and 
experimenting. ELM is a dynamic, cyclical theory of learning composed of four stages, which follow one after another. The stages include:

$\checkmark$ concrete experience,

$\checkmark$ observation of and reflection on that experience,

$\checkmark$ formation of abstract concepts based upon the reflection,

$\rightarrow$ testing the new concepts;

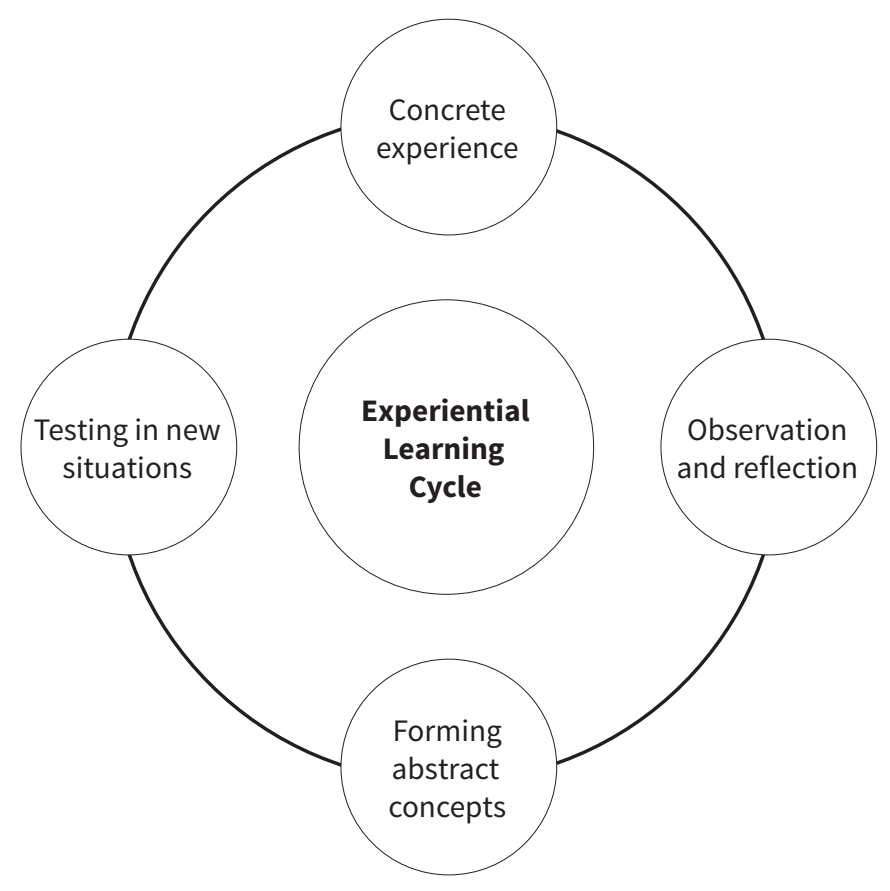

Figure 2.3. Four stages of learning. Kolb's Experiential Learning Cycle

Source: Kolb (1984).

According to Kolb (1976, p. 21), the experiential learning model presents how experience is translated into concepts, which in turn are used as guides in the choice of new experiences. The logic of the Kolb's four-stage learning cycle, illustrated as Figure 2.3, is following. Concrete experience (deriving from events) gives the ground for observation and reflection. The reflections are assimilated and in order to be useful they are formed into abstract concepts. The implications being result of abstract concepts are tested in new situations and are foundations for new experiences. The learner systematically follows each stage of the cycle and the role of the teacher or instructor is to provide links between these stages. 
Kolb (1984, p. 30) further explains that effective learning demands from the learner four types of abilities, corresponding to four stages of learning process. These abilities are:

$\Delta$ concrete experience abilities - the role of the learner is to be able to involve themselves fully, openly and without bias in new experiences, $\checkmark$ reflective observation abilities - the role of the learner is to be able to reflect on and observe their experiences from many perspectives,

$\checkmark$ abstract conceptualizing abilities - the role of the learner is to be able to create concepts that integrate their observations into logically sound theories,

$\checkmark$ active experimentation abilities - the role of the learner is to be able to use these theories to make decisions and solve problems.

Next to describing four stages of learning process and linked to them four abilities demanded from learner, the experiential learning model provides also information on how the learner acquires and transforms information from experience. Kolb proposes that information may be grasped through direct and immediate experiences (apprehension) or a recreation/interpretation of them (comprehension). Transformation of experience takes place through extension (active test of experiences) or intention (inner reflecting on experiences). Putting together these two dimensions - grasping and transformation allows differentiating four different types of knowledge: divergent (grasping by apprehension and transforming by intention), assimilative (grasping by comprehension and transforming by intention), convergent (grasping by comprehension and transforming by extension) and accommodative (grasping by apprehension and transforming by extension).

Kolb (1974) also describes four different learning styles of learners. This typology, being a result of research and clinical observation, is known as Learning Style Inventory (LSI). It includes divergers, assimilators, convergers and accommodators:

$\checkmark$ Divergers are individuals who view situations from many perspectives and rely heavily upon brainstorming and generation of ideas.

$\Delta$ Assimilators are individuals who use inductive reasoning and have the ability to create theoretical models.

$\checkmark$ Convergers are individuals who rely heavily on hypothetical-deductive reasoning.

$\checkmark$ Accommodators are individuals who carry out plans and experiments and adapt to immediate circumstances.

The basic characteristics of four learning styles are included in Table 2.3 They are also presented on the Figure 2.4, which is more advanced illustration of ELM. 


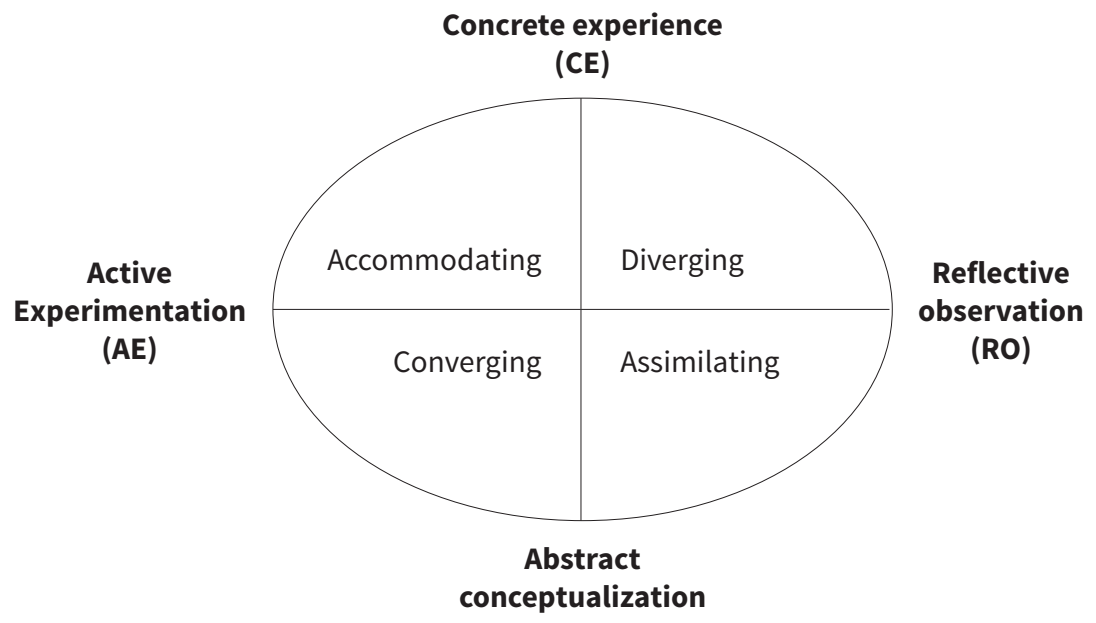

Figure 2.4. Experiential learning model and basic learning styles

Source: Kolb (1984).

\begin{tabular}{|l|l|l|l|l|}
\hline Characteristic & \multicolumn{1}{|c|}{ Divergers } & \multicolumn{1}{|c|}{ Assililators } & \multicolumn{1}{|c|}{ Convergers } & \multicolumn{1}{|c|}{ Accomodators } \\
\hline $\begin{array}{l}\text { Dominant } \\
\text { learning ability }\end{array}$ & $\begin{array}{l}\text { Concrete } \\
\text { experience } \\
\text { and Reflective } \\
\text { Observation }\end{array}$ & $\begin{array}{l}\text { Abstract Con- } \\
\text { ceptualization } \\
\text { and Reflective } \\
\text { Observation }\end{array}$ & $\begin{array}{l}\text { Abstract Con- } \\
\text { ceptualization } \\
\text { and Active Ex- } \\
\text { perimentation }\end{array}$ & $\begin{array}{l}\text { Concrete Experi- } \\
\text { ence and Active } \\
\text { Experimentation }\end{array}$ \\
\hline $\begin{array}{l}\text { Best conditions } \\
\text { for performing }\end{array}$ & $\begin{array}{l}\text { In situations } \\
\text { when a } \\
\text { generation of } \\
\text { idea is needed }\end{array}$ & $\begin{array}{l}\text { In situations } \\
\text { when } \\
\text { understanding } \\
\text { a broad range of } \\
\text { information and } \\
\text { putting them } \\
\text { into logical form } \\
\text { is needed }\end{array}$ & $\begin{array}{l}\text { In situations } \\
\text { when finding } \\
\text { practical uses } \\
\text { for ideas and } \\
\text { theories is } \\
\text { needed }\end{array}$ & $\begin{array}{l}\text { In situations } \\
\text { when carrying } \\
\text { out plans and } \\
\text { involving in new } \\
\text { and challenging } \\
\text { experiences is } \\
\text { needed }\end{array}$ \\
\hline Interests & $\begin{array}{l}\text { Broad cultural } \\
\text { interest, } \\
\text { Gathering } \\
\text { information, } \\
\text { Arts, History }\end{array}$ & $\begin{array}{l}\text { Ideas, theories } \\
\text { and abstract } \\
\text { concepts, } \\
\text { Information and } \\
\text { Science }\end{array}$ & $\begin{array}{l}\text { Technics and } \\
\text { application } \\
\text { Technology and } \\
\text { specialisations }\end{array}$ & $\begin{array}{l}\text { "hand-on" } \\
\text { experiences } \\
\text { Action-oriented } \\
\text { careers, e.g. } \\
\text { business, } \\
\text { marketing, sales }\end{array}$ \\
\hline $\begin{array}{l}\text { Personal } \\
\text { characteristics }\end{array}$ & $\begin{array}{l}\text { Imaginative } \\
\text { and emotional } \\
\text { introverts }\end{array}$ & $\begin{array}{l}\text { Rational } \\
\text { introverts }\end{array}$ & $\begin{array}{l}\text { Extraverts with } \\
\text { ability to solve } \\
\text { problems and } \\
\text { make decisions }\end{array}$ & $\begin{array}{l}\text { Extraverts } \\
\text { trusting "gut" } \\
\text { feelings rather } \\
\text { than logical } \\
\text { analysis }\end{array}$ \\
\hline
\end{tabular}




\begin{tabular}{|l|l|l|l|l|}
\hline Characteristic & \multicolumn{1}{|c|}{ Divergers } & \multicolumn{1}{|c|}{ Assililators } & \multicolumn{1}{c|}{ Convergers } & Accomodators \\
\hline $\begin{array}{l}\text { Learning } \\
\text { optimum }\end{array}$ & $\begin{array}{l}\text { Work in groups, } \\
\text { listening with } \\
\text { an open mind } \\
\text { and receiving } \\
\text { personalized } \\
\text { feedback }\end{array}$ & $\begin{array}{l}\text { Readings, } \\
\text { lectures, } \\
\text { exploring } \\
\text { analytical } \\
\text { models }\end{array}$ & $\begin{array}{l}\text { Experiments } \\
\text { with new ideas, } \\
\text { simulations, } \\
\text { laboratory } \\
\text { assignments, } \\
\text { and practical } \\
\text { applications }\end{array}$ & $\begin{array}{l}\text { Learning from } \\
\text { experiences, } \\
\text { Team working } \\
\text { to complete } \\
\text { assignments, to } \\
\text { set goals, to do } \\
\text { field work, and } \\
\text { to test out differ- } \\
\text { ent solutions }\end{array}$ \\
& & & & \\
\end{tabular}

Table 2.3. Learning Style Inventory Source: Kolb et al. (2001).

\section{Peter Jarvis' critics on Kolb's model of experiential learning}

One of the most recognized continuators but also critics of Kolb's model of experiential learning is Peter Jarvis $(1987,1995)$. Jarvis reproached Kolb for not deepening the problem of knowledge. For him learning has to be situated and contextual. His idea was to prove that there is more than one response to the particular learning situation. He used Kolb's model and rebuilt it.

Jarvis was focusing on different responses to learning. He distinguished three different paths of learning: non-learning, some non-reflective learning, and reflective learning. The trajectories of each path are presented on Figure 2.5. Starting from non-learning, which is represented by boxes from 1 to 4 on Figure 2.5, in this path an individual is not responding to learning situation or responds in a very limited way through patterned behaviours. In case of non-reflective learning, the learning may happen in different ways. For example, there are some experiences that occur without much thinking and conscious practice (boxes 1-3 to 6 to either 4 or 9), or when individuals are acquiring some manual skills (boxes $1-3$ to 5 to 8 to 6 to either 4 or 9 ). The other example of non-reflective learning is memorisation (boxes 1-3 to 6 to 8 to 6 to either 4 or 9). Also in reflective learning, learning process can occur in different ways, like:

- Contemplation (boxes $1-3$ to 7 to 8 to 6 to 9 ), when experience leads to intellectual decision about it,

- Reflective practice (boxes 1-3 to 7 to 5 to 6 to 9), when reflection relates to action (reflection in and reflection on actions).

- Experiential learning (boxes 1-3 to 6 to 5 to 7 to 8 to 6 to 9), when pragmatic knowledge is learned. 


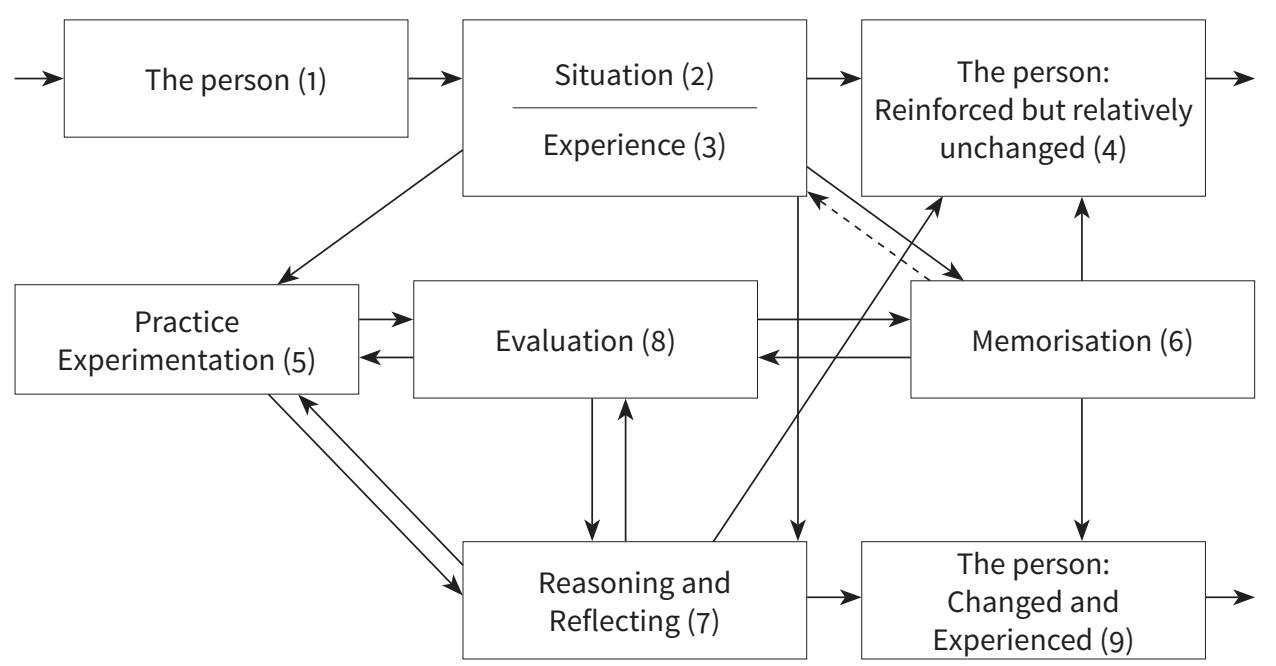

Figure 2.5. Jarvis' model of experiential learning Source: Jarvis (1994).

\section{Learning Styles by Honey and Mumford}

Basing on works of Kolb (1984), Honey and Mumford (1986) created four distinct learning styles: Activist, Theorist, Pragmatist and Reflector. The definitions of particular styles are included in Table 2.4.

\begin{tabular}{|l|l|}
\hline Learning style & \multicolumn{1}{c|}{ Definition } \\
\hline Activist & $\begin{array}{l}\text { Activists involve themselves fully and without bias in new experiences. } \\
\text { They enjoy the here and now, and are happy to be dominated by imme- } \\
\text { diate experiences. They are open-minded, not sceptical, and this tends } \\
\text { to make them enthusiastic about anything new. Their philosophy is: "I'll } \\
\text { try anything once". They tend to act first and consider the consequenc- } \\
\text { es afterwards. Their days are filled with activity. They tackle problems } \\
\text { by brainstorming. As soon as the excitement from one activity has died } \\
\text { down they are busy looking for the next. They tend to thrive on the chal- } \\
\text { lenge of new experiences but are bored with implementation and longer } \\
\text { term consolidation. They are gregarious people constantly involving } \\
\text { themselves with others but, in doing so, they seek to centre all activities } \\
\text { around themselves. }\end{array}$ \\
\hline Theorist & $\begin{array}{l}\text { Theorists adapt and integrate observations into complex but logically } \\
\text { sound theories. They think problems through in a vertical, step-by-step } \\
\text { logical way. They assimilate disparate facts into coherent theories. They } \\
\text { tend to be perfectionists who won't rest easy until things are tidy and fit } \\
\text { into a rational scheme. They like to analyse and synthesize. They are keen } \\
\text { on basic assumptions, principles, theories models and systems thinking. }\end{array}$ \\
\hline
\end{tabular}




\begin{tabular}{|c|c|}
\hline Learning style & Definition \\
\hline & $\begin{array}{l}\text { Their philosophy prizes rationality and logic. "If it's logical, it's good." } \\
\text { Questions they frequently ask are: "Does it make sense?" "How does } \\
\text { this fit with that?" "What are the basic assumptions?" They tend to be } \\
\text { detached, analytical and dedicated to rational objectivity rather than } \\
\text { anything subjective or ambiguous. Their approach to problems is con- } \\
\text { sistently logical. This is their 'mental set' and they rigidly reject any- } \\
\text { thing that doesn't fit with it. They prefer to maximise certainty and feel } \\
\text { uncomfortable with subjective judgements, lateral thinking and any- } \\
\text { thing flippant. }\end{array}$ \\
\hline Pragmatist & $\begin{array}{l}\text { Pragmatists are keen on trying out ideas, theories and techniques to see } \\
\text { if they work in practice. They positively search out new ideas and take } \\
\text { the first opportunity to experiment with applications. They are the sort } \\
\text { of people who return from courses brimming with new ideas that they } \\
\text { want to try out in practice. They like to get on with things and act quick- } \\
\text { ly and confidently on ideas that attract them. They tend to be impa- } \\
\text { tient with ruminating and open-ended discussions. They are essential- } \\
\text { ly practical, down to earth people who like making practical decisions } \\
\text { and solving problems. They respond to problems and opportunities 'as } \\
\text { a challenge'. Their philosophy is "There is always a better way" and "If } \\
\text { it works it's good". }\end{array}$ \\
\hline Reflector & $\begin{array}{l}\text { Reflectors like to stand back to ponder experiences and observe them } \\
\text { from many different perspectives. They collect data, both first hand and } \\
\text { from others, and prefer to think about it thoroughly before coming to } \\
\text { a conclusion. The thorough collection and analysis of data about ex- } \\
\text { periences and events is what counts so they tend to postpone reaching } \\
\text { definitive conclusions for as long as possible. Their philosophy is to be } \\
\text { cautious. They are thoughtful people who like to consider all possible } \\
\text { angles and implications before making a move. They prefer to take } \\
\text { a back seat in meetings and discussions. They enjoy observing other } \\
\text { people in action. They listen to others and get the drift of the discussion } \\
\text { before making their own points. They tend to adopt a low profile and } \\
\text { have a slightly distant, tolerant unruffled air about them. When they act } \\
\text { it is part of a wide picture which includes the past as well as the present } \\
\text { and others' observations as well as their own. }\end{array}$ \\
\hline
\end{tabular}

Table 2.4. Different learning styles according to Honey and Mumford. Source: direct quotation from Honey and Mumford (1986). 


\subsubsection{Humanistic approach to learning from experience}

\section{Malcolm Knowles and his humanistic approach to learning from experience}

The next important figure for the discussion on experiential learning is Malcolm Knowles (1913-1997), a famous American theorist and practitioner of adult education, especially recognized for coining the term andragogy $\mathrm{y}^{2}$ and developing theory of andragogy, i.e. adult learning. Knowles developed a humanistic approach to learning, which referred to great extent to self-directed learning and experiences. Learning in his view is a long-life process of continuing inquiry (Knowles 1980, p. 40). He believed that the mission of education is not to produce knowledgeable individuals (through transmitting knowledge) but competent ones, i.e. ones who are able to apply acquired knowledge in different contexts. This view on education was the result of perceiving the world as full of accelerating changes.

The concept of andragogy came into life with an observation that children and adults learn in a different way. The learning of adults is specific enough to develop a separate field devoted only to them - andragogy. According to Knowles the andragogy is based on five assumptions about self-concept, experience, readiness to learn, orientation to learning and motivation to learn. The idea is to help adult learners learn, although they stay responsible for their own learning and they are conscious of the learning process. The assumptions about andragogy concern the nature of adult learner. They are as following (Knowles, 1984, p. 12):

1. Self-concept: As a person matures his or her self-concept moves from one of being a dependent personality toward one of being a self-directed human being.

2. Experience: As a person matures he or she accumulates a growing reservoir of experience that becomes an increasing resource for learning.

3. Readiness to learn: As a person matures his or her readiness to learn becomes oriented towards the developmental tasks of his or her social roles.

4. Orientation to learning: As a person matures his or her time perspective changes from one of postponed application of knowledge to immediacy of application, and accordingly his or her orientation toward learning shifts from one of subject-centeredness to one of problem-centeredness.

2 In fact, German educator Alexander Kapp used the term andragogy earlier, in 1833. 
5. Motivation to learn: As a person matures the motivation to learn becomes more internal.

Particularly interesting is Knowles' view that adults need experiential learning. According to the researcher, experience is especially relevant for adult learners, as with age individuals accumulate higher number of experiences, they are more conscious of them and are able to (self) reflect. Experiences are the source for learning resulting in generating knowledge, which is possible to apply in practice. They are acquired actively, intentionally and purposefully. The learning process is learner-centred, autonomous, self-controlled and needs to be relevant to (professional) life of the learners. Learners by gaining experience thus learning build their identity. As Knowles appreciated group and collaborative learning, he considered individuals to be the source of learning through exchanging experiences to each other. Experiences may enrich learning practices and be shared between adult learners. The role of educator is helping individuals to develop the attitude that learning is a lifelong process and to acquire the skills for self-directed learning (Knowles 198o, p. 28). The learning techniques recommended by Knowles (1980) and related to experiential learning are: laboratory experiments, discussions, problem solving cases, simulation exercises, field experience etc.

\subsubsection{Modern constructivism and learning}

The late 1980 os and 1990 os brought attention to constructivism and social constructivism in learning. Constructivism is a learning theory and theory of knowledge whose fundaments were created by many before mentioned researchers, like: Piaget (regarded as the founder), Vygotsky or even Dewey. The theory states that humans construct their own and subjective understanding of the world they live in, through experiencing their ideas and reflecting upon them. Constructivism changed the view on the nature of knowledge (as the one created, not absorbed) and nature of learning (as reflected and experience-based). Comparing with behaviourism, it started to be regarded as more natural process of learning and better corresponding to the needs of the learner. Currently, there are many schools of constructivism, like social constructivism, radical constructivism, or critical constructivism. The development of constructivism in learning was to large extent supported by advancement of cognitive psychology.

The main idea of constructivism is that learners themselves create knowledge. They do not just acquire knowledge by repetition, imitation and memorization. Learners are engaged in learning and actively 
participate in the process of generating knowledge. They are involved in creating their own understanding of the world and construct meanings to what they have learned both in personal and social aspect. The learners experience and reflect on the experiences. They continuously test own hypothesis about world, they constantly compare their views and try to adapt them to own situation. Individuals confront what they know with the ideas that they come in contact with (Richardson, 1997).

In constructivism, knowledge arises as a result of interactions of a learner with environment and its stimuli. Individuals interpret these stimuli. Created knowledge is then subjective and contextualized. This means that there is no knowledge independent of the learner but the meaning he or she assigns to experiences. In constructivism knowledge receives more personal and social meaning. Constructive learning means both individual and collaborative learning. Learners individually and collectively assign meaning to a phenomenon, idea, activity or an object that they experience.

The change from behaviourism to constructivism in education means the change of the role of teacher from instructor to mediator and knowledge from being transmitted to being created. Learners are more in the centre of this process, which makes them more active, participative, individualistic, autonomous and independent, but also allows them to be responsible for learning. As Krueger (2007, p. 125) writes: The constructivist approach to human learning enhances learning how to learn, as students move from changing their deep cognitive structures to a metacognitive capability for understanding the changes they are making and the changes they need to make to become more expert. Having a strong sense of how they "connect the dots" affords human beings the ability to direct their own learning.

Cooperstein and Kocevar-Weidinger (2004), after Good and Brophy (1994), mention four main principles of constructive learning. These rules are as following:

1. Learners are not passive elements of learning process but construct their own meanings. The process of transferring knowledge is not easy. They need to take a conscious effort to make sense out of received information to be able to use knowledge in some new contexts. The effort lies in being able to create or discover the knowledge that would suit their belief system.

2. Learning should stand on prior knowledge. Learners have to match prior knowledge with new information in order to make some sense of it. They analytically compare and critically question what they learn, break or accept assumptions, all in order to achieve progress. 
3. The learning process is reinforced by social interaction. When constructivist learning is situated in social setting learners take a chance to share and confront their ideas with co-learners, especially in case of some conflicts that have to be solved. Learning in groups enables to vocalize the knowledge and discuss it.

4. Meaningful learning is developed through authentic tasks. The tasks should be selected in a way to influence these activities that are possible to encounter in real life.

One of the models of learning or pedagogy in constructivism is discovery learning, which is close to learning by doing concept. Discovery learning is inquiry-based type of learning, which means that it is a method in which learners are instructed and facilitated to create problem-based knowledge on their own. The main assumption about this method is that discovering oneself information and being able to apply it in practice teaches learners solving problems and thus is very important for their development and independence in thinking but also learning outcomes. Learners do not receive ready solutions but need to find themselves answers to the questions they struggle with. In seeking explanations, they have to creatively relate different information and facts, and refer to the experiences and knowledge they gained before. By doing this, they are able to remember more and exploit the knowledge in practice. Next to inquiry-based and problem-based focus, also experiments, cases-based and simulation-based learning are considered to be part of pedagogy of discovery learning. Discovery learning seems to be more appropriate for adults thus experienced learners. These types of learners possess enough cognitive skills and motivation to engage into learning and find meaning in their lives. The concept of discovery learning originates from the works of Jerome Bruner (1967).

\subsection{The fundaments of experiential learning and experience-based education}

The repetitive and overwhelming conclusion deriving from the analysis of philosophical, psychological and educative writings related to the topic of experience and learning is that experience is a complex phenomenon, which cannot be investigated merely as doing something or as participating in something. Experiencing goes beyond just happening or trying. Experiences mean the actual life-experiences of individuals and they cannot 
be given, they have to be collected and accumulated by the learner. Experience has two interconnected facets; one is more mechanical - resulting from taking actions and one mental - resting on reflecting. It involves both acting and thinking. The meaning of experience is difficult to grasp as it has both active and passive nature.

Everybody experiences but learning from experiences has to be learned and taught, which opens door for education. Applying the experience concept into learning is promising but also challenging as it refers to the natural human way of discovering the world. Experiential learning means connecting learning with real life. Experience is involved in all learning. It is at the same time the fundament and stimuli for learning practices. Both past and current experiences and both personal and collective experiences decide on how learners learn. Experiential learning is a natural process that happens beyond any limits, set by time, place or structure; but essential for individuals to confront with the world. Experiential learning is built upon the ideology of conscious individuals being able to learn and be responsible for self-development. Experiential learning is a long-life process of gaining and accumulating new knowledge. It gives grounding for learning and new knowledge creation, ready to be applied in any context.

Experiences have a positive return. The outcome of experiential learning is a constructed knowledge. Important aspect of experiential learning is that the knowledge is subjectively created by the learner and depends on the context of the learning process. The process of creating knowledge is continuous, thus the outcome is never the end stage of the process. It is liquid. The notion of experience includes exploitation of created knowledge in the future. Without possibility to apply knowledge in the future its value decreases and the possibility to gain experiences is lower. The experiences need to be relevant and continuous. In this sense, learning is a transition between different and relevant experiences leading to the thoughtful action taking. The more experiences an individual possesses, the more chances they will find their application in life. Apart from the number of experiences, their quality matters. However, the quality of experience is not assigned to the experience. It depends on the reflective skills of the learners, as well as the meaning that they will attribute to these experiences and their application in future. This again supports the argument of an important role of education in learning from experiences.

The process of learning from experiences depends on the level of maturity of the learners, i.e. their previous experiences and ability to learn from them. Children and adults learn in a different way, as they possess different number and quality of experiences. This is particularly important for education practices. It seems to be inadvisable to expect that for 
example university students, who are usually young people, share the same experiences as the experts in the fields they are educated in. More focus should be put on teaching reflective and critical thinking next to the process of gaining experience (which to some extent goes naturally with age and education).

Experiential learning should also lead to some transformation of the learner. Learning means transforming experiences into knowledge but also transformation of an individual. Ideally, it leads to some change, breaking old assumptions, creating new knowledge and quality. The process might include some conflicts, disparities, or disagreements.

Experiential learning also has a transactional character. The transaction takes place between the learner and the environment. It is a twoway relational process. It means that the learner and the environment influence each other and in consequence the created knowledge is derivative of individual and social (collective) knowledge. Experiential learning is interested not only in experiences per se but also their consequences for future. Transactional character of experiences is connected with the fact that learners link their past with the presence leading to the future.

The fundaments of experiential learning and experience-based education need to be built on concepts like: action, reflection, knowledge and experience. These concepts should not be investigated in separation but rather by referring to each other. They are intertwined in one process. Focusing on just one aspect of this process is always a limitation. As Freire suggested, putting attention only to action means investigating just activism and stressing only reflection - verbalism. Studying both actions and reflections without including an outcome of their interaction, that is knowledge, is also an important shortage. The learning process has to be knowledge-oriented. Knowing better is a sense of learning. Basing the process on experiences allows including and synthetizing all these elements. Experiences are the vehicle for learning of all types. In this sense, all learning is experience-based. Experiences are needed for reflective observation, active experimentation and abstract conceptualisation.

The complexity and ambiguity of experience is not enough recognized by entrepreneurship education research. While there are some parallels between the directions of development of different disciplines describing the notion of experience, there are also some important shortages on the entrepreneurship side. We arrive here to the essential claim of this monograph that in the entrepreneurship field experience is still often understood incompletely and even superficially. Although both doing and reflecting are recognized as an essence of entrepreneurial 
learning, the coexistence and interplay between actions and reflections are marginalised or neglected. There are separate studies on the role of action in entrepreneurial learning and ones on the merits of reflections in this process. Nevertheless, it often happens that neither actions nor reflections are embedded in a broader sense of experiencing. This seems to be an important shortage that entrepreneurship and entrepreneurship education struggle with by treating experience as an important element of entrepreneurial behaviour or mindset but not investigating its structure and dynamics. To prove that claim, the next chapter describes first how action, reflection and experience are understood in entrepreneurship education domain. Knowing it, it is possible to suggest some steps to overcome the lack of coherence and consistency in understanding entrepreneurial experience as a basis of entrepreneurship and entrepreneurship education. As a separate consideration, in the next chapter, the synthesis of action and reflection is offered and the concept of entrepreneurial praxis is introduced. 



\section{Chapter III \\ Towards the theory of entrepreneurial praxis}

For apart from inquiry, apart from the praxis, individuals cannot be truly human.

Paulo Freire

\section{Introduction}

Experiential learning has an established place in the tradition of education, both in theory and practice. Soaking into philosophical, psychological and educational disputes about experience and experiencing in chapter two, finally brings us to the stage of building fundaments of experiential learning in an entrepreneurship context and experience-based entrepreneurship education. After the review of different perspectives on experience and relating it to what we know about entrepreneurship education from chapter one, we may conclude that entrepreneurship has experiential nature and can be understood and investigated as an experiential learning process. However, despite a widespread recognition of experiential approach, its cross-discipline grounding is not well-recognized by entrepreneurship and entrepreneurship education disciplines.

This chapter questions the practices embodied in current educational practice within experiential learning and further introduces the concept of entrepreneurial praxis. First, it discusses different elements of the learning process in experience-based entrepreneurship education. In particular the relationships between entrepreneurship education, action, reflection and experience are investigated. Next, the selected advanced experiential learning approaches to entrepreneurship and consequences of entrepreneurial experiences are presented. The attention is given to dynamic learning perspective of entrepreneurship and critical experiences presented by Cope (2005) and experiential learning in the context of entrepreneurial opportunities by Corbett (2005). The chapter also includes entrepreneurial learning as an experiential process by Politis $(2005,2008)$. 
This part of the chapter ends up with enumerating some lessons from contemporary understanding of experiential learning in entrepreneurship context. Finally, the chapter includes the discussion on the potential of praxis in entrepreneurship research. It identifies major characteristics of entrepreneurial praxis and presents entrepreneurship as a research field built on entrepreneurial praxis.

What is claimed is that experiencing has to be a method of learning in order to bring benefits for the learner.

\subsection{Different elements of the learning process in experience-based entrepreneurship education}

This monograph offers a relatively new and not deeply enough investigated concept through which entrepreneurship and entrepreneurship education may be understood. It reinterprets the philosophical concept of praxis in context of entrepreneurship and further explores its meaning for entrepreneurship education. Investigating entrepreneurship as praxis, i.e. as the interplay of thinking and acting, enables to overcome some unnecessary disagreements in entrepreneurship an entrepreneurship education. It offers a more integrating dialogue and cohesion in the disciplines. Applying praxis enables to overcome this problem and to use one concept through and along different schools and approaches.

The result of this chapter is the view on entrepreneurial learning process through the lenses of praxis, that is the synthesis and interplay of action and reflection. What has been claimed after reviewing selected writings in philosophy of education, general education and psychology in chapter two, is that there are no two heterogenetic and separate elements of learning: action and reflection, but one process where they are intertwined and interrelated. The difference between action and reflection only has functional or instrumental character and their value comes when they appear together within a broadly understood experience. This perception of the learning process is influenced by great philosophers and educators like Dewey (pragmatic conceptualization of experience), Piaget (cognitive development), Lewin (social experiences), Bandura (social learning theory), Zimmerman (self-regulated learning), Freire (concept of praxis), Kolb (experiential learning model), Revans (action 
learning), Mezirow (transformative learning), Knowles (humanistic approach to learning). However, so far this way of understanding the learning process has not been broadly theorized and applied in entrepreneurship education and entrepreneurship fields. Although the fields tend to stress importance of action and reflection, it does not discuss them in a comprehensive way. What is missing is a convincing framework or theory of entrepreneurial learning process, basing on which entrepreneurial learning could be better understood and some recommendations for entrepreneurship education practice could be formulated. To start building this kind of theory, the concept of entrepreneurial praxis is introduced and discussed.

Investigating entrepreneurship education in the context of praxis concept enables to overcome some unnecessary disagreements in the field of entrepreneurship and entrepreneurship education. Praxis offers more integrating dialogue as it corresponds to both cognitive and humanistic approach to education. The challenge of both fields built on the praxis concept is to identify and understand the meaning of action and reflection and links between them. In order to achieve that, the foundations of these two poles have to be clarified and related to the concept of experience. Therefore, the chapter starts with a discussion on the relationships between entrepreneurship education and action, followed by the discussion on the links between entrepreneurship education and reflection, and ends up by synthetizing the experience-based learning in entrepreneurship education.

\subsubsection{Action in entrepreneurship education}

Although the issue of fragmentary and insufficient approach to the concept of experience in entrepreneurship education was already raised in chapter two, the problem is more complex - even actions, considered separately to experience, are not brought into discussion enough on entrepreneurship. As Corbett and Katz (2012, ix) notice, it is supremely ironic that for a field defined by an action, the discipline of entrepreneurship has had such an inconsistent tradition of actually studying action.

As it was already stressed, entrepreneurship education, both in theoretical and practical endeavours, tends to have a definite action focus but in fact the research results as well as practice of teaching are still not satisfactory. Putting more attention on action-oriented learning is a result of a conviction that focusing on doing makes education closer to entrepreneurial practice. Action orientation in entrepreneurship education illustrates the behavioural stream in entrepreneurship 
- entrepreneurs respond to the consequences of their entrepreneurial actions and act again. Actions mean some entrepreneurial behaviour in a particular moment and situations, and leading to venture creation. As a result, entrepreneurship education is based on the assumption that entrepreneurs or aspiring entrepreneurs learn by doing (Fiet, 2000). In consequence, educators put attention on trying to translate actions into teaching practice. Usually it means developing pedagogies of experiential learning, problem solving, or project-based learning (Jones and English, 2004) but in fact it means engaging students in entrepreneurial projects. Although having the opportunity to work in an entrepreneurial environment is very beneficial for students, learning entrepreneurship should not stop at this point, as the fundamental aim of learning is to generate some knowledge, not only to make students active. However, the existing studies on action approach in entrepreneurship education are often not enhancing the practice, as they are not comprehensive. The theory cannot support practice yet. Unfortunately, still not enough is known how acting and learning interact in entrepreneurial processes and how from this interaction knowledge is generated. One of the main problems is that in light of previous discussion on experience focusing merely on actions is a significant limitation and simplification. In this case, the learning process is misinterpreted and perceived in a too mechanistic view. Learning cannot be seen as solely as "actual doing" as the doing part is intentional and deliberate. Being active and engaging in actions is only one part of the learning process, although it is as essential as allowing to learn from experience. The other problem with action-oriented approach to entrepreneurship is also that despite huge support, it is not commonly applied (Lackéus, 2013). It calls more effort and engagement from students, teachers, as well as the education institution. In fact action orientation in entrepreneurship education is not only understood enough but also stays at declarative level.

\subsubsection{Reflection in entrepreneurship education}

For the learning to occur, an action should be accompanied with a reflection. Actions and reflections may appear parallel or consecutively one after another. They are tightly linked and interdependent. Actions form some kind of an external experience whereas reflections might be regarded as an internal experience; both belong to the complete learning process. In general, reflecting is a process of self-introspection to realise something. The role of reflection in experiencing and learning was 
stressed by previously mentioned prominent educators, such as: Dewey, Kolb or Mezirow. For example, Dewey (1976, p. 6) defines reflection as active, persistent, and careful consideration of any belief or supposed form of knowledge in the light of the grounds that support it and the further conclusions to which it tends.

Learning comes through reflection on the taken action but not just through any sort of thinking. It is activated by significant higher order mental processes. Reflection has to be critical and analytical to offer new knowledge and new understanding of the world, even if it would mean resigning from previous logic or breaking existing assumptions. It also has to bring some consequences for learners and give a meaning for them. Similarly to actions, reflecting needs to be intentional, deliberate and purposeful. Reflecting is a conscious process. Reflections enable achieving personal aims and taking transformative and constructive actions in future. They lead to changes bearing consequences for learners' lives.

Reflection enables a passage from what has been done to the new experience. It links different experiences so they do not appear as isolated events but rather form a continuum of experiences, as suggested by Dewey (1946). Learning is activated by the intertwined processes of gathering experiences and reflecting on them. Moreover, the quality of experience and learning depends on the deepness and accuracy of reflection. Reflection enables an evaluation of the experience and its relevance for the future.

Entrepreneurship education argues for a more reflectively based learning. In entrepreneurship education context, reflection was discussed for example by Cope and Watts (2000), Cope (2003), Pittaway and Cope (2007), Jones (2010), Neck and Greene (2011) or Higgings et al. (2013).

The term reflection is capacious. Neck et al. (2014, p. 16) adapted Brockbank and McGill (2007) offer six types of reflections. All of them are useful in generating knowledge from experiencing. The typology includes:

- Narrative reflection (description of what happened),

- Emotional reflection (focusing on feelings and emotions),

- Percipient reflection (perceptions and their influence on experiences),

- Analytical reflection (processes or elements of the events and their connections and interrelations),

- Evaluative reflection (assessing experiences and identifying the criteria for their evaluation),

- Critical reflection (considering the experience and approach, identifying alternatives or contradictions; reflecting on what was learned about self in the process). 


\subsubsection{Experiences in entrepreneurship education}

The idea that entrepreneurs learn from experiences comes from observations that very often, the second or subsequent business venture is actually more successful than the first one (Politis, 2008). This means that during experiencing some knowledge about business emerges and is efficiently used in the next ventures. At first glance, the value of experience is recognized in contemporary entrepreneurship education and the experience-based pedagogy celebrated. Entrepreneurship education is believed to bring the best results if equipped with entrepreneurial competence, the learner takes action leading to gaining experiences, enabling to generate new knowledge and being the foundation for some transformation of the learner. Learners learn in the entrepreneurial environment by taking entrepreneurial decisions leading to entrepreneurial actions, i.e. through experiencing. However, looking more carefully, experiences are considered superficially and are investigated mainly from one side - emphasising doing over reflecting. Although both sides of experience, action and reflection, are considered in research practice, the former dominates and the latter is still marginalised. They are rarely considered as one process and there are not enough attempts to reconcile these two perspectives, even if it usually means copying the ideas from general education. The entrepreneurship education does not sufficiently consider the reflective part of experiences and does not draw enough from older philosophies, psychological and educational traditions, for example from pragmatism. Experiences should be treated as a mechanism for developing knowledge through learning. The problem is that there is still not enough known about how the entrepreneurial knowledge is actually gained. The challenge is that there are numerous trajectories of entrepreneurial development, not one predefined way of becoming an entrepreneur and learning how to successfully start up a business.

Appreciation of experiential learning in general education brought an interest of entrepreneurship and entrepreneurship education scholars. As a result, experience-based learning started to be identified tightly with entrepreneurship and entrepreneurship education. The basic assumption of experiential learning in entrepreneurship context is that entrepreneurs learn from their past experiences, thus entrepreneurial knowledge may be generated through experiences and the entrepreneurial learning takes form of experiencing. 


\subsection{Advanced learning perspectives in entrepreneurship field}

\subsubsection{Dynamic learning perspective of entrepreneurship and critical experiences}

Cope (2005) is one of the first researchers who offers a more advanced learning perspective of entrepreneurship and integrative conceptualisation of entrepreneurial learning process. He highlights dynamic and contextual character of entrepreneurial learning and indicates its three aspects: dynamic temporal phases, interrelated processes, and overarching characteristics. The researcher is interested in both learning prior to business start-up and learning during the entrepreneurial process. In learning before venture creation process important role play:

$\checkmark$ entrepreneurial preparedness - personal and business skills and attributes gained before the new venture creation;

$\triangleright$ learning history - prior experiences and learning that prepared entrepreneur to start their venture; entrepreneurs looks backward and inward, reflecting on the adequacy of past experiences, and predicting how they can be applied in entrepreneurship in future.

$\checkmark$ learning task - what entrepreneur has to learn;

Cope recognizes the role of significant "events" or "episodes" in entrepreneurial learning. Individuals learn from critical experiences. Critical experiences can be both negative and positive in nature, as facing exceptional challenges and overcoming uncommon problems stimulates learning process. Critical experiences are not the only source of learning for entrepreneurs. They also constantly learn while running their companies. Learning then has more routinized, regular and repetitive character. However, in the case of entrepreneurial learning, learning from critical experience is more promising than the accumulation of more routinized and habitual "incremental" learning (Cope, 2005, p. 382). Cope (2005, p. 392) sums up: Entrepreneurial learning is not characterized by the notions of stability, consistency, or predictability. Rather, it has been demonstrated that the concepts of metamorphosis, discontinuity, and change more appropriately encapsulate the dynamics of this phenomenon.

Cope raises the problem of complexity of interdependence between reflection and action. In this relation there is place for critical experiences as they produce "reflection - for - action". Similarly to Dewey, he sees more benefits in focusing on the present and the future, not in the past. Individuals should learn from past experience keeping in mind solutions for more contemporary and future problems. 


\subsubsection{Experiential learning in the context of entrepreneurial opportunities}

The potential and importance of experiences is visible while discussing experiences from the perspective of opportunities, the core concept through which entrepreneurship is contemporary understood. The number and quality of experiences influence the number and quality of opportunities. The more valuable entrepreneurial experiences one has, the more probable that he or she identifies attractive opportunities and exploits them successfully.

Depending the experiences one has, he or she identifies different opportunities. Collection of experiences combined with information possessed defines the choice of being an entrepreneur. Following that idea, opportunities per se are not enough to become an entrepreneur. They need to be approached with at least the initial amount of experiences to be recognized and evaluated and become part of experiencing to be exploited. Adopting the premise that an opportunity is expressed through real actions (Dimov, 2011) shifts the focus to the entrepreneur as an experiencing actor.

One of the most influential theories on entrepreneurial opportunities was proposed by Alvarez and Barney (2007). Basing on teleological theories of human action, researchers made a distinction between discovery and the creation of opportunity, concentrating on the nature of opportunities, entrepreneurs and the decision-making context. They suggested that in discovery and creation, there is a different set of actions that are most effective. In fact, these actions are dependent on experiences accumulated. Experiences are useful both in creating and discovering opportunities. In the first case, experience enables to match even seemingly unrelated events, the second supports creative endeavours of individual.

Corbett (2005) examines experiential learning in the context of opportunity processes. He advocates the role of learning within entrepreneurial processes. First, he notices that knowledge is a static concept, which might be activated if put into use, for example by cognitive mechanism or heuristics. However, this activation does not mean learning. For Corbett, the cognitive mechanisms used by entrepreneurs in processing information into knowledge leading to entrepreneurial action are the result of learning process. He finds previous studies focusing more on storing and using information, but ignore transforming it and acquiring it thus learning. For Corbett, following Kolb (1984), learning is a social process by which knowledge is created through the transformation of experience (Corbett, 2005, p. 474). 
Corbett claims that experience is central to the learning process and introduces experiential learning theory in context of entrepreneurship and exploiting entrepreneurial opportunities. Experiential learning theory is process oriented. Its relevance to entrepreneurship research Corbett (2005, p. 482) explains in following words: By transforming experience into new knowledge, ELT allows individuals to discover new outcomes from their learning, which is just what entrepreneurs do when they are attempting to uncover new means-ends relationships.

Corbett adapts earlier introduced theory of experiential learning of Kolb into entrepreneurship. He comes up with the idea that different learning modes proposed by Kolb (1984) are more effective during different stages of the opportunities process. In other words, differences in learning influence the opportunity process - what type opportunities are discovered by whom. It means that individuals with a particular learning mode are more likely to be successful in particular phases of entrepreneurial process. The learning modes: convergent, assimilation, divergent, accommodative were introduced in chapter 2. As an illustration of the process of opportunity identification and exploitation Corbett chose the model introduced by Lumpkin et al. (2004). In this model entrepreneurial process consists of four subprocesses of preparation, incubation, evaluation and elaboration, and one event. Corbett matches the subprocesses with the learning modes in following pairs:

- preparation with convergent mode,

- incubation with assimilation mode,

- evaluation with divergent mode,

- elaboration with accommodative mode.

Corbett's research has had a big influence on entrepreneurship research and provoked more investigation on the relation between learning and venture creation. His research convinces that all learners can find a role within the process of opportunity identification and exploitation. However, even more important might be that all individuals who want to get engaged in venture creation are able to do so. Corbett explains that although we all have a tendency toward one learning mode, not all stages of opportunity process are essential for launching a business.

\subsubsection{Entrepreneurial learning as an experiential process}

Politis (2005) notices an important shortage of previous research trying to relate experiences and company's results. She stresses that experiences through the process of transformation lead first to entrepreneurial knowledge and only then they can influence company's performance. 
However, this influence may have indirect character. She also criticises that researchers imply a too static perspective on the process of entrepreneurial learning. She notes that not enough attention is given to the ways or methods entrepreneurs, through experiences, create entrepreneurial knowledge that enables them to start and manage their ventures. She also highlights the difference between "entrepreneurial experience" and "entrepreneurial knowledge". The first one means direct experience - participation or observation, whereas the second wisdom that derives from experience.

Similarly to Kolb (1984) and Corbett (2005), Politis understands experiential process as the process within which experiences of the entrepreneur are transformed into knowledge. She offers a conceptual framework explaining the process of experiential entrepreneurial learning and including entrepreneurs' career experience, the transformation process, and entrepreneurial knowledge as its three essential elements (see Figure 3.1).

Although in her work Politis often refers to Kolb's Experiential Learning Model, she is making a note that entrepreneurial learning does not have to follow its predetermined sequence of a four stages learning cycle. She perceives it as a more complex process within which individuals transform their experiences into knowledge in different ways. Learning is influenced by many types of factors and is contextual. This perspective is not stressed enough in Kolb's understanding of experiential learning.

The framework proposed by Politis clarifies that the entrepreneurial learning process is influenced by:

$\checkmark$ the link between entrepreneurs' career experiences (start-up experience, management experience, and industry-specific experience) and the development of entrepreneurial knowledge (A). The more career experiences an individual has, the more effective he or she is in identifying and exploiting entrepreneurial opportunities and coping with newness and uncertainty.

$\checkmark$ the way of transforming an experience into knowledge in relation to the created knowledge (B). Solely prior experience or only an act of transformation does not mean learning from experiences. Experiences have to be acted upon. They have to be continuously created and recreated. Experiences might be transformed either through exploration (taking new actions, experimenting) or exploitation (taking actions basing on prior knowledge). Both modes are equally good. If the entrepreneur relies more on exploration in transforming experience into knowledge, the more effective he or she is in identifying and exploiting entrepreneurial opportunities. If the entrepreneur relies more on exploitation, the more effective he or she is in coping with newness. 
$\Delta$ a set of factors shaping entrepreneurs' style of transforming experiences into knowledge (C). This set of factors includes: the outcome of previous entrepreneurial events, the predominant logic or reasoning of the entrepreneur, and the entrepreneur's career orientation.

The outcome of the previous entrepreneurial event might be a failure or a success. Failures give more ground for experimentation, whereas successes strengthen confidence and persistence. If an individual experienced more entrepreneurial failures, he or she is rather transforming experiences into knowledge through exploration. If an individual experienced more entrepreneurial successes, he or she is rather relying on exploitation.

Taking into account Sarasvathy's (2001) two logics of reasoning: causation and effectuation, if the entrepreneur relies more on effectuation, he or she more often uses explorative mode of transforming an experience into knowledge. If the entrepreneur relies more on causation while reasoning, he or she more often uses an exploitative mode.

Also different kinds of career motivations can influence types of learning. Entrepreneurs with a transitory or a spiral career orientation choose a rather explorative mode of transforming an experience into knowledge. Entrepreneurs with a linear or an expert career orientation choose a rather exploitative mode.

Politis's study has an important implication for learning and teaching. She questions the assumptions that education and training have a strong impact on creating entrepreneurial knowledge. Instead, she proposes focusing on teaching critical thinking, creativity and being reflective. These may increase motivation and ability to create entrepreneurial knowledge.

Similarly, Krueger (2007) highlights the importance not only of experiences per se but of how individuals process their experience. The nature of the experience, whether it was positive or negative, is less important than what learners have learned at a deeper level through this experience. In other words, not only being exposed to entrepreneurial activity matters, but also the quality of that experience.

\section{The consequences of entrepreneurial experiences}

The attempts to understand how through experiences new entrepreneurial knowledge is raised are not sufficient. According to Politis, there might be two reasons for that. First is that experiences are treated as stocks. It was already Reuber and Fischer (1999) who noticed that it is better to talk about the stream of changing in time experiences instead of stock at a particular moment. 
There is a difference between experiences and knowledge deriving from them (Politis, 2008; Reiber and Fischer, 1999). These two concepts are related but the transformation has to take place in order to obtain some knowledge from experiences. The transformation may take form of exploitation or exploration (March, 1991; Politis, 2008; Minniti and Bygrave, 2001). In exploitation, entrepreneurs take similar actions to the actions taken before and use pre-existing knowledge, whereas in exploration they create new knowledge being the result of taking new actions. The second reason is that a too static approach is applied to investigate entrepreneurial experiences. Politis (2008, p. 45) explains that learning process merely refers to the logic of explaining the casual relationships between entrepreneurs' previous experience and the performance of the subsequent venture. Little attention is hence devoted to how entrepreneurs, through experience, develop entrepreneurial knowledge that enables them to recognize and act on entrepreneurial opportunities and to organize and manage new ventures.

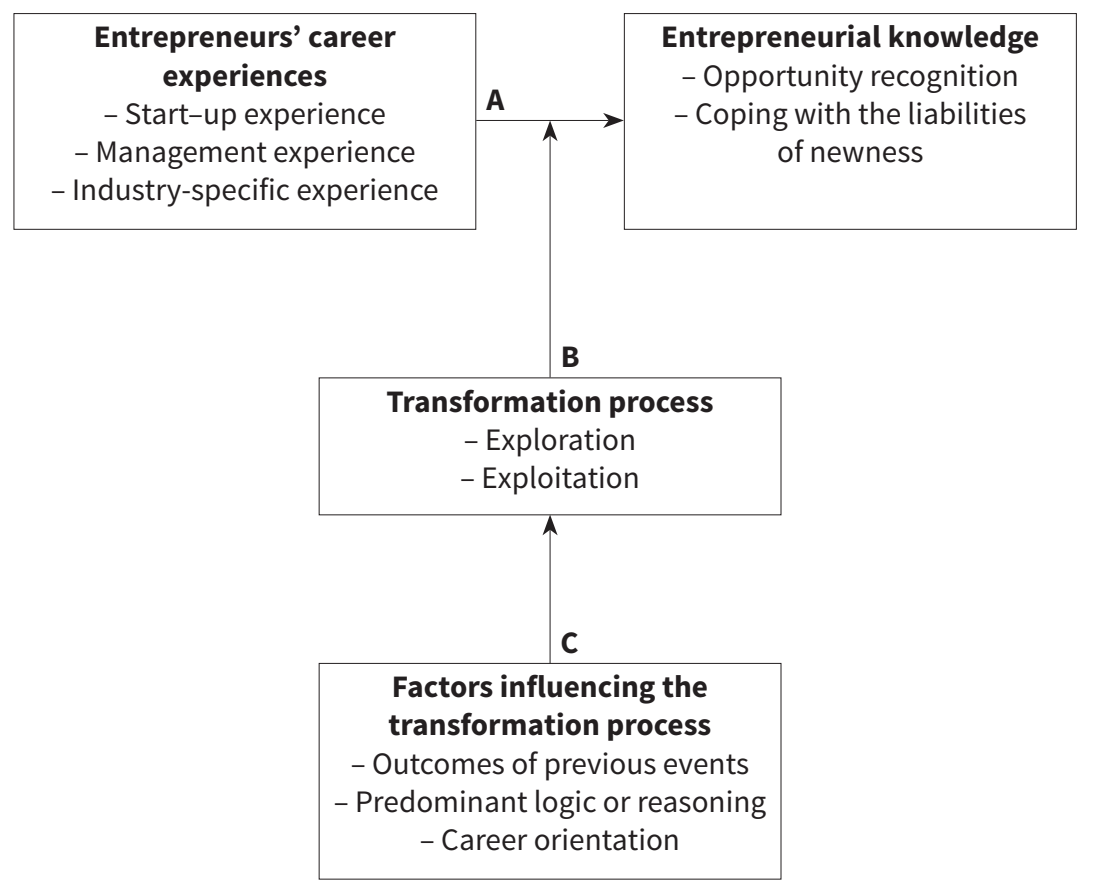

Figure 3.1. Conceptual framework of entrepreneurial learning as an experiential process

Source: Politis (2005). 


\subsubsection{Lessons from contemporary understanding of experiential learning in entrepreneurship education}

Synthetizing and drawing conclusions from the major writings on experiential learning in entrepreneurship context:

1. Entrepreneurial learning is a dynamic and continuous process, which may be disrupted by some discontinuities in form of significant events, which turns to be critical and a powerful source of learning. Entrepreneurial learning includes both unexpected episodes and routines or regularities. This makes the learning process concept only partly predictable and universal.

2. Learning is a never-ending process. It is impossible to conclude what are the results of learning, as the results become the grounds and source of future experiences and knowledge. Infinity of learning and its process orientation go together with understanding entrepreneurship as a phenomenon of emergence and entrepreneur as an emergent identity.

3. Experiences play an important role in entrepreneurial learning process. Entrepreneurial learning is experiential in nature. However, experiences do not influence entrepreneurial processes directly. They rather activate entrepreneurial knowledge that has a potential to impact venture creation. Through learning, experience becomes useful and meaningful in the entrepreneurial process.

4. Acquiring knowledge is not enough to learn. The essence of entrepreneurial learning is creating, forming and reforming, entrepreneurial knowledge. Created knowledge leads to new experiences and new ventures.

5. Similarly, not only gaining experiences is important but also transforming them. The transformation takes place through learning. Entrepreneurs have to make sense of their experiences and advance their entrepreneurial competences.

6. Experiences are subjective in nature. They are part of the entrepreneurs' life stories. Exploring the entrepreneurs' learning processes means uncovering life experiences and their meanings for entrepreneurs' life.

7. Learning in entrepreneurial context also means adaptation. The entrepreneur constantly has to adapt to the chaotic, uncertain and ever changing world. Their actions need to be adjusted to the uncertain environment that they operate in. Adaptation allows for development and progress. It compels intelligence, analytical and critical thinking. 
8. Both entrepreneurship and learning are socially situated processes and are related to change. Experiences are important in transformative type of learning. Entrepreneurial experience is not entrepreneurial knowledge, but the latter is transformed and generated from the former. This transformation may take a form of exploitation and exploration, and the success of learning depends on the appropriate balance between these two forms.

9. Experiential learning is influenced by the environment of the learner. It can be facilitated and enhanced by educators. To be powerful, the relationship between the learner and the educator needs to be based on non-judgement. Experiential learning demands the active role of the learner. It is a participative process that needs engagement of the learner.

10. Experiential learning is not only progressive but also emancipatory. It liberates learners allowing them to choose freely a career path coherent to their accumulated experiences.

11. Experiential learning seems to be a particular adequate for entrepreneurship education as at its core, entrepreneurship relates to taking action leading to gaining entrepreneurial knowledge. However, experiencing in not a blind trial and error method but should be a systematised, especially in its reflective part.

The relatively fresh idea of experiential learning, which could be much more further developed within entrepreneurship studies, is that learning means human adaptation. This perspective comes from psychology and education and could bring some new light on the entrepreneurial behaviour. The ability to adapt to changes in changing environment could illuminate entrepreneurial profile. Therefore entrepreneurship could not only be perceived as a force destroying old patterns and replacing them with new one as Etzioni (1987, p. 175) suggests.

Highlighting experience as a key concept in learning corresponds to both cognitive and humanistic approach to education. The process of learning is not purely cognitive; also the affective and conative side of personality and intelligence interfere. Nevertheless, the results of the learning are cognitive in nature. Experiential learning and education are considered to be part of constructivist paradigm of learning (Kyrö, 2005), however the theories and frameworks deriving from both cognitive and behavioural paradigms increase its understanding and usability. Experiential entrepreneurship education does not have to be analysed only from the perspective of constructivism. Studies on the psychological understanding of experience bring the conclusion that behavioural and cognitive approaches have to combine in a constructivist setting. 
For educators, some suggestions regarding entrepreneurship education could be synthesised in few points:

1. Educators should not expect mastery or perfection from learners, as they are not achievable and even impossible to define. Instead, they should expect progress, understood as a change into more entrepreneurial behaviour and thinking.

2. A good student is not the one who does not make a mistake but the one who is able to deal with them. Educators should encourage students to take action but also try not to make it a blind try and error. Experiencing in not blind trial and error practice method but should be a systematised way of learning from actions, thus also need development of its reflective part.

3. The quality of learning and teaching depends on both the student and educator. Thus it depends on the relationship between them. The cooperation between the learner and educator should be built on partnership, trust and responsibility.

4. The necessary element of successful learning is learners' motivation. The role of the educator is to build engagement prior to providing entrepreneurial knowledge. Building engagement and motivation, creating entrepreneurial knowledge stock by experiencing thus reflective actions, continue learning to excel.

5. Another issue worth considering before starting experiential education in entrepreneurship is to realise the profile of learners. The question is whether learners have grown up and are mature enough to be put into the world created by the adults. It is Dewey (1946) who notices that the knowledge and skills of mature persons does not have to have directive value for the experience of individuals who are not mature. Dewey (1946, p. 8) writes: Basing education upon personal experience may mean more multiplied and more intimate contacts between the mature and the immature that ever existed in the traditional school.

\subsection{Towards the entrepreneurial praxis}

\subsubsection{Characteristics of entrepreneurial praxis}

The idea of this monograph is to attempt to look at entrepreneurship differently, through the eyes of entrepreneurial learning. The logic behind this proposition is as follows. There is still lack of a "common denominator" 
which could be a starting point or at least a point of reference for many different studies in entrepreneurship. It may be assumed that all existing approaches, perspectives or lenses through which entrepreneurship so far has been investigated are particular cases of greater sense of entrepreneurship. There is an access to the greater sense of entrepreneurship only through these particular cases. They are all embodiments of the greater sense of entrepreneurship. All these cases appear in discourse, however the greater sense of entrepreneurship is transcendent as it goes beyond them. They are all right in their logics and are in line with general sense of entrepreneurship but their simple accumulation is not enough to understand the complexity and dynamics of entrepreneurship as they are intertwined and interrelated. The proposition is to include into entrepreneurship discussion the concept of praxis, which due to the context of investigation could be named entrepreneurial praxis. Entrepreneurial praxis could be the concept linking many perspectives on entrepreneurship.

Praxis has been already introduced and discussed in chapter two while discussing philosophy of education in Ancient Greece and philosophy of Freire. It was presented as the synthesis and interplay between action and reflection, thus the core of experiencing. Being a relatively fresh concept in entrepreneurship, praxis needs first to be characterised by its qualities and specifics in this new context.

First of all, entrepreneurial praxis is a process. This process takes places in different layers of reality: the world of objects, the world of perception, and the world of imagination. The most distinctive characteristic of entrepreneurial praxis is that it takes form of the constant dialogue between these different layers of reality, between entrepreneurs' actions and reflections, all leading to an entrepreneurial idea exploitation. The transition between the layers, thus crossing the structures of reality, fulfils the understanding of reality and enables its better exploitation. Thus the entrepreneurial praxis concept is based on the assumption of multiplicity of reality and human ability to cross its layers in order to complete their entrepreneurial ideas.

Entrepreneurial praxis is a conscious and critical process of improvements based on trying and reflecting which supports dialogue. Powerful reflection requires previous and consecutive action. Reflected action enables a mindful and responsive mindset. Awareness of oneself and of reality exposes the entrepreneur to the entrepreneurial opportunities. The critical approach and interpretation of oneself and reality empower the judgments and provoke questions. Entrepreneurs ask questions or create situations for the solutions that might be found only in doing. Thoughts are applied by doing. However doing here is not just a mechanical act, not even behaviour, but it involves creativity and information. The actions are aimed 
and purposeful. Through praxis entrepreneurs transform reality. They understand the objects they create but also these objects' understandings.

What is important from entrepreneurship point of view, is that praxis is very much situation oriented. Results of praxis take place in a real, not an imaginary, reality. As Carr and Kemmis (1986, p. 190-191) describe: Praxis has its roots in the commitment of the practitioner to wise and prudent action in a practical, concrete, historical situation (...). The significance of praxis is that it is a response to a real historical situation in which an actor is compelled to act on the basis of understanding and commitment.

In case of entrepreneurial praxis, this practical, concrete and historical situation is the entrepreneurial process leading to business idea execution in particular time and in particular space. Entrepreneurs refer to the situation they find themselves - they interpret and make judgments about the reality and act accordingly. Then they can observe and analyse the consequences of their actions to make better choices and decisions in the future. In this sense in praxis retrospective thinking leads to prospective action.

Praxis through subjectivity leads to objectivity. Venture creation cannot be perceived either as a purely subjective process, or as an objective one, but rather is an event in which subjectivity and objectivity are unified. Praxis materializes, thus it relates to objectively existing object (achieved through mechanistic process) but at the same time influences the object. It does not fully belong to natural world. The difference of subjectivity and objectivity is often used in entrepreneurship discussion as a cleavage point for ontologically different discussions, such as a debate whether entrepreneurial opportunities objectively exist and are discovered by entrepreneur or they are subjective and created by entrepreneurs (e.g. Alvarez and Barney, 2007). Praxis includes both subjectivity and objectivity.

Important aspect of entrepreneurial praxis is also its actors' commitment and responsibility. In entrepreneurial praxis actions are aimed, creative, informed and committed. Entrepreneurial responsibility is not just a state of mind or just a reaction to the situation, it is more a conscious response to what happens around an individual. This reply derives from inner conviction about rightness of thinking and obligation to act in a specific way. As Kurczewska (2014, p. 215) explains: Without taking action, responsible behaviour is not complete. It stops on intentional or declarative level but does not lead to any actions which are translated into changes in material world. In this sense entrepreneurial responsibility would mean moral obligation to follow business ideas leading to venture creation with all attending circumstances and all available resources, with the best possible efforts made. Thus a responsible entrepreneur is an acting man, taking 
responsibility for the opportunity he discovered or created, identifying with this opportunity and finally exploiting if it meets his evaluation criteria. He is conscious of the consequences of his behaviour for himself, for the team, community and society.

Importantly, praxis leads to liberation of entrepreneurs. The liberation is achieved by sense making. Interaction of reflection and action is a result of trying to make sense out of the world. Praxis is socially constructed and reconstructed. It is meaningful for the entrepreneur and in consequence it gives the entrepreneur the feeling of emancipation. The above discussion on the characteristics of entrepreneurial praxis leads to the question how entrepreneurship may be redefined as a field built on praxis.

\subsubsection{Entrepreneurship as a research field built on entrepreneurial praxis}

In order to launch a discussion on entrepreneurship as a research field built on entrepreneurial praxis, it is necessary to refer back to the question on what makes entrepreneurship a separate and distinctive domain. One of the most convincing arguments is that entrepreneurship investigates the individual and social processes, which are not fully embedded in any other disciplines; although they partly may belong to other domains. Hence, more studies on integrating material and social worlds are certainly welcome in entrepreneurship research. However, after some reflections, the uniqueness of the entrepreneurship phenomenon lays in covering and integrating material, social, but also mental worlds. Out of the mental world, through social interaction, entrepreneurial ideas come into existence in the material world. To prove that uniqueness of entrepreneurship concerns its ability to cross different layers of reality, it is sufficient to look closer at the concept of opportunities. Opportunities belong to mental sphere as they are born in the mind of the entrepreneur. They are also socially constructed through interactions with networks, experts, clients, suppliers and other stakeholders of an entrepreneurial process. Opportunities are social structures of relations. Whether they are created or discovered (Alvarez and Barney, 2007), opportunities to be exploited require an intertwined process of acting and thinking in order to appear in the material world. Therefore, entrepreneurship is a process of construction and changing throughout reality. It is a process full of reflexivity, awareness and creativity, but also the process requiring actual actions.

What is claimed here is that following this cross-reality path is possible through praxis. Therefore, conducting research on entrepreneurial praxis 
is a unique occasion to investigate how idealism through social interaction gives material effects. Moreover, this process of crossing between realities is accompanied by metaphysical experiences, which completes the understanding of being and becoming entrepreneur. Thus, having a concept embracing these different layers of the world but also blending and consolidating these realities would be beneficial for the field. It could be a starting point for a new perspective on theory building.

The next characteristic making entrepreneurship phenomenon unique is a broad time dimension. The essence of entrepreneurship lies in temporal dynamics (Bird and Page West III, 1997). Entrepreneurs, by using past experience, act in the present with current resources in order to create a better future in the form of new products, services, market etc. In this sense they are individuals who are able to match past, presence and future. The utility of praxis in constructing reality might be supported if it is perceived through the prism of continuity and change. Praxis enables continuity in time and allows changes of the dynamics between actions and thoughts.

Entrepreneurial praxis is not simply a practice of an entrepreneur; it is a mutual dependence and integration of the entrepreneur's thoughts and actions. Uncovering the interplay between reflecting and acting offers reconciliation of different views on entrepreneurship coming from different realities, like idealism or materialism. The result of praxis takes place in the inner and outer world. Through praxis, subjectivity and objectivity are united which restricts many ontological and epistemological discussions in entrepreneurship research, such as mentioned earlier controversies around objectivity and subjectivity of opportunities.

In the entrepreneurship field, praxis means intertwined process of dialectical movements that go from action to reflection and from reflection upon action to a new action, resulting in entrepreneurial venture. Therefore, reflection and action should not be polarised and investigated separately in entrepreneurship research. They appear together, stay intertwined and interdependent, and are equally important in entrepreneurial processes. Entrepreneurial process is praxis and by praxis an entrepreneur transforms reality. This suggests that entrepreneurial actions take place if they are preceded by critical thought. Actions take form through thinking. It does not mean that there is a linear relation between acting and thinking but rather each builds upon the other.

The entrepreneurship field is focused on processes of becoming (Bygrave, 1989/2003; Kuratko, 2005) and emergence. They relate to processes of creating something out of nothing, ex nihilo. Entrepreneurial praxis is also a process. Following process approach, it is necessary to investigate its dynamics understood as changes but also interplay between actions and 
reflections. However, the interest of the discipline should be put on this interplay, not only on actions and insights separately. The challenge is to be able to reconstruct an entrepreneurial process that is both: generic - all processes that are "entrepreneurial" are covered, and distinct - only entrepreneurial processes do this (Moroz and Hindle, 2011).

The entrepreneurial praxis concept corresponds to human approach in entrepreneurship research. Entrepreneurs are the source of understanding of reality and have an ability to transform it according to their own plans, visions, ideas and imagination. The transformation is achieved by the ability to conduct an internal and critical dialogue, based on subjective perception, but leading to objective outcomes - changes in reality. Entrepreneurial results are the effect of inner negotiations of the individual. Entrepreneurship is expressed through praxis. 


\section{Chapter IV \\ Responsibility and \\ entrepreneurship education}

The price of greatness is responsibility.

Winston Churchill

\section{Introduction}

The final chapter of the monograph is devoted to the concept of responsibility and its meaning for entrepreneurship education. It explains the reasons behind responsibility-based learning and education for social purpose. It introduces the concepts of entrepreneur as homo ethicus, as well as retrospective and prospective entrepreneurial responsibility. The chapter initiates first steps to build the concept of entrepreneurial responsibility in entrepreneurship education.

Responsibility seems to be an important aspect of entrepreneurial processes. In entrepreneurship research, the topic of responsibility has been discussed mainly from the perspective of social responsibility and sustainable development. Less attention has been given to responsibility as a moral issue that guides entrepreneurial behaviour. However, it seems that responsibility plays some role in venture creations thus studying it could bring more accurate understanding of entrepreneurial processes.

By entrepreneurial responsibility a moral responsibility is understood. It is a responsibility for both past decisions and actions, as well as their consequences in future. It is a reactive force, being realised in entrepreneurial actions and dependent on individual who are in interactions with others. Responsibility is a criterion of evaluation of entrepreneur's decisions and their consequences in form of actions. It is a kind of reaction to the circumstances and attitude towards. Entrepreneurs are creators of not only the value in economic terms but also values in ethical sense.

In this chapter education is viewed in light of responsibility. It is claimed that entrepreneurship education should be aimed at teaching 
learners taking personal and cognitive responsibility for ventures. The chapter ends with suggestions regarding implementing entrepreneurial responsibility into entrepreneurship education practice. The suggestions include:

- enhancing consciousness of importance of entrepreneurial responsibility among learners,

- creating learning environment of freedom and autonomy,

- combining individual responsibility with a collective one,

- implementing project and task oriented courses,

- teaching consequences of one's decisions and actions,

- including ethical and moral aspects of entrepreneurial decisions and actions into curricula,

- showing illustrative cases,

- embedding teaching of entrepreneurial responsibility in experience-based pedagogy,

- including psychological aspects into entrepreneurship education,

- changing the role of educator from instructor to facilitator.

\subsection{Reasons behind responsibility-based learning. Education for social purpose}

Before immersing into entrepreneurial responsibility topic, it is important to ask again what is the aim of entrepreneurship education. Most of the answers focus on functional and preparatory role of entrepreneurship education that is to prepare learners to become more entrepreneurial and to be able to operate and survive on the competitive market (to become entrepreneurs). According to European Commission (2015) the purpose of entrepreneurship education is to develop entrepreneurial capacities and mindsets. Despite broad understanding of both terms, entrepreneurial capacities and entrepreneurial mindset, this view is shared by many researchers and educators. The question is whether there is an actual need for more entrepreneurs or for more "better" entrepreneurs, whereas the "better" means entrepreneurs who effectively contribute to the development of society and economy. The second question is whether there is a need for many more entrepreneurs or for entrepreneurially thinking and acting individuals but not necessarily business owners. In other words, should entrepreneurship be introduced as a profession or more as a life philosophy? 
The aims of entrepreneurship educations are stated in different ways. Van Gelderen (2010) argues that the primary aim is to develop capacity among learners for autonomous action so the learner is able to enact business opportunity. According to Hill (1988), it should be focused on increasing awareness and understanding of the process of business ventures. For Jones and English (2004), it is a process of teaching individuals how to recognize commercial opportunities, building their self-efficacy, and transferring entrepreneurial knowledge and skills. All these referred goals of entrepreneurship education, although they accentuate different aspects of entrepreneurship, are correct. However, most of these understandings of the purpose of entrepreneurship education are limited to one view. They prioritize number of entrepreneurs over their quality. Shane and Venkataraman (2000, p. 218) defined the field of entrepreneurship as the scholarly examination of how, by whom, and with what effects opportunities to create future goods and services are discovered, evaluated and exploited. This definition changed the field of entrepreneurship and became the most cited one. In a natural way, entrepreneurship education in defining its goals followed Shane and Venkataraman's definition. As a result, most of approaches to entrepreneurship education accept that successful entrepreneurship education means that the learner creates or discovers opportunity, is able to evaluate it and finally exploit it. Not questioning the unquestionable role of opportunities in entrepreneurial processes, but many studies do not address the problem of the nature of opportunity and its value in human terms. The attention is put on identifying opportunities with the objective that the more the better. In evaluating opportunities the focus is on quality of opportunities in economic terms - whether they are economically viable. Referring to the mentioned above goals of entrepreneurship education one may ask:

- Are all autonomous actions of entrepreneurs good for society?

- Are all identified and enacted business opportunities valuable for society?

- Is awareness and reflectivity of the entrepreneur the sufficient condition of the "goodness" of entrepreneurial process?

An important but scarcely investigated research topic in entrepreneurship is the moral and ethical considerations around entrepreneurial opportunity process (Harris et al., 2009; Hannafey, 2003). While teaching various techniques of grasping and developing business opportunities, it is rarely mentioned that every opportunity creates some responsibility for the person who discovered or created it. Setting up a new business and implementing new innovations are only desired when the learner is able to take responsibility for their consequences. However, the majority of the discussions on entrepreneurial knowledge and skills are held without 
many considerations on how these will be used. Also when transformation as a part of entrepreneurial learning is considered, the element of responsibility is missing in most of the frameworks trying to explain the complexity and outcomes of this process. The topic of responsible generation of business ideas and enacting them is ignored both in theory and practice of teaching.

\section{Next question to be asked in entrepreneurship field}

Tracking back the evolution of entrepreneurship as a research field, the question what does an entrepreneur do (behavioural school of entrepreneurship) has dominated over the question who is the entrepreneur (trait school of entrepreneurship). The breakthrough was the article by Gartner (1989) “'Who is the entrepreneur?' Is The Wrong Question", in which he questioned the existence of the universal set of qualities and personal traits of entrepreneurs. According to Gartner (1989), the question of who is an entrepreneur was not adequate, because answering it does not bring a coherent definition of an entrepreneur and does not enrich the understanding of entrepreneurship. The author proposed to look at entrepreneurs from the behavioural perspective, i.e. to refer to how they behave and he discussed their entrepreneurial competences. However, defining entrepreneur or entrepreneurship through doing seems not to be sufficient. Actions may bring harm and not desired consequences. What is needed in economy and society is the responsible behaviour of entrepreneurs, i.e. entrepreneurs who are responsible for the actions they take and for any consequences related to these actions. Innovativeness and creativity, often perceived as the core of entrepreneurial mindset, are essential but only if accompanied with responsibility to act ethically and for a good purpose. Actions should also be taken with a respect to moral or ethical code, not to harm any element of entrepreneurial ecosystem, both in its social and economic dimensions. Setting up a new business and implementing new innovations are only desired when the learner is able to take responsibility for their consequences. Therefore entrepreneurship education should focus on learning through thoughtful, conscious and responsible doing.

\section{Change in direction of thinking about entrepreneurship education}

An important aspect to reflect on in entrepreneurship discourse is to be conscious whether we focus on entrepreneurs as they are wished to be or describe them as they actually are. Both views are needed but these two pictures do not have to be identical. However, in entrepreneurship research rather positive than normative approach dominates. Researchers 
rather try to better understand entrepreneurial behaviour and entrepreneurial processes. However, enhancing entrepreneurial policy and entrepreneurship education calls for more guidelines and suggestions enabling their execution, therefore value-laden opinions. The research is aimed not only to diagnose the world but also contribute to make it better. Entrepreneurial processes, at least to some extent, are able to be dependent on entrepreneurship education, which may stimulate them in order to be more effective and valuable.

The existence and performance of a company is not only the result of economic powers and market play, but it also, if not above all, represents the decisions of its owners (entrepreneurs) who are guided by morals and personal ethos. The responsibility of an entrepreneur then is much more than maximizing profits and realising strategy of a company. It does not mean that profits or a strategy are not important. They are critical, but the sense of entrepreneurship and entrepreneurial identity is beyond profit making. The entrepreneur has free will and decides to behave and enact in a particular way. Entrepreneurship is a derivative of entrepreneur's personal code of behaviour and ethics. Unfortunately, so far in research moral or ethical considerations regarding business concerned rather large organizations than small business and individual entrepreneurs (Spence and Rutherford, 2003).

Entrepreneurs generally put emphasis on ethical behaviour (Bucar and Hisrich, 2001). According to Harris et al. (2009), the existing literature regarding ethics and entrepreneurship may be categorized into three broad topics of: entrepreneurial ethics, social venturing, and entrepreneurship and society.

The entrepreneurial ethics theme calls for searching answers for the following questions (Harris et al., 2009):

- How do entrepreneurs differ from non-entrepreneurs with respect to ethics?

- How do entrepreneurs make ethical decisions?

- What particular ethical dilemmas arise from entrepreneurship?

- How does technological innovation impact entrepreneurial ethics?

- How do organizational ethics develop in a new venture?

- How does stakeholder theory apply to new ventures?

In social venturing theme researchers ask (Harris et al., 2009):

- What is social entrepreneurship?

- What distinctive ethical issues arise in social ventures? How is performance measured?

- What about disenfranchised entrepreneurs?

- How do social ventures differ from traditional ventures? 
- What is the role of 'purpose' in social entrepreneurship? In traditional entrepreneurship?

When entrepreneurship and society intersection is concerned the questions are following (Harris et al., 2009):

- What role does entrepreneurship play in social welfare?

- What is the role of entrepreneurship in macroeconomic development?

- What other societal roles does entrepreneurship play?

- How do entrepreneurs enact social change?

- In what ways can entrepreneurship be socially unproductive?

- What are the ethics of opportunity exploitation?

There are two different ways through which entrepreneurship is viewed in societies. One relates entrepreneurship to rivalry, competition, capitalism and exploitation. This view is more popular in countries with high economic and social inequalities. The second perceives entrepreneurship as a tunnel to growth, innovation and (self) development, but also a way to solve many social problems. Democratic education serves social purpose and builds the capacity for democratic renewal. These two different views on entrepreneurship influence the way entrepreneurship education is perceived and designed. The first view corresponds more to education aimed at professionalization, whereas the second to the view of education for social purpose. The characteristics of education for professionalization and education for social purpose are included in table 4.1.

\begin{tabular}{|l|l|l|}
\hline Criteria & Education for professionalization & Education for social purpose \\
\hline Focus & $\begin{array}{l}\text { Focus on individual and individual } \\
\text { actions }\end{array}$ & $\begin{array}{l}\text { Focus on community and society, } \\
\text { collective actions }\end{array}$ \\
\hline Goal & $\begin{array}{l}\text { Employment and career, } \\
\text { Self-development }\end{array}$ & $\begin{array}{l}\text { Development of society members } \\
\text { leading to progress of societies; } \\
\text { Empowering and liberating society } \\
\text { members }\end{array}$ \\
\hline Society & As a context & As a core \\
\hline Profession & As a goal & As a mean for social change \\
\hline Values & Individualistic & Collective \\
\hline Knowledge & $\begin{array}{l}\text { Mainstream, } \\
\text { Brought and transmitted from } \\
\text { "outside" }\end{array}$ & Created from the needs of society \\
\hline
\end{tabular}

Table 4.1. Education for professionalization and for social purpose Source: own compilation. 


\subsection{The fundaments of entrepreneurial responsibility}

Williams (2004) distinguishes two approaches to moral responsibility. One view interprets it as responsibility for actions as stemming from our ability to exercise self-control. Moral responsibility is possible because individuals have free will and freely choose their actions independently. The second approach positions attributions of responsibility in terms of on-going relationships with one another (Williams, 2004). As Williams enumerates, this view highlights the aspects of mutual accountability, moral education, and assessments of character. Both approaches seem to be important for entrepreneurial responsibility.

Responsibility is not merely a state of mind or the reaction to the situation, it is a more a conscious response to what happens around an entrepreneur. This response derives from inner conviction about the rightness of thinking and obligation to act in an adequate way. Responsibility is reflected in executing actions that are coherent with entrepreneur's identity, values and ethics. A distinctive feature of responsibility is that it is taken for actions despite the consequences. Actions are necessary conditions for the responsible behaviour to be completed. Responsibility does not stop on an intentional or declarative level but leads to actions. In this sense entrepreneurial responsibility means moral obligation to follow entrepreneurial opportunities leading to venture creation with all attending circumstances and all available resources, with the best possible efforts made. A responsible entrepreneur is an acting individual, taking responsibility for the discovered or created opportunity, who exploits it if it meets his ethical evaluation criteria. He is conscious of the consequences of his behaviour for himself, for the team, community and society.

Entrepreneurial responsibility might be developed among learners. The study of Kurczewska $(2013,2014)$ conducted on university students shows that the evolution of responsibility in authentic entrepreneurial learning starts with enhancing responsibility for self and self-development. Together with commitment, learners start to care about others and learn to take but also to share responsibility. Next, their responsibility refers to a broader audience - the community and society, they exist in. The escalation of entrepreneurial responsibility starts with self-centred learning, then it transforms into a more social and collaborative learning and finally becomes entrepreneurial learning. 


\section{Dehumanization of responsibility in entrepreneurship research}

In entrepreneurship research, responsibility is almost solely discussed from the point of view of social responsibility of companies, which, in turn, is adapted from the concept of corporate social responsibility. Surprisingly, despite an obvious human character of responsibility, it is associated more with firms rather than individuals. Much less is known about individual or moral responsibility, thus the nature and role of entrepreneur's responsibility. Moreover, even if the term moral entrepreneur appears, it is regarded as a person running a social enterprise, although it should be related to all entrepreneurs regardless of the type of business they run. In this sense all companies are social, as morality, ethics and social awareness should represent all entrepreneurs. Of course it may be argued that responsibility of companies (especially small ones which are usually the focus of entrepreneurship research) are the derivatives of responsibility of their entrepreneurs. However, it seems to be a too big simplification as the values, attitudes or motives always belong to the individual who may only transpose it into the company's philosophy, mission or strategy. Entrepreneurial responsibility is not a corporate social responsibility. It is also not limited to firms with primarily social objectives. Separation between social entrepreneurship and entrepreneurship in terms of responsibility seems not to be right. The differences between corporate social responsibility, social entrepreneurship and entrepreneurial responsibility are presented in Table 4.2.

\begin{tabular}{|l|l|l|l|}
\hline Criteria & $\begin{array}{c}\text { Corporate Social } \\
\text { Responsibility (CSR) }\end{array}$ & $\begin{array}{c}\text { Social } \\
\text { Entrepreneurship (SE) }\end{array}$ & $\begin{array}{c}\text { Entrepreneurial } \\
\text { Responsibility (ER) }\end{array}$ \\
\hline Coverage & $\begin{array}{l}\text { Big companies having } \\
\text { a social component } \\
\text { in their missions or } \\
\text { strategies }\end{array}$ & $\begin{array}{l}\text { Firms with primarily } \\
\text { social objectives }\end{array}$ & All firms and ventures \\
\hline Occurrence & $\begin{array}{l}\text { CSR starts when profits } \\
\text { are high enough to } \\
\text { invest in socially aware } \\
\text { projects }\end{array}$ & $\begin{array}{l}\text { SE starts from the } \\
\text { idea generation } \\
\text { and is focused on } \\
\text { solving some social } \\
\text { or environmental } \\
\text { problems }\end{array}$ & $\begin{array}{l}\text { ER is present at every } \\
\text { stage of entrepreneurial } \\
\text { process, from idea gen- } \\
\text { eration till opportunity } \\
\text { exploitation and man- } \\
\text { aging the venture; } \\
\text { it does not have to be } \\
\text { related with any social } \\
\text { or environmental issues }\end{array}$ \\
\hline $\begin{array}{l}\text { Aim and its } \\
\text { nature }\end{array}$ & $\begin{array}{l}\text { CSR is part of a strategy } \\
\text { of the company to im- } \\
\text { prove social image and }\end{array}$ & $\begin{array}{l}\text { SE is part of the identity } \\
\text { of the firm (usually } \\
\text { quite strong) }\end{array}$ & $\begin{array}{l}\text { ER is a natural attitude } \\
\text { guiding entrepreneurs } \\
\text { in their choices }\end{array}$ \\
\hline
\end{tabular}




\begin{tabular}{|c|c|c|c|}
\hline Criteria & $\begin{array}{c}\text { Corporate Social } \\
\text { Responsibility (CSR) }\end{array}$ & $\begin{array}{c}\text { Social } \\
\text { Entrepreneurship (SE) }\end{array}$ & $\begin{array}{c}\text { Entrepreneurial } \\
\text { Responsibility (ER) }\end{array}$ \\
\hline $\begin{array}{l}\text { Aim and its } \\
\text { nature }\end{array}$ & $\begin{array}{l}\text { promote a brand } \\
\text { Primacy of business } \\
\text { goals }\end{array}$ & Primacy of social goals & $\begin{array}{l}\text { Accordance with human } \\
\text { actions }\end{array}$ \\
\hline Driving force & Growth and wealth & $\begin{array}{l}\text { Social mission and } \\
\text { change }\end{array}$ & Ethics and morality \\
\hline Result & Progress of economies & Progress of societies & $\begin{array}{l}\text { Progress of humans and } \\
\text { societies }\end{array}$ \\
\hline Form & $\begin{array}{l}\text { Usually philanthropy } \\
\text { and charity }\end{array}$ & $\begin{array}{l}\text { Business activity } \\
\text { solving social problems }\end{array}$ & $\begin{array}{l}\text { All decisions and } \\
\text { activities are taken } \\
\text { with ER } \\
\text { ER is based on the } \\
\text { idea of giving back to } \\
\text { community }\end{array}$ \\
\hline $\begin{array}{l}\text { Operational } \\
\text { areas }\end{array}$ & Traditional business; & $\begin{array}{l}\text { Beyond traditional } \\
\text { business, like: poverty } \\
\text { alleviation, health care, } \\
\text { education, environmen- } \\
\text { tal preservation, com- } \\
\text { munity regeneration, } \\
\text { welfare projects }\end{array}$ & $\begin{array}{l}\text { Traditional and non- } \\
\text { traditional business }\end{array}$ \\
\hline Scale & $\begin{array}{l}\text { Big scale } \\
\text { Huge promotion } \\
\text { Global reach }\end{array}$ & All scales & $\begin{array}{l}\text { No scale } \\
\text { No promotion } \\
\text { Local reach (usually) }\end{array}$ \\
\hline Values & $\begin{array}{l}\text { Corporate values, pre- } \\
\text { defined by strategists } \\
\text { and marketing special- } \\
\text { ists according to firm's } \\
\text { profile, type of custom- } \\
\text { ers and firm's objectives }\end{array}$ & $\begin{array}{l}\text { Individual values } \\
\text { translated directly into } \\
\text { firm's values }\end{array}$ & $\begin{array}{l}\text { Individual values of the } \\
\text { entrepreneur which } \\
\text { derive from his ethics } \\
\text { and morality }\end{array}$ \\
\hline Scope & $\begin{array}{l}\text { A separate part of a } \\
\text { company deals with } \\
\text { CRS } \\
\text { Relates to particular } \\
\text { activities of a company, } \\
\text { usually exposed to } \\
\text { audience }\end{array}$ & $\begin{array}{l}\text { Integral part of a firm } \\
\text { Relates to social } \\
\text { problems }\end{array}$ & $\begin{array}{l}\text { Natural attitude } \\
\text { Relates to each decision } \\
\text { taken by entrepreneur }\end{array}$ \\
\hline $\begin{array}{l}\text { Personal } \\
\text { costs }\end{array}$ & Do not exist & $\begin{array}{l}\text { Exist and are taken into } \\
\text { consideration }\end{array}$ & $\begin{array}{l}\text { Exist and are taken into } \\
\text { consideration }\end{array}$ \\
\hline
\end{tabular}

Table 4.2. Differences between corporate social responsibility, social entrepreneurship and entrepreneurial responsibility

Source: own compilation. 


\section{Why the discussion on entrepreneurial responsibility should be enhanced?}

Responsibility should not be neglected from entrepreneurship research and discussion, as it is important at each stage of entrepreneurial process. Responsibility shapes the nature of ventures but also influences the intentions to start up a business. The morality of entrepreneurs decides on spotting the opportunity, its evaluation and the decision whether to exploit it. The effect of the entrepreneurial process is a creation of a value. This value is a derivative of entrepreneur's values and identity being linked with responsibility. However, as Hannafey (2003, p. 102) wrote: The present research is unclear about the precise ethical meaning of entrepreneurial responsibility and obligation.

Discussions in entrepreneurship mirror their times. In the world that is becoming more and more complex, disharmonic and diverse, creating endless opportunities, full of unexpected events and numerous changes, individuals need more guidelines. Crisis of state and church, traditional providers of some ethical guidelines, provokes more discussions on responsibility and morality. This need is enhanced by the loss of confidence in transparency and honesty of markets and institutions. As a result, many individuals are lost and miss some directions or protocol. Business ethics may differ by country due to different historical, social or economic situation (Vogel, 1992). Responsibility is more universal and thus might be regarded as a part of entrepreneurship education.

As Fischer et al. (2005) notice, the nature of entrepreneurship is to break existing rules and stretch the frontiers. Entrepreneurs bring new ideas, products, technologies and innovative production methods. These new situations provoke lots of ethical dilemmas and the need for some universal guiding principles. In a dynamic environment, while operating in uncertainty, entrepreneurs need to confront and cope with the unknown, equipped with some reference point helping them to take right decisions. Entrepreneurs are perceived as change agent, but the change has to bring a positive outcome in universal sense. Therefore, entrepreneurial action should mean appropriate actions.

What should also be clarified and distinguished is the difference between duty and responsibility. Duty is the issue that must or has to be done, such as in case of entrepreneurs paying taxes or paying employees. Responsibility is the thing that has no obligation, but an individual does it because it is important to him or her. It is a voluntarily act being the result of an individual choice. Caring for customers, employees and products is a responsibility. Responsibility and care go hand-in-hand and might be accompanied with some sacrifice. It has a deeper value than duty. 


\subsubsection{Entrepreneur as homo ethicus}

David McClelland (1961) was one of the first researchers asking about ethics and responsibility in entrepreneurship. In his motivation theory he associates achievement with taking responsibility for finding solutions to problems, finalizing tasks, realizing objectives etc. Entrepreneurs are successful if they feel responsibility for achieving assumed goals. Possessing the knowledge and being able to find a solution for company's problems or challenges means that the entrepreneurs also have to take responsibility for any consequences of their actions.

All human relations wear a notion of responsibility. Therefore taking responsibility is not an individual disposition or attribution but always an issue related to and evaluated by others. Entrepreneurs take decisions affecting many other individuals, such as employees, customers, suppliers, or business partners. The challenge is that there is usually no absolute "right" and "wrong". Decisions are shaped by interactions between individuals and the socio-cultural environment.

Entrepreneurial ethics is still merely taught at the universities. If it is included, it is usually limited to learning about business ethics and corporate social responsibility, presented either from historic or philosophical point of view or through cases (often negative ones). What is missing is developing programs and methods that not only increase awareness of the problem of responsibility and ethics, but also equip students with some standards, solutions and courage to be responsible for their decisions and actions. So it is not just learning about but also, if not mainly, for. This means that education would not only provide knowledge and understanding but also influence attitudes and behaviours.

The intersection between entrepreneurship research and the entrepreneurial responsibility concept is interesting and promising. It exists at each stage of entrepreneurial process. The ethical dilemmas of entrepreneurs may relate to:

- The ownership of business idea and contribution to the idea development,

- The usage of all types of resources,

- Entrepreneurial team dynamics (recruitment, composition of the team, fairness in distributing tasks and their evaluation, relationships between team members, salaries, dividing shares),

- The way business ideas are presented to potential investors,

- Relationships with customers (for examples how the base of customers is build),

- Relationship with suppliers, partners and other co-operators,

- Product development and pricing, 
- Marketing and advertisement (the way products or services are presented),

- Closing up business or dealing with bankruptcy,

- Balancing between professional and private life;

In each of these cases entrepreneurs may struggle as they conflict more capitalistic vision of rapid growth and money earning as usually ethics drives business less than potential profits.

\section{What does it mean to be entrepreneurially responsible?}

Cook-Sather (2010, p. 556) wrote: Responsibility refers to the social force that binds one to the courses of action demanded by that force. To be responsible is to be answerable or accountable for something within one's power, control, or management; it is to be able to make sense of and respond within one's sphere of association; it is to take action based on one's sense of connection and answerability to the self and to others.

Synthetizing this definition and positioning it in entrepreneurship context, responsibility is a reactive force, answerable and realised in entrepreneurial actions and dependent on the individual but in interactions with others. Responsibility is a relational concept, shaped by social force. It means that ethics of an entrepreneur, his values and attitudes, are coinciding with values and attitudes of society. Their functionality is built through social interactions and relationships. Without social world around entrepreneur morality thus discrimination between right and wrong would be problematic. Entrepreneurs are social agents but they might be also perceived as moral agents.

Responsibility is a criterion of evaluation of entrepreneur's decisions and their consequences in the form of actions. It is also kind of reaction to the circumstances and attitude towards. Entrepreneurial responsibility is not only awake when some problems emerge but it is an everyday attitude and a factor taken into consideration in entrepreneurial decisions. Responsible entrepreneur knows his roles as being entrepreneur means being conscious of own responsibility. Being responsible means being able to distinct between right and wrong, not only from individual perspective but in a much broader sense.

Entrepreneurs, as all individuals, have free will. It means they may or not think and behave in responsible or irresponsible way. In their choices they are guided by rationality but also intuition and personal values. Entrepreneurs rely on their judgments when taking decisions. Being responsible means being reactive. Not thoughts but reactions of entrepreneurs are important. Entrepreneurs are evaluated by their performance. Responsibility "materializes" in the situation when the entrepreneur faces conflicting solutions to some issues which are desirable but different in 
terms of ethics or in the situation where two different principles guiding entrepreneur are conflicting ones. What should be stressed is that entrepreneurs are not ethical or unethical per se but their entrepreneurial decisions and actions lead to both ethical and unethical consequences.

\section{Values and entrepreneurship}

The issue of entrepreneurial responsibility is linked to values. Previous entrepreneurship research regarding values mostly focused on cultural values (Davidsson and Wiklund, 1997; Hofstede, 2003; Mueller and Thomas, 2001; Schwartz, 1992; Noseleit, 2008; Liñán et al., 2013). Personal values have been studied much less in the entrepreneurship field, although they have the potential to explain entrepreneurial process better (Holland and Shepherd, 2011). Entrepreneurs are creators of not only the value in economic terms but also values in ethical sense. Individual values might be regarded as the lenses through which entrepreneurial actions, their desirability and feasibility, are evaluated. They induce valences of perspective outcomes, influence decisions (Holland and Shepherd, 2011) and play a role of guiding principles while making choices. They influence motivated behaviour (Schwartz, 2006).

\subsubsection{Retrospective and prospective entrepreneurial responsibility}

The word "responsibility" comes from the politics and even in philosophy, to great extent, it has been discussed in political context. Surprisingly, the word does not have long philosophical traditions (Ricoeur, 2000). It started to be discussed more widely no sooner than in $18^{\text {th }}$ century. However, from the perspective of personal concern and free will, it was brought into light only in $2 \mathrm{O}^{\text {th }}$ century (Williams, 2015).

Understanding of the concept of responsible actions calls for going back to ethics, to begin with Aristotle's Nicomachean Ethics, or Ethics and Poetics. In light of Aristotle's views, actions are done not for doing per se but to serve some purpose (Ackrill, 1978). All actions should come along with eudaimon that is "the highest good" all human activity is oriented towards. Aristotle made a distinction between voluntary and involuntary (or non-voluntary actions). The first ones, led by desire or practical motive, bear a notion of responsibility for their results. However, the moral virtue depends on an individual (an agent), not an action.

Responsibility concerns ethical dimension of entrepreneurs' actions. Entrepreneurs hold responsibility for the decisions taken in the past 
but also take responsibility for future consequences of their actions. These two forms of responsibility might be called retrospective and prospective entrepreneurial responsibility. Prospective responsibility refers to issues entrepreneurs decide to deal with and roles (also duties, obligations) entrepreneurs have. Retrospective responsibility refers to what entrepreneurs have already accomplished or fail to accomplish, to their accountability. These two forms of responsibility are linked. Without prospective responsibility, individuals do not hold retrospective responsibility.

\subsection{Towards entrepreneurial responsibility in entrepreneurship education}

There are still not enough considerations in entrepreneurship discourse considering that business ideas, opportunities and ventures may be valuable and invaluable, constructive and destructive, useful and harmful, bringing progress and depleting. The statement that entrepreneurship means only growth should not be repeated without relating to the ethics of entrepreneurs and their responsibility for the consequences of all actions that they take in their business life. In the broad discussion on entrepreneurial opportunities where the sense of entrepreneurship lies in pursuing opportunities it is ignored that this pursuit should not take place regardless of the ethics and morality of entrepreneur. Not every opportunity should be exploited but only the opportunity that an entrepreneur is able to take responsibility for, whether it relates to social entrepreneurship or not. A similar situation of ignorance of ethics and responsibility issue may be noticed in entrepreneurship education field.

The links between education and responsibility are obvious. It was already Dewey (1946) who linked education with democracy understood not only as freedom but also as responsibility. Responsibility is an intellectual attitude that is not possible without reflections. Responsibility is an important part of experiential learning. Hoover and Whitehead (1975, p. 25) define existence of experiential learning when a personally responsible participant(s) cognitively, affectively, and behaviourally processes knowledge, skills, and/or attitudes in a learning situation characterized by a high level of active involvement. However, this approach is unique. Entrepreneurial learning is classically defined 
after Rae as learning to recognise and act on opportunities, and interacting socially to initiate, organise and manage ventures (Rae, 2005). In the light of previous discussions, adding "in a responsible way" would be beneficial.

In this monograph it is claimed that the aim of entrepreneurship education is to enhance only theses entrepreneurial processes that lead to valuable ventures and prevents individual to consider damaging and unethical options. The way to achieve it is to include some components that would pay attention on entrepreneurship responsibility into the entrepreneurship curricula. As Rae (2010, p. 599) wrote, education is an important formative medium for influencing entrepreneurial culture and behaviours. He continues by stating that the role of education is to shape ideas of what it means to be an entrepreneur and it is an obligation of each entrepreneur to act in a way that does not make any harm. The idea is to mainstream entrepreneurial responsibility as a concept that helps to build a society of entrepreneurs that are aware of the impact of their decisions and actions, and in this way to build a better world.

By agreeing that entrepreneurial responsibility can enrich the learning process, the next step is to propose some recommendations how to execute entrepreneurship education including entrepreneurial responsibility element in practice. This less common component of entrepreneurship education belongs more to learning through or for than learning about entrepreneurship, if we use traditional division of forms of education. It is also situated in rather practical paradigm of learning and teaching. It does not exclude of course some theoretical foundations of responsibility (as the concept rooted in philosophy, psychology and sociology) as an introduction to the course.

\section{How to teach entrepreneurial responsibility?}

Entrepreneurship education enhancing entrepreneurial responsibility makes the learner take responsibility for his own entrepreneurial learning process and further equips him with competences enabling to grasp opportunities and following them until their responsible exploitation. Considering the importance of meaning of responsibility in entrepreneurship, the consequent challenge is to try to find out how to teach it in a way to foster personal and social responsibility. The suggestions are following:

- Enhancing consciousness of importance of entrepreneurial responsibility

The idea is to design teaching interventions that provide learners with a deeper understanding of the role of entrepreneurs in society and 
economy, the meaning of their decisions leading to actions, along with the consequences they might have for all members of ecosystem. To achieve that, teaching how to adapt broader perspective in perceiving the world, sensitivity to social problems and social justice would be important elements of teaching entrepreneurial responsibility programs. Also, putting more accents on sense-making aspect of entrepreneurship could be beneficial for better understanding of the role and importance of entrepreneurial responsibility.

- Creating learning environment of freedom and autonomy

There is a strong tie between responsibility and freedom understood as autonomy of decisions. If students are given freedom and autonomy, they need to learn how to be responsible for their actions. Creating an environment of freedom, i.e. a free choice between alternatives, makes responsibility a relevant concept to be taught. In practice, it means that applying constructivist approach to entrepreneurship education, with action-based learning at its base, is adequate as it creates the conditions for more autonomic learning.

- Combining individual responsibility with a collective one

Although, in modern society sharing responsibility is an important competence, during learning collective responsibility should be accompanied with learning individual responsibility. It may be achieved by making students individually responsible for a particular assignment, which is part of the idea of individually tailored education, based on individual learning contracts.

- Implementing project and task oriented courses

Evolvement of entrepreneurial responsibility goes together with engagement in doing something. To make learners involved in entrepreneurship education, the project specifics should correspond to learner's interests to ensure better identification with these projects.

- Teaching consequences of one's decisions and actions

The responsibility means that the learner understands the consequences of their decisions and actions. Entrepreneurs are usually not afraid of doing something but of the freedom they get by launching their own ventures and responsibility that is always linked with this freedom. Insecurity accompanying entrepreneurship is the price of liberation and realising own ideas.

- Including ethical and moral aspects of entrepreneurial decisions and actions into curricula

As responsibility is a moral and ethical issue, including more elements of ethics into entrepreneurship programs is recommended. Entrepreneurial responsibility could be taught as a part of social entrepreneurship courses, but as it was explained, should not be limited to them. 
The problem is that the pedagogy of social entrepreneurship is also in its infancy and usually is not a priority for educators (Tracey and Phillips, 2007). Including entrepreneurial responsibility into the entrepreneurship course curricula requires the need to focus more on difficult issues as morality and ethics, values, or social impact. These all are sensitive issues and are more context laden. The idea to overcome some potential conflicts in this field could be to discuss these problems with students and work out some consensus at the beginning of the course or session devoted to entrepreneurial responsibility.

- Showing illustrative cases

One of the recommended methods in teaching entrepreneurial responsibility could be to familiarise learners with positive examples or cases illustrating how entrepreneurs dealt with complex reality. Although functioning in uncertain environment, where not all consequences of their actions can be anticipated, entrepreneurs take responsibility for them. Meetings with potential role models, during which learners could ask entrepreneurs not only about how they come up with business ideas and how they implemented them into life, but about their ethical dilemmas and feelings accompanying their entrepreneurial decisions, could also benefit teaching practices.

- Embedding teaching of entrepreneurial responsibility in experience-based pedagogy

Taking the specifics of responsibility issue, to understand its value, the experience-based pedagogy can serve. Particularly all active methods, including simulations, experiments, problem-based learning and situated learning. Actively engaged students are able to feel what it means to take responsibility and what practice it involves. Confronting own views with values, perceptions and attitudes of others may teach a lot. This necessarily has to be followed by reflecting exercises to make students conscious of their learning process. Raising awareness of responsibility has a potential to ease the start-up processes but also help to take right decisions while keeping business ventures.

- Including psychological aspects into entrepreneurship education

To make learners understand the need of taking responsibility of their decisions and actions some courses on psychology might be useful. During these classes they would learn the mechanisms of altruistic versus egoistic behaviours, need for supporting others and being co-responsible for the results of their behaviour. To be responsible, learners have to become confident in what (and what for) they are doing, and in the potentials and power of their actions. Self-efficacy, which is traditionally associated with entrepreneurial traits, helps learners to achieve desired greater confidence. They need to believe that they are able to change a lot in their lives, communities and society. 
- Changing the role of educator from instructor to facilitator

Finally, adding responsibility components into entrepreneurship education revisits the role of the educator. The role of the teacher in entrepreneurial responsibility is to more be like the interpreter of reality and facilitator of the responsible entrepreneurial process than instructor or business advisor. He or she needs to assist the learning and provoke the situation where taking responsibility might be practiced. 


\section{Conclusions}

The idea of this monograph was to break stereotypes about entrepreneurship education, particularly in the field of experience-based education, and launch some discussion on the role of responsibility in entrepreneurship education. The idea was also to stress the need for regular attention to the links between theory and practice of entrepreneurship education and at the same time to claim that there is no canonical way to teach entrepreneurship.

In this monograph entrepreneurial experiences and entrepreneurial responsibility are argued to be key categories for entrepreneurship education and entrepreneurial learning, both understood as a part of human development taken place in social context, thus in broader sense than just a venture creation in strictly business terms. Although learning has started to be regarded as a part of entrepreneurial processes, its importance and dynamics have not been appreciated enough in entrepreneurship research (Corbett, 2005). The monograph emphasizes the role and meaning of experiences in creating entrepreneurial knowledge leading to venture creation and more entrepreneurial selves. It synthetises and integrates different theories and frameworks on experience-based learning, and adapts them into entrepreneurship. It intends to advance the theoretical knowledge of entrepreneurial learning and experience-based entrepreneurship education by gathering research from philosophy, psychology and education. The basic premise is that the behaviour of individuals depends on their experiences as all comparisons are made to some reference points. The monograph offers a conceptual framework that regards entrepreneurial learning as an experiential process, where experiences concern both actions and reflections. The discussion leads to the conclusion that heavily promoted action-oriented approach to entrepreneurship education 
switches attention from the learning and knowledge creation. Actions in order to be powerful and meaningful have to be accompanied by reflections and responsibility for its consequences. Taking Schön $(1983,1987)$ distinction between "reflection-on practice" from "reflection-in-practice" to create entrepreneurial individuals both need to be learned.

The monograph represents understanding of entrepreneurship as a phenomenon related more to general human and social development than economic progress. It regards entrepreneurship from individuals' perspective but also in social terms. Entrepreneurship is perceived as a continuous cycle of learning by experiencing, acting and reflecting. It is less capitalistic or neoliberal version of entrepreneurship education but more its humanistic version. Entrepreneurship is rather understood as a learning process aimed at venture creation and life philosophy.

Accumulated results of the study lead to the modern concept of education. This concept is aimed at enabling learners to responsibly participate in and experience different but real entrepreneurial activities. It is based on symmetric dialogue between the learner and the teacher. Through experiencing authentic entrepreneurial learning, i.e. by doing and reflecting, learners develop entrepreneurial identity and readiness to become responsible entrepreneurs. Modern entrepreneurship education stands for the education that is not separated from life, where entrepreneurial competences might be regarded as life competences.

\section{The most characteristic qualities of education}

Focus on collecting experiences, that is through inducing both actions and reflections. Authentic experiences that are internalized by the learner support their future entrepreneurial ventures. Facing different situations and contexts ensures heterogeneity of the learner's experiences and reflecting practices ensure that the potential of actions is fully exploited.

Importance of personal reflection. Learners generate knowledge from experiences through reflecting on them. The research shows the important role of individual and group reflection practices. Reflecting enables continuity between experiences.

Transformative nature of learning. Successful learning process is of transformative nature. It happens through personal shift (in thinking, frames of references, points of views, assumptions, patterns of behaviour) and by making meaning of learner's experiences. To be successful the transformation has to be mindful, responsive and conscious to the learner. Only achieving the meta-level of mental constructs enables successful learning.

Less clear division of roles between teacher and learner. In the modern concept of entrepreneurship education, both the teacher and learner 
create the space for learning and teaching; they co-learn and co-teach. The absence of clear guidance followed by not clear-cut roles of teacher and learner makes education entrepreneurial per se as participants have to take risk and build their entrepreneurial identity in an autonomic way. This is in contrast to hierarchical model of relations between teacher and learner, in which the order and roles are clearly defined.

Stimulation of all constructs of intelligence and personality of learners (affective, conative and cognitive). Entrepreneurship education equips learners with cognitive perspective enabling them to define different situations and understand the world but it should also include affection (emotions) and conation (motivation and will). Learners should feel responsible for their actions and their impact and should strive to become more entrepreneurial.

Modern entrepreneurship education relates to evidence-based practice. Following Biesta (2007) who examines basic assumptions of evidence-based education, the concept of projection of a business life is close to the practice of entrepreneurship. The entrepreneurship education is for both social and professional purpose.

The cconcept of education is connected with an idea of existentialism where individuals take responsibility for their lives, for their education, engagement and actions. Entrepreneurial education is existential due to its authenticity that is needed at the core of human existence and the acting, feeling and living individual at its centre.

\section{Propositions}

Basing on the previous claims, three groups of propositions are developed to increase understanding of experiential entrepreneurial learning and entrepreneurial responsibility. The following propositions summarize the discussion presented in this monograph and may serve as a starting point for further research:

$\checkmark$ Propositions regarding entrepreneurial experiences:

Proposition 1. The number and quality of experiences and the way that they are used have an explanatory power why some individuals become entrepreneurs.

Proposition 2. Entrepreneurial experience to be complete has to include entrepreneurial action accompanied with reflection on its contents, nature and consequences. Between actions and reflections there is a constant interplay and interdependence.

Proposition 3. Entrepreneurial actions are the fuel for the entrepreneurial experiences if they are purposeful and intended. They constitute the core of entrepreneurial experiences. 
Proposition 4. There is no experience without reflections. Reflections to be effective cannot be random and casual but purposeful. It is possible to learn to reflect on experience.

Proposition 5. Entrepreneurial experiences lead to entrepreneurial knowledge which defines the entrepreneur and enables him or her to take right decisions. The structure of knowledge is more important than its amount.

Proposition 6. Entrepreneurial experience depends on previous entrepreneurial experience and influence forthcoming one. Entrepreneurial experiences are in continuum and have a cumulative effect. The more entrepreneurial experiences an individual has, the more successes in entrepreneurial ventures they have a chance to achieve.

$\checkmark$ Propositions regarding experience-based entrepreneurship education:

Proposition 1. Experience-based learning is contextual and situative. Effective experience-based education allows the learner to be engaged in meaningful actions and teach him or her how to reflect on and in these actions.

Proposition 2. Effective experience-based education is dependent on and adjusted to the level and deepness of past learning experiences of the learners, especially their reflective thinking competences.

Proposition 3. In entrepreneurial context, it is not only important to gain entrepreneurial experiences but to be able to transform them to be valuable. The transformation takes place through learning. Entrepreneurs have to make sense of their experiences and advance their entrepreneurial competences.

Proposition 4. To be effective entrepreneurship education should lead to individual development and self-fulfilment but also be collective and serve social purpose. The experiential learning has a cumulative effect. It is a process of both individual development and socialization.

Proposition 5. Experience-based learning evolves in the learner individually but also is shaped by social context and particular social situation.

$\checkmark$ Propositions regarding entrepreneurial responsibility and responsibility-based entrepreneurship education:

Proposition 1. Entrepreneurship is a social phenomenon evaluated in a social and societal context. To be regarded as valuable and desired by society, entrepreneurs have to be responsible for all their decisions leading to actions.

Proposition 2. In the meaning of entrepreneurial responsibility both prospective and retrospective responsibility are included. Entrepreneurs are responsible for consequences of their decisions as well as they hold responsibility for the decisions taken in the past. 
Proposition 3. Evolvement of entrepreneurial responsibility goes together with engagement and commitment in entrepreneurial ventures.

Proposition 4. Entrepreneurial responsibility is evaluated through reactions of entrepreneurs, i.e. their decisions leading to actions, not by their intentions or values.

Proposition 5. The process of effective entrepreneurial leaning goes together with the growth of students' responsibility.

Proposition 6. Teaching curricula in entrepreneurship field should include responsibility issue. Entrepreneurially engaged students are able to feel what it means to take responsibility and what kind of practices it involves. Confronting own views with values, perceptions and attitudes of others teach them taking broader perspective and respect for diversity. Raising awareness of responsibility has a potential to ease the startup processes but also help to take right decisions while keeping business ventures.

\section{Matching theory and practice}

The monograph was aimed to bridge between learning theories and teaching practices in entrepreneurship field by developing and deepening the concepts of experience-based learning and entrepreneurial responsibility. To bring closer the theory and practice in entrepreneurship education the following undertakings are recommended:

- developing learning strategies enabling to solve problems emerging in entrepreneurship;

- deepening how learners construct knowledge in entrepreneurship context;

- developing self-awareness of learning in learners;

- recognizing all constructs of intelligence and personality of learners (affection, cognition, conation) and their role in learning;

\section{The contribution}

The idea of the monograph was to revisit and develop the concept of experience-based learning and experience-based entrepreneurship education. It is aimed to contribute to the theoretical discussion and practice of entrepreneurship education in many ways. First of all it synthetises different approaches to experiences and experiencing represented by different fields: philosophy, psychology, and education. Secondly, it relates the concept of experience to entrepreneurship and entrepreneurship education. It demonstrates how experiential learning has been adapted by entrepreneurship education and indicates some shortcuts and biases which are the results of emphasizing some aspects of experiencing and forgetting the others. To reconcile different perspectives, 
the concept of praxis, that is synthesis and interplay between actions and reflections, is offered and discussed. Thirdly, the theoretical discussion on experience and its presence in contemporary entrepreneurship education frameworks and pedagogies leads to some recommendations how to teach entrepreneurship to make learners act and think in entrepreneurial way.

The idea of the monograph was also to launch a discussion on the role of entrepreneurial responsibility in entrepreneurship education and learning. It is claimed that entrepreneurship education should be aimed at teaching learners taking personal and cognitive responsibility for ventures. In light of the research, responsibility may be regarded as a criterion of evaluation of entrepreneur's decisions and their consequences in form of actions. Responsibility is a kind of reaction to the circumstances and attitude towards. Entrepreneurs are creators of not only the value in economic terms but also values in ethical sense. Responsibility concerns ethical dimension of entrepreneurs' actions. Entrepreneurs hold responsibility for the decisions taken in the past but also take responsibility for future consequences of their actions. 


\section{References}

Alvarez, S.A., Barney, J.B. (2007) 'Discovery and creation: alternative theories of entrepreneurial action', Strategic Entrepreneurship Journal, 1: 11-26 (2007), pp. 11-26.

Aronowitz, S. (1993) 'Paulo Freire's radical democratic humanism', in McLaren P. \& Leonard P. (eds.) Paulo Freire: A critical encounter, London: Routledge, pp. 8-24.

Artino, A.R., Jr. (2008) 'Cognitive load theory and the role of learner experience: An abbreviated review for educational practitioners', AACE Journal, 16(4), pp. 425-439.

Baker, T., Nelson, R. E. (2005) 'Creating something from Nothing: Resource Construction through Entrepreneurial Bricolage', Administrative Science Quarterly, 50(3), pp. 329-366.

Bandura, A. (1977) Social learning theory. Englewood Cliffs, NJ: Prentice Hall.

Bandura, A. (1982) 'Self-efficacy mechanism in human agency', American Psychologist, 37(2), pp. 122-147.

Bandura, A. (1992) 'Exercise of personal agency through the self-efficacy mechanisms', in Schwarzer, R. (ed.), Self-efficacy: Thought control of action. Washington, DC: Hemisphere.

Bandura, A. (1989) 'Human Agency in Social Cognitive Theory', American Psychologist, 44, pp. 1175-1184.

Bandura, A. (1989b) 'Social cognitive theory', Annuals of child development, 6 , pp. 1-60.

Bandura, A. (1995) Self-Efficacy in Changing Societies. Cambridge University Press.

Baron, R.A. (2006), 'Opportunity Recognition as Pattern Recognition: How Entrepreneurs "Connect the Dots" to Identify New Opportunities', Academy of Management Perspectives, 20(1), pp. 104-119.

Baron, R.A. (2008) 'The role of affect in the entrepreneurial process', Academy of Management Review, 33, pp. 328-340.

Barrows, H.S., Tramblyn, R.M. (1980) Problem-based learning: An approach to medical education. Springer Publishing Company.

Barrows, H.S. (1996) 'Problem-based learning in medicine and beyond: 
A brief overview', in Wilkerson, L. \& Gijselaers, W.H. (eds.), Bringing problem-based learning to higher education: Theory and practice. San Francisco: JosseyBass, pp. 3-12.

Béchard, J.P., Grégoire, D. (2005) 'Understanding teaching models in entrepreneurship for higher education', in Kyrö, P. and Carrier, C. (eds) The Dynamics of Learning Entrepreneurship in a Cross-cultural University Context. Tampere: Faculty of Education, University of Tampere, pp. 104-34.

Biesta, G. (2007) 'Why "What Works" Won't Work: Evidence-Based Practice And The Democratic Deficit In Educational Research', Educational Theory, 57, pp. 1-22.

Bird, B.J., West III, G.P. (1997) 'Time and entrepreneurship', Entrepreneurship Theory and Practice, 22(2), pp. 5-10.

Blenkin, G.M., Edwards, G., Kelly, A.V. (1992) Change and the Curriculum. London: Paul Chapman Publishing.

Boud, D., Keogh, R., \& Walker, D. (1985) Reflection: Turning Experience into Learning. London: Kogan Page.

Boud, D., \& Walker, D. (1990) 'Making the most of experience', Studies in Continuing Education, 12(2), pp. 61-80.

Boud, D., \& Walker, D. (1998) 'Promoting reflection in professional courses: The challenge of context', Studies in higher education, 23(2), pp. 191-206.

Boyd, E.M., \& Fales, A.W. (1983) 'Reflective learning key to learning from experience', Journal of Humanistic Psychology, 23(2), pp. 99-117.

Boyd, N.G., Vozikis, G.S. (1994) 'The influence of Self-Efficacy on the Development of Entrepreneurial Intentions and Actions', Entrepreneurship Theory and Practice 18(4), pp. 63-77.

Breunig, M. (2005) 'Turning experiential education and critical pedagogy theory into praxis', Journal of Experiential Education, 28(2), pp. 106-122.

Brockbank, A. \& McGill,I. (2007) Facilitating Reflective Learning in Higher Education. 2nd edition. Buckingham: SRHE/Open University Press.

Bruner, J. (1967) On Knowing: Essays for the Left Hand. Boston: Harvard University Press.

Bucar, B., Hisrich, R.D., (2001) 'Ethics of business managers vs. entrepreneurs', Journal of Developmental Entrepreneurship, 6 (1), pp. 59-83.

Burgoyne, J.G., \& Hodgson, V.E. (1983) 'Natural learning and managerial action: a phenomenological study in the field setting', Journal of Management Studies, 20(3), pp. 387-399.

Bygrave, W.D. (1989) 'The entrepreneurship paradigm (I) revisited: A philosophical look at its research methodologies', Entrepreneurship Theory and Practice 14(I), pp. 7-26.

Bygrave, W.D., Hofer, C.W. (1991) 'Theorizing about Entrepreneurship', Entrepreneurship: Theory and Practice, 16(2), pp. 13-22.

Bygrave, W.D. (2003) 'The entrepreneurial process', in Bygrave, W.D., Zacharakis A. (eds.), The Portable MBA in Entrepreneurship, 3rd edition, New York: John Wiley and Sons, pp. 1-27.

Cardon, M.S., Zietsma, C., Saparito, P., Matherne, B.P., Davis, C. (2005) 'A tale of passion: New insights into entrepreneurship from a parenthood metaphor', Journal of Business Venturing, 20, pp. 23-45. 
Cardon, M.S., Wincent, J., Sing, J., Drnovsek, M., (2009) 'The nature and experience of entrepreneurial passion', Academy of Management Review, 34, pp. 511-532.

Cardon, M.S., Foo, M.D., Shepherd, D., Wiklund, J., (2012) 'Exploring the heart: entrepreneurial emotion is a hot topic', Entrepreneurship in Theory Practice, 36, pp. 1-10.

Carr, W., Kemmis, S. (1986) Becoming Critical. Education, knowledge and action research. Lewes: Falmer.

Carrier, C. (2007) 'Strategies for teaching entrepreneurship: what else beyond lectures, case studies and business plans?', in Fayolle, A. (ed.), Handbook of research in entrepreneurship education, Vol. 1, Cheltenham: Edward Elgar, pp. 143-172.

Carrier, C. (2005) 'Pedagogical challenges in entrepreneurship education', in Kyrö, P., Carrier, C. (eds.), The dynamics of learning entrepreneurship in a cross-cultural university context, Hämmeenlinna: University of Tampere, pp. 136-158.

Carver, C.S., \& Scheier, M.F. (1981) Attention and self-regulation: $A$ control theory approach to human behavior. New York: Springer.

Chandler, G.N., DeTienne, D.R., Mumford, T.V. (2007) 'Causation and effectuation: measurement development and validation', Frontiers of Entrepreneurship Research, Vol. 27: Iss. 13.

Clark, B.W., Davis, C.H., Harnish, V.C. (1984) 'Do courses in entrepreneurship aid in new venture creation?', Journal of Small Business Management, 22, pp. 126-32.
Clarke, J., Holt, R. (2010) 'Reflective Judgment: Understanding Entrepreneurship as Ethical Practice', Journal of Business Ethics, Vol. 94, pp. 317-331. Cohen, J.D. (2005) 'The Vulcanization of the Human Brain: A Neural Perspective on Interactions Between Cognition and Emotion', Journal of Economic Perspectives, 19(4), pp. 3-24.

Cook-Sather, A. (2010) 'Students as Learners and Teachers: Taking Responsibility, Transforming Education, and Redefining Accountability,' Curriculum Inquiry, 40:4 (September 2010), pp. 555-575.

Cooper, S., Bottomley, C., Gordon, J. (2004) 'Stepping out of the classroom and up the ladder of learning: An experiential learning approach to entrepreneurship education', Industry and Higher Education, 18(1), pp. 11-22.

Cooperstein, S.E., Kocevar-Weidinger, E. (2004) 'Beyond active learning: A

constructivist approach to learning', Reference Services Review, 32(2), pp. 141-148.

Cope, J. (2003) 'Entrepreneurial learning and critical reflection discontinuous events as triggers for 'higher-level' learning', Management learning, 34(4), pp. 429-450.

Cope, J. (2005) 'Toward a dynamic learning perspective of entrepreneurship', Entrepreneurship Theory and Practice, 29(4), pp. 373-397.

Cope, J., Watts, G. (2000) 'Learning by doing - An exploration of experience, critical incidents and reflection in entrepreneurial learning', International Journal of Entrepreneurial Behaviour \& Research, 6(3), p. 104. 
Corbett, A.C. (2005) ‘Experiential learning within the process of opportunity identification and exploitation', Entrepreneurship Theory and Practice, 29 (4), pp. 473-491.

Corbett, A.C., Katz, J.A. (2012) 'Introduction: The Action of Entrepreneurs', in Corbett, A.C., Katz, J.A. (ed.) Entrepreneurial Actions. Advances in Entrepreneurship, Firm Emergence and Growth, 14, pp. ix-xix.

Davidsson, P., Wiklund, J. (1997) 'Values, beliefs and regional variations in new firm formation rates', Journal of Economic Psychology, 18, pp. 179-199.

Davidsson, P., Tonelli, M. (2013) 'Killing our darling: why we need to let go of the entrepreneurial opportunity construct', in Davidsson, P. (ed.) Conference Proceedings: Australia Centre for Entrepreneurship (ACE) Research Exchange Conference 2013, Brisbane, QLD: Australia Centre for Entrepreneurship, Queensland University of Technology.

DeNoble, A.F., Jung, D., Ehrlich, S. (1999) 'Entrepreneurial Self-efficacy: the Development of a Measure and its Relationship to Entrepreneurial Action', Frontiers of Entrepreneurship Research, Wellesley, MA: Babson College.

DeTienne, D., Chandler, G. (2004) 'Opportunity identification and its role in the entrepreneurial classroom: A pedagogical approach and empirical test', Academy of Management Learning \& Education, 3: pp. 242-257.

Dewey, J. (1906) 'The experimental theory of knowledge', Mind, 15(59), pp. 293-307.

Dewey, J. (1938) The theory of inquiry. New York: Holt, Rinehart \& Wiston.
Dewey, J. (1946) Experience and education. New York: The Macmillan Company.

Dewey, J. (1910/1997) How we think. Courier Dover Publications, New York.

Dewey, J. (1916/2007) Democracy and Education: An Introduction to the Philosophy of Education. Sioux Falls, SD, NuVision Publications.

Dewey, J. (2013) Experience and Nature. New York: Dover Publications, Inc.

Dillenbourg, P. (1999) 'What do you mean by collaborative learning?', in Dillenbourg P. (ed.), Collaborative-learning: Cognitive and Computational Approaches. Oxford: Elsevier, pp. 1-19.

Dimov, D. (2011) 'Grappling with the Unbearable Elusiveness of Entrepreneurial Opportunities', Entrepreneurship Theory and Practice, 35: pp. 57-81.

Dutta, D., Crossan, M. (2005) 'The Nature of Entrepreneurial Opportunities: Understanding the Process Using the $4 \mathrm{I}$ Organizational Learning Framework', Entrepreneurship Theory and Practice, 29(4), pp. 425-449.

Edelman, L.F., Manolova, T.S., \& Brush, C.G. (2008) 'Entrepreneurship education: Correspondence between practices of nascent entrepreneurs and textbook prescriptions for success', Academy of Management Learning \& Education, 7(1), pp. 56-70.

Etzioni, A. (1987) 'Entrepreneurship, Adaptation and Legitimation', Journal of Economic Behavior and Organization, pp. 175-189.

Etzkowitz, H. (2004) 'The evolution of the entrepreneurial university', International Journal of Technology and Globalisation, 1(1), pp. 64-77.

European Commission (2006) Fostering entrepreneurial mindsets through 
education and learning, Communication from the Commission to the Council, the European Parliament, the European Economic and Social and the Committee of the Regions, Brussels 13.2.2006 (COM/2006/0033).

European Commission (2012) Rethinking Education: Investing in Skills for better Socio-Economic Outcomes, Brussels, November 2012.

European Commission (2013) Entrepreneurship Education: A Guide for Educators, Brussels, June 2013.

Ewell, P. (1997) 'Organizing for learning: A new imperative', AAHE Bulletin 50, pp. 3-6.

Fayolle, A. (2010) 'Insights from an international perspective on entrepreneurship education', in Fayolle A. (ed.), Handbook of research in entrepreneurship education, Vol. 3, International Perspectives, Cheltenham UK, Northampton MA USA: Edward Elgar.

Fayolle, A. (2013) 'Personal views on the future of entrepreneurship education', Entrepreneurship \& Regional Development, 25(7-8), pp. 692-701.

Ferry, N.M., \& Ross-Gordon, J.M. (1998) 'An inquiry into Schön's epistemology of practice: Exploring links between experience and reflective practice', Adult Education Quarterly, 48(2), pp. 98-112.

Feys, M., Anseel, F.,Wille, B. (2011) 'Improving Feedback Reports: The Role of Procedural Information and Information Specificity', Academy of Management Learning \& Education, Vol. 10, No. 4, pp. 661-681.

Fiet, J. (2000) 'The theoretical side of teaching entrepreneurship', Journal of Business Venturing 16, pp. 1-24.
Fiet, J. (2000) 'The pedagogical side of entrepreneurship theory', Journal of Business Venturing 16, pp. 101-117.

Fisscher, O., Frenkel, D., Lurie, Y., Nijhof, A. (2005) 'Stretching the frontiers: Exploring the relationships between entrepreneurship and ethics', Journal of Business Ethics 60 (3), pp. 207-209.

Foo, M.D. (2011) 'Emotions and Entrepreneurial Opportunity Evaluation', Entrepreneurship: Theory and Practice 35(2), pp. 375-393.

Freire, P. (1996) Pedagogy of the Oppressed. London: Penguin Books Limited.

Freire, P. (1970) Cultural action for freedom. Cambridge: Harvard Educational Review.

Freire, P. (1973) Education for critical consciousness. New York: Seabury Press.

Freire, P. (1976) Education, the practice of freedom. London: Writers and Readers Publishing Cooperative.

Freire, P. (1985) The politics of education: culture, power, and liberation. South Hadley, Mass.: Bergin \& Garvey.

Freire, P. (1998) Pedagogy of freedom: ethics, democracy and civic courage. Lanham: Rowman \& Littlefield Publishers.

Freire, P. (1998) Teachers as cultural workers: letters to those who dare teach. Boulder, Colo.: Westview Press.

Gartner, W. (1989) '“Who Is an Entrepreneur?” Is the Wrong Question', Entrepreneurship Theory and Practice 5, pp. 47-67.

Gelderen van, M. (2010) 'Autonomy as the guiding aim of entrepreneurship education', Education + Training, Vol. 52 Issue 8/9, pp. 710-721

Gibb, A.A. (1987) 'Enterprise cultureits meaning and implications for 
education and training', Journal of European Industrial Training, 11(2), pp. 2-38.

Gibb, A. (2002) 'In Pursuit of a New 'Enterprise ' and 'Enterpreneurship ' Paradigm for Learning, Creative Destruction, New Values, New ways of Doing Things and New Combinations of Knowledge', International Journal of Management Review 4(3), pp. 233-269.

Good, T. and Brophy, J. (1994) Looking in classrooms. 6th ed. New York: Harper Collins.

Greeno, J.G., Collins, A.M., \& Resnick, L.B. (1996) 'Cognition and learning', in Berliner D.C. \& Calfee R.C. (eds.), Handbook of educational psychology. New York: MacMillan, pp. 15-46.

Grichnik, D., Smeja, A., Welpe, I. (2010) 'The importance of being emotional: How do emotions affect entrepreneurial opportunity evaluation and exploitation?', Journal of Economic Behavior and Organization, 76(1), pp. 15-29.

Hannafey, F.T., (2003) 'Entrepreneurship and ethics: a literature review', Journal of Business Ethics, 46, pp. 99-110.

Harris, J.D., Sapienza, H.J. \& Bowie, N.E. (2009) 'Ethics and entrepreneurship', Journal of Business Venturing, Vol. 24, pp. 407-418.

Harrison, R., \& Leitch, C. (1994) 'Entrepreneurship and leadership: The implications for education and development', Entrepreneurship and Regional Development, 6, pp. 112-125.

Hayton, J.C., Cholakova, M. (2012) 'The Role of Affect in the Creation and Intentional Pursuit of Entrepreneurial Ideas', Entrepreneurship Theory and Practice, 36(1), pp. 41-68.
Hegel, G.W.F. (1977) The Phenomenology of Spirit (The Phenomenology of Mind). Oxford: Oxford University Press.

Heinonen J., Poikkijoki S.A. (2006) 'An entrepreneurial-directed approach to entrepreneurship education: mission impossible?', Journal of Management Development, Vol. 25, No 1, pp. 80-94. Heinonen, J.,Hytti, U. (2010) 'Back to basics: the role of teaching in developing the entrepreneurial university', The International Journal of Entrepreneurship and Innovation, 11 (4), pp. 283-292.

Heward, W.L., Cooper J.O. (1992) 'Radical behaviorism: A productive and needed philosophy for education', Journal of Behavioral Education, Volume 2, Issue 4, pp. 345-365.

Higgins, D., Smith, K., Mirza, M. (2013) 'Entrepreneurial Education: Reflexive Approaches to Entrepreneurial Learning in Practice', Journal of Entrepreneurship 22: pp. 135-160.

Hjorth, D. (2003) 'In the tribe of Sisyphus: Rethinking Management Education From an "Entrepreneurial" Perspective', Journal of Management Education, 27(6), pp. 637-653.

Holland, D.V., Shepherd, D.A. (2011) 'Deciding to Persist: Adversity, Values, and Entrepreneurs' Decision Policies', Entrepreneurship Theory and Practice. 37 (2), pp. 331-358.

Honey, P., Mumford, A. (1986) The Manual of Learning Styles. Maidenhead: Peter Honey.

Hookway, C., 'Pragmatism', in Zalta E.N. (ed.), The Stanford Encyclopedia of Philosophy. Winter 2013 Edition.

http://plato.stanford.edu/archives/win2013 /entries/pragmatism/ (access: $4^{\text {th }}$ November 2014). 
Hoover, D., Whitehead, C. (1975) An experiential-cognitive methodology in the first course in management: Some preliminary results. Conference proceedings from: Simulation games and experiential learning in action. Bloomington, Indiana, April, pp. 25-30.

Hofstede, G. (2003) Culture's consequences: comparing values, behaviors, institutions and organizations across nations. 2nd edition. Newbury Park: Sage Publications.

Hubba, M.E., Freed, J.E. (2000). Learner-centered assessment on college campuses: Shifting the focus from teaching to learning. Needham Heights, MA: Allyn \& Bacon.

Hytti U., O'Gorman C. (2004) 'What is "enterprise education"? An analysis of the objectives and methods of enterprise education programmes in four European countries', Education + Training, Vol. 46 Iss: 1, pp. 11-23.

Itin, C.M. (1999) 'Reasserting the Philosophy of Experiential Education as a Vehicle for Change in the 21st Century', Journal of Experiential Education, 22(2), pp. 91-98.

Jack, S.L., \& Anderson, A.R. (1999) 'Entrepreneurship education within the enterprise culture Producing reflective practitioners', International Journal of Entrepreneurial Behaviour \& Research, 5(3), p. 110.

Jarvis, P. (1994) 'Learning', ICE301 Lifelong Learning, Unit 1(1), London: YMCA George Williams College.

Jarvis, P. (1995) Adult and Continuing Education. Theory and practice. $2^{\text {nd }}$ edition, London: Routledge.

Jarvis, P. (1987) Adult Learning in the Social Context. London: Croom Helm.
Johannisson, B. (1991) 'University training for entrepreneurship: Swedish approaches', Entrepreneurship \& Regional Development, 3(1), pp. 67-82.

Johannisson, B., Landstrom, H., Rosenberg, J. (1998) 'University training for entrepreneurship - an action frame of reference', European Journal of Engineering Education, 23(4), pp. 477-496. Johnson, B.E. (2013) The Role Ethics of Epictetus: Stoicism in Ordinary Life. Lexington Books, Lanham.

Johnstone, B.A. (2006) 'Ethnographic methods in entrepreneurship research', in Neergaard, H., Ulhoi, J.P. (eds.), Handbook of Qualitative Research Methods in Entrepreneurship, Edward Elgar, Cheltenham, pp. 97-121.

Jones, O., Holt, R. (2008) 'The creation and evolution of new business ventures: an activity theory perspective', Journal of Small Business and Enterprise Development, 15 (1), pp. 51-73.

Jones C., English, J. (2004) 'A contemporary approach to entrepreneurship education', Education and Training 46 (8/9), pp. 416-423.

Jones, C. (2010) 'Entrepreneurship education: revisiting our role and its purpose', Journal of Small Business and Enterprise Development, 17, 4, pp. 500-513.

Kalyuga, S., Ayres, P., Chandler, P., Sweller, J. (2003) 'The expertise reversal effect', Educational Psychologist, 38, pp. 23-31.

Kant, I. (1900) Ueber Paedagogik. Boston: D.C. Heath and Co..

Katz, J.A. (1994) 'Modeling Entrepreneurial Career Progressions: Concepts and Considerations', Entrepreneurship Theory and Practice, 19(2), pp. 23-39. 
Katz, J.A. (2003) 'The Chronology and Intellectual Trajectory of American Entrepreneurship Education', Journal of Business Venturing, 18(2), pp. 283-300.

Kickul, J., Gundry, L.K., Barbosa, S.D., Whitcanack, L. (2009) 'Intuition Versus Analysis? Testing Differential Models of Cognitive Style on Entrepreneurial Self-Efficacy and the New Venture Creation Process', Entrepreneurship Theory and Practice, 33 (2), pp. 439-453.

Kirby, D.A. (2004) 'Entrepreneurship education: can business schools meet the challenge', Education + Training , 46 (8/9), pp. 510-519.

Kirby, D. (2007) 'Changing the entrepreneurship education paradigm', in Fayolle, A. (ed.), Handbook of research in entrepreneurship education, Vol. 1. Cheltenham: Edward Elgar, pp. 21-45. Klapper, R., Tegtmeier, S. (2010) 'Innovating entrepreneurial pedagogy - examples from France and Germany', Small Business and Enterprise Development 17(4), pp. 552-568.

Klein, P.G. (2008) 'Opportunity discovery, entrepreneurial action, and economic organization', Strategic Entrepreneurship Journal, 2: pp. 175-190.

Knowles, M. (1975) Self-Directed Learning. Chicago: Follet.

Knowles, M.S. (1980) The modern practice of adult education: From pedagogy

to andragogy. Chicago: Follett.

Knowles, M. (1984) The Adult Learner: A Neglected Species. $3^{\text {rd }}$ edition. Houston: Gulf Publishing.

Knowles, M. (1984) Andragogy in Action. San Francisco: Jossey-Bass.

Kolb, D.A. (1974) 'Management and the learning process', in Kolb, D.A., Rubin, I. M., McIntyre, J.M. Organizational
Psychology: A Book of Readings, Englewood Cliffs, NJ: Prentice-Hall, pp. 27-42.

Kolb, D.A. (1976) The Learning Style Inventory: Technical Manual. Boston, MA: McBer \& Co.

Kolb, D.A. (1984) Experiential learning: Experience as the source of learning and development. Vol. 1. Englewood Cliffs, NJ: Prentice-Hall.

Kolb, D.A., Boyatzis, R.E., Mainemelis, C. (2001) 'Experiential Learning Theory: Previous Research and New Directions', in Sternberg, R.J., Zhang, L.F. (eds), Perspectives on Thinking, Learning, and Cognitive Styles, Mahwah, NJ: Lawrence Erlbaum, pp. 227-247.

Kolb, A., Kolb, D. (2008) 'Experiential Learning Theory: A Dynamic, Holistic Approach to Management Learning, Education and Development', in Armstrong, S.J., Fukami, C. (eds.), Handbook of Management Learning, Education and Development. London: Sage Publications.

Kolovelonis, A., Goudas, M., Dermitzaki, I. (2011) 'The effect of different goals and self-recording on self-regulation of learning a motor skill in a physical education setting', Learning and Instruction, 21 (3), pp. 355-364.

Kolvereid, L., Moen Ø. (1997) 'Entrepreneurship among business graduates: does a major in entrepreneurship make a difference?', Journal of European Industrial Training 21/4, pp. 154-160.

Krueger, N. (2009) The microfoundations of entrepreneurial learning and education. The handbook of university wide entrepreneurship. Cheltenham, UK: Elgar.

Krueger, N.F. (2007) 'What lies beneath? The experiential essence of 
entrepreneurial thinking', Entrepreneurship Theory and Practice, 31(1), p. 123.

Krueger, N. F. (2003) 'The cognitive psychology of entrepreneurship', in Handbook of entrepreneurship research. New York, NY: Springer, pp. 105-140

Kuratko, D.F. (2005) 'The emergence of entrepreneurship education: Development, trends, and challenges', Entrepreneurship Theory and Practice 29 (5), pp. 577-598.

Kurczewska A. (2013) 'What can we learn from our students? - The study on the evolvement of students' entrepreneurial conation when they are responsible for their learning process', Periodical of Entrepreneurship Education 1/2013, Scientific Association for Entrepreneurship Education, pp. 63-83.

Kurczewska, A. (2014) 'Transformative learning illustrated! Entrepreneurship education as a projection of a business life', The Journal of American Business Review, Cambridge, Vol. 2, Num. 2, Summer 2014, pp. 209-217.

Kyrö, P. (2005) ‘Entrepreneurial learning in a cross-cultural context challenges previous learning paradigms', in Kyrö, P., Carrier, C. (eds.), The Dynamics of Learning Entrepreneurship in a Cross-Cultural University Context. Hämeenlinna: University of Tampere.

Kyrö, P. (2008) 'A theoretical framework for teaching and learning entrepreneurship', International Journal of Business and Globalisation, 2 (1), pp. 39-55.

Kyrö, P., Kurczewska A., Osei-Bonsu N. (2011) 'Different approaches to opportunity process and their consequences for teaching practice', Proceedings of ICSB Conference, Stockholm, June 2011.

Kyrö, P., Kurczewska, A., Moisala, A. (2011), 'How opportunities become exploited? - the videography method to recreate the opportunity process', Proceedings of RENT XXV - Research in Entrepreneurship and Small Business - 25th Conference, 16-18 November 2011, Bodo, Norway.

Lackeus, M. (2013) Developing Entrepreneurial Competencies - An Action-Based Approach and Classification in Education, Licentiate Thesis, Chalmers University of Technology, SE-412 96 Gothenburg, Report number L2013:070.

Lamont, L. (1972) 'What entrepreneurs learn from experience', Journal of Small Business Management, 10 (3), pp. 36-41.

Landström, H. (2010) 'Foreword', in Fayolle A. (ed.), Handbook of Research in Entrepreneurship Education, Volume 3, International Perspectives, Edward Elgar, Cheltenham, UK and Northampton, MA, US.

Lena, L., Wong, P.-K. (2003) 'Attitude towards entrepreneurship education and new venture creation', Journal of Enterprising Culture, 11(4), pp. 339-357. Lave, J., Wenger, E. (1991) Situated learning: Legitimate peripheral participation. Cambridge, UK: Cambridge university press.

Lee, S., Chang, D., Lim, S.B. (2005) 'Impact of Entrepreneurship Education: A Comparative Study of the U.S. and Korea', International Entrepreneurship and Management Journal, 1, pp. 27-43.

Leitch, C.M., Harrison, R.T. (1999) 'A process model for entrepreneurship education 
and development', International Journal of Entrepreneurial Behaviour \& Research, 5(3), pp. 83-109.

Lilge, F. (1974) 'Philosophy and Education in Hegel', British Journal of Educational Studies, 22 (2), pp. 147 - 165.

Liñán, F. (2004) 'Intention-based models of entrepreneurship education', Piccolla Impresa / Small Business, 3, pp. 11-35.

Liñán, F., Fernández, J., Romero, I. (2013) 'Necessity and opportunity entrepreneurship: The mediating effect of culture', Revista de Economia Mundial, 01/2013 (33), pp. 27-51.

Liu, Y., Xu, J., Weitz, B.A. (2011) 'The Role of Emotional Expression and Mentoring in Internship Learning', Academy of Management Learning \& Education, 10(1), pp. 94-110.

Locke, J. (1700) An essay concerning human understanding. Pater-Nofter-Row: Black Swan.

Locke, J. (1693/1880) Some Thoughts Concerning Education. National Society's Depository.

Löbler, H. (2006) 'Learning entrepreneurship from a constructivist perspective', Technology Analysis \& Strategic Management, 18(1), pp. 19-38.

Lumpkin, G.T., Hills, G., Shrader, R. (2004) 'Opportunity recognition', in Welsch H.P. (ed.), Entrepreneurship: The way ahead. New York: Routledge, pp. 73-90. Lumpkin, G.T., Lichtenstein, B.B. (2005) 'The role of organizational learning in the opportunity-recognition process', Entrepreneurship Theory and Practice, 29(4), pp. 451-472.

March, J.G. (1991) 'Exploration and exploitation in organizational learning', Organization Science, 2 (2): pp. 71-87.
McClelland, D.C. (1961) The Achieving Society. New York: Van Nostrand.

McMullen, J.S., Plummer, L.A., Acs, Z.J., (2007) 'What is an Entrepreneurial Opportunity?', Small Business Economics (28), pp. 273-283.

Mezirow, J. (1978) 'Perspective transformation', Adult Education Quarterly, 28(2), pp. 100-110.

Mezirow, J. (1990) 'How critical reflection triggers transformative learning', in Mezirow J. \& Associates (eds.), Fostering critical reflection in adulthood, San Francisco: Jossey-Bass.

Mezirow, J. (1991) Transformative dimensions of adult learning. San Francisco: Jossey-Bass.

Mezirow, J. (1995) 'Transformation Theory of Adult Learning', in Welton M. (ed.), In Defense of the Lifeworld, New York: SUNY Press, pp. 39-70.

Mezirow, J. (1996) 'Contemporary paradigms of learning', Adult Education Quarterly, 46(3), pp. 158-172

Mezirow, J. (1999) Transformative Dimensions of Adult Learning, San Francisco: Jossey-Bass.

Mezirow, J. (2000) 'Learning to Think Like an Adult: Core Concepts of Transformation Theory', in Mezirow J. and Associates (eds.), Learning as Transformation: Critical Perspectives on a Theory in Progress, San Francisco: Jossey-Bass, pp. 3-35.

Minniti, M., Bygrave, W. (2001) 'A dynamic model of entrepreneurial learning', Entrepreneurship: Theory and Practice, 23 (4), pp. 41-52.

Neck, H.M., \& Greene, P.G. (2011) 'Entrepreneurship education: known worlds and new frontiers', Journal of 
Small Business Management, 49(1), pp. 55-70.

Mises, L. von (1949) Human Action: A Treatise on Economics. $4^{\text {th }}$ edition. San Francisco: Fox \& Wilkes.

Morris M.H. (2014) Annals Of Entrepreneurship Education And Pedagogy - 2014. Edward Elgar, Cheltenham, UK and Northampton, MA, US.

Moroz, P., Hindle, K. (2011) 'Entrepreneurship as a Process: Toward Harmonizing Multiple Perspectives', Entrepreneurship Theory and Practice, 36(4), pp. 781-818.

Mueller, S.L. and Thomas, A.S. (2001) 'Culture and Entrepreneurial Potential: A Nine Country Study of Locus of Control and Innovativeness', Journal of Business Venturing, 16(1), pp. 51-75.

Neck, H. \& Greene, P. (2011) 'Entrepreneurship education: Known worlds and new frontiers', Journal of Small Business Management, 49 (1), pp. 55-70.

Neck, H.M., Greene, P.G., Brush, C.G. (2014) Teaching entrepreneurship: A practice-based approach. Edward Elgar Publishing, Cheltenham.

Noseleit, F. (2008) 'The entrepreneurial culture: guiding principles of the self-employed', Jena economic research papers, No. 2008, 034.

O'Connor, A. (2013) 'A conceptual framework for entrepreneurship education policy: Meeting government and economic purposes', Journal of Business Venturing, Volume 28, Issue 4.

Oosterbeek, H., van Praag M., Jsselstein A. (2008) 'The Impact of Entrepreneurship Education on Entrepreneurship Competencies and Intentions: An Evaluation of the Junior Achievement Student
Mini-Company Program', Discussion Paper Series, IZA DP No. 3641, pp. 1-24.

Palich, L.E., Bagby, D.R. (1995) 'Using cognitive theory to explain entrepreneurial risk-taking: Challenging conventional wisdom', Journal of Business Venturing 10 (6), pp. 425-438

Pepin, M. (2012) 'Enterprise education: a Deweyan perspective', Education+ training, 54(8/9), pp. 801-812.

Peterman, N.E., Kennedy, J. (2003) 'Enterprise education: Influencing students' perceptions of entrepreneurship', Entrepreneurship Theory and Practice 28 (2), pp. 129-144.

Phillips, D.C. and Siegel, H. (2013) 'Philosophy of Education', in Zalta, E.N. (ed.), The Stanford Encyclopedia of Philosophy (Winter 2013 Edition), http://plato.stanford.edu/archives/win2013/entries/education-philosophy/ (access: $20^{\text {th }}$ October 2015).

Piaget, J. (1964) 'Development and learning', in Ripple, R., Rockcastle, V. (eds), Piaget rediscovered, Ithaca, NY: Cornell University, pp. 7-19.

Piaget, J. (1973) To understand is to invent: The future of education. New York: Grossman Publishers.

Pittaway, L., Cope, J. (2007) 'Simulating entrepreneurial learning integrating experiential and collaborative approaches to learning', Management learning, 38(2), pp. 211-233.

Politis, D. (2005) 'The Process of Entrepreneurial Learning: A Conceptual Framework', Entrepreneurship Theory and Practice, 29(4), pp. 399-424.

Politis, D. (2008) 'The process of entrepreneurial learning: a conceptual framework', in Harrison, R.T., Leitch, C. (eds), 
Entrepreneurial Learning: Conceptual Frameworks and Applications, London: Routledge, pp. 44-71.

Rae, D. (2000) 'Understanding entrepreneurial learning: A question of how?', International Journal of Entrepreneurial Behaviour \& Research, 6(3), pp. 146-159.

Rae, D., Carswell, M. (2001) 'Towards a conceptual understanding of entrepreneurial learning', Journal of Small Business and Enterprise Development, 8(2), pp. 150-158.

Rae, D. (2010) 'Universities and enterprise education: responding to the challenges of the new Era', Journal of Small Business \& Enterprise Development, Vol. 17 Iss: 4, pp. 591 - 606.

Rasheed, H.S. (2000)' Developing Entrepreneurial Potential in Youth: The Effects of Entrepreneurial Education and Venture Creation', http://usasbe.org/ knowledge/proceedings/proceedingsDocs/USASBE2001proceedings-063. PDF (access: 15th of October 2014)

Rasmussen, E.A. Sørheim, R. (2006) 'Action-based entrepreneurship education', Technovation, 26(2), pp. 185-194.

Rerup, C. (2005) 'Learning from Past Experience: Footnotes on Mindfulness and Habitual Entrepreneurship', Scandinavian Journal of Management, 21 , pp. 451-72.

Reuber, R.A., Fischer, E.M. (1993) 'The learning experiences of entrepreneurs', in Churchill, N.C., Birley, S., Bygrave, W.D., Doutriaux, J., Gatewood, E.J., Hoy, F.S., Wetzel, W.E. (eds), Frontiers of entrepreneurship research, Wellesley, MA: Babson College Press, pp. 234-245. Reuber, R.A., Fischer, E.M. (1999) 'Understanding the consequences of founders' experience', Journal of Small Business Management, 37(2), pp. 30-45.

Revans, R.W. (1998) ABC of action learning. Lemonas \& Crane, London.

Revans, R.W. (1980) Action Learning: New Techniques for Management. London: Blond \& Briggs.

Revans, R.W. (1982) The Origins and Growth of Action Learning. Bromley: Chartwell Bratt.

Revans, R.W. (1983) The ABC of Action Learning. Bromley: Chartwell-Brat.

Revans, R.W. (2011) ABC's of action learning. Burlington, VT: Gower.

Richardson, V. (ed.) (1997). Constructivist teacher education: Building a world of new understandings. London: Falmer.

Ricoeur, P. (2000) The Just, Chicago and London: University of Chicago Press.

Roberts, J.W. (2012) Beyond Learning By Doing: Theoretical Currents in Experiential Education. New York: Routledge.

Rodgers, C. (2002) 'Defining reflection: Another look at John Dewey and reflective thinking', The Teachers College Record, 104(4), pp. 842-866.

Rokeach, M. (1973) The Nature of Human Values. New York: Free Press.

Rorty, R. (1999) Philosophy and social hope. London: Penguin UK.

Rousseau, J.-J. (2007) Emile. Teddington: Echo Library.

Ruohotie, P., Koiranen, M. (2000) 'In the Pursuit of Conative Constructs into Entrepreneurship Education', Journal of Entrepreneurship Education, 3, pp. 9-22.

Saks, N.T., Gaglio, C.M. (2002) 'Can opportunity identification be taught?', Journal of Enterprising Culture, 10(4), pp. 313-347. 
Saunders, W.L. (1992) 'The constructivist perspective: Implications and teaching strategies for science', School Science and Mathematics, 92(3), pp. 136-141.

Sarasvathy, S. (2008) Effectuation: elements of entrepreneurial expertise. Northampton: Edward Elgar Publishing.

Sarasvathy, S, Dew, N. (2005) 'New Market Creation through Transformation', Journal of Evolutionary Economics 2005, 15, pp. 533-565.

Sarasvathy, S. (2001) 'Causation and effectuation: Toward a theoretical shift from economic inevitability to entrepreneurial contingency', Academy of Management Review 26(2), pp. 243-263.

Sarasvathy S., Venkataraman S. (2010) 'Entrepreneurship as Method: Open Questions for an Entrepreneurial Future', Journal of Small Business Management, 48 (3 2010): pp. 421-440.

Schön, D. (1983) The Reflective Practitioner. New York: Basic Books.

Schön, D. (1987) Educating the Reflective Practitioner. London: Jossey-Bass.

Schwartz, S.H. (1992) 'Universals in the content and structure of values: Theory and empirical tests in 20 countries', in Zanna M. (ed.), Advances in experimental social psychology, New York: Academic Press, pp. 1-65.

Schwartz, S.H. (2006) 'Basic Human Values: Theory, Measurement, and Applications', Revue française de sociologie, $47 / 4$.

Semetsky, I. (2009) 'Deleuze as a Philosopher of Education: Affective Knowledge/Effective Learning', The European Legacy, 14:4, pp. 443-456.

Semetsky, I. (2010) 'The Folds of Experience, or: Constructing the pedagogy of values', Educational Philosophy and Theory, vol. 42, issue 4.

Seo, M.G., Barrett, L.F., Bartunek, J.M. (2004) 'The role of affective experience in work Motivation', Academy of Management Learning and Education, 29(3), pp. 423-439.

Shane, S., Venkataraman, S. (2000) 'The promise of entrepreneurship as a field of Research', The Academy of Management Review, 25(1), pp. 217-226.

Short, J.C., Ketchen, D.J., Shook, C.L., Ireland, R.D. (2010) 'The concept of "opportunity" in entrepreneurship research: past accomplishments and future challenges', Journal of Management, 36, pp. 40-65.

Sitzmann, T., Kely, K., Brown, K., Bauer, K. (2010) 'Self-Assessment of Knowledge: A Cognitive Learning or Affective Measure?', Academy of Management Learning \& Education, 9(2), pp. 169-191.

Shrivastava, P. (2010) 'A Pedagogy of Passion for Sustainability', Academy of Management Learning and Education, volume 9, number 3, September 2010. Skinner, B.F. (1976) About behaviorism. New York: Vintage Books.

Skinner, B.F. (1968) The Technology of Teaching, New York: Appleton-Century-Crofts. Spence, L.J., Rutherford, R., (2003) 'Small business and empirical perspectives in business ethics: an editorial', Journal of Business Ethics, 47, pp. 1-5.

Snow, R.E., Corno, L., \& Jackson, D. (1996) 'Individual Differences in Affective and Conative functions', in Berliner D.C., Calfee, R.C. (eds.), Handbook of Educational Psychology, New York: Simon \& Schuster. Macmillan, pp. 243-310. 
Sweller, J. (1988) 'Cognitive load during problem solving: Effects on learning', Cognitive Science, 12, pp. 257-285.

Sweller, J. (1991) 'Some modern myths of cognition and instruction', in Biggs, J.B. (ed.), Teaching for Learning: The view from cognitive psychology, ACER, Radford House, Vic., Australia.

Sweller, J. (1994) 'Cognitive load theory, learning difficulty and instructional design', Learning and Instruction, 4, pp. 295-312.

Taylor, E.W. (1998) 'The Theory and Practice of Transformative Learning: A Critical Review', Information Series no. 374. Columbus: ERIC Clearinghouse on Adult, Career, and Vocational Education, Center on Education and Training for Employment, College of Education, the Ohio State University.

Taylor, D.W., Thorpe, R. (2004) 'Entrepreneurial learning: a process of co-participation, Journal of Small Business and Enterprise Development, 11 (2), pp. 203-211.

Thorndike, E.L. (1898), 'Animal intelligence: An experimental study of the associative processes in animals', Psychological Monographs: General and Applied, 2(4), pp. i-109.

Thorndike, E.L. (1913) Educational Psychology, Vol. 2. Teachers college. Columbia University.

Thorndike, E.L. (1913) Introduction to the Theory of Mental and Social Measurements. Teachers college. Columbia University.

Thorndike, E.L. (1932) The Fundamentals of Learning. Teachers college, Columbia university.
Tracey, P., Phillips, N. (2007) 'The distinctive challenge of educating social entrepreneurs: a postscript and rejoinder to the special issue on entrepreneurship education', Academy of Management Learning \& Education, 6 , pp. 264-71.

Usher, R., Edwards, R. (1994) Postmodernism and Education. London: Routledge. Van Cleve, M., Young, P. (1976) Philosophy and the American school: An introduction to the philosophy of education. $2^{\text {nd }}$ edition. Lanham, MD: University Press of America, Inc.

Van Gelderen, M. (2010) 'Autonomy as the guiding aim of entrepreneurship education', Education + Training, Vol. 52(8/9), pp. $710-721$.

Vanevenhoven, J. (2013) 'Advances and Challenges in Entrepreneurship Education', Journal of Small Business Management, 51, pp. 466-470.

Venkataraman, S. (1997) 'The distinctive domain of entrepreneurship research: An editor's Perspective', in Katz, J., Brockhaus, R. (eds.), Advances in entrepreneurship, firm emergence and growth, Greenwich, CT: JAI Press, pp. 119-138.

Vesper, K.H. (1982) 'Introduction and summary of entrepreneurship research', in Kent, C.A., Sexton, D.L., Vesper K.H. (eds), Encyclopedia of entrepreneurship, Englewood Cliffs: Prentice-Hall, $x x x i-x x x v i i i$.

Vogel, D. (1992). 'The Globalization of Business Ethics: Why America Remains Distinctive', California Management Review (Fall), pp. 30-49.

Welpe, I.M., Spörrle, M., Grichnik, D., Michl, T., Audretsch, D.B. (2011), 'Emotions and Opportunities: The 
Interplay of Opportunity Evaluation, Fear, Joy, and Anger as Antecedent of Entrepreneurial Exploitation', Entrepreneurship Theory and Practice 36(1), pp. 69-96.

Welter, F. (2010) 'Contextualizing Entrepreneurship-Conceptual Challenges and Ways Forward', Entrepreneurship Theory and Practice, 35 (1), pp. 165-184.

Williams, G. (2004) 'Two Approaches to Moral Responsibility', Richmond Journal of Philosophy, 6 (Spring 2004).

Wolman, B.B. (2012) 'Contemporary Theories and Systems in Psychology', Springer Science \& Business Media, 2012.

Wood, A. (1998) 'Hegel on Education', in A.O. Rorty (ed.) Philosophy as Education. London: Routledge.

Zimmerman, B.J. (1989) 'A social cognitive view of self-regulated academic learning', Journal of Educational Psychology, Vol. 81(3), Sep 1989, pp. 329-339.

Zimmerman, B.J. (1990) 'Self-regulated learning and academic achievement: An overview', Educational Psychologist, 25, pp. 3-17.

Zimmerman, B.J., Bandura, A. (1994) 'Impact of self-regulatory influences on writing course attainment', American Educational Research Journal, 31, pp. 845-862.

Zimmerman, B.J. (1995) 'Self-regulation involves more than metacognition: $\mathrm{A}$ social-cognitive perspective', Educational Psychologist, 30(4), pp. 217-221.

Zimmerman, B.J. (2000) 'Attaining self-regulation: A social cognitive perspective', in Boekaerts, M., Pintrich, P.M., Zeidner, M. (eds), Handbook of self-regulation, San Diego: Academic Press, pp. 13-39.

Zimmerman, B.J., Schunk, D.H. (2001) Self-regulated learning and academic achievement: Theoretical perspectives. $2^{\text {nd }}$ edition. Mahwah, NJ: Erlbaum.

Zimmerman, B.J. (2002) 'Becoming a self-regulated learner: An overview', Theory Into Practice, 41 (2), pp. 64-70.

Zimmerman, B.J. (2008) 'Investigating self-regulation and motivation: Historical background, methodological developments, and future prospects', American Educational Research Journal, 45(1), pp. 166-183.

Zimmerman, B.J., Moylan, A.R. (2009) Self-regulation: Where metacognition and motivation intersect, in Hacker, D.J., Dunlosky, J., Graesser, A.C. (eds.), Handbook of metacognition in education, New York: Routledge, pp. 299-316.

Zimmerman, B.J. (2011) 'Motivational sources and outcomes of self-regulated learning and performance', in Zimmerman, B.J, Schunk, D.H. (eds), Handbook of self-regulation of learning and performance, New York: Routledge, pp. 49-64. 



\section{List of tables}

\section{Chapter I}

Table 1.1. Characteristics of changes from traditional education towards more contemporary one 33

Table 1.2. Three basic models of entrepreneurship education 35

Table 1.3. The evolution of pedagogy $\quad 37$

Table 1.4. Comparison of teacher-centred and learner-centred paradigms $\quad 38$

Table 1.5. Teaching entrepreneurship as a process and as a method 42

Table 1.6. Three types of learning $\quad 47$

Chapter II

Table 2.1. Five basic teaching philosophies 66

Table 2.2. Traditional versus progressive education $\quad 70$

Table 2.3. Learning Style Inventory 99

Table 2.4. Different learning styles according to Honey and Mumford (1986) 101

\section{Chapter IV}

Table 4.1. Education for professionalization and for social purpose

Table 4.2. Differences between corporate social responsibility, social entrepreneurship and entrepreneurial responsibility 



\section{List of figures}

Chapter I

Figure 1.1. Effectuation logic

\section{Chapter II}

Figure 2.1. Bandura's triadic reciprocal causation model 82

Figure 2.2. Process of self-regulated learning 85

Figure 2.3. Four stages of learning. Kolb's Experiential Learning Cycle 97

Figure 2.4. Experiential learning model and basic learning styles 99

Figure 2.5 Jarvis' model of experiential learning 101

\section{Chapter III}

Figure 3.1. Conceptual framework of entrepreneurial learning as an experiential process 
Agnieszka Kurczewska is aresearcherinthefield ofentrepreneurship and entrepreneurship education. She holds a post-doctoral degree in economics (dr hab. in Polish). Currently she has a position of an assistant professor at the Faculty of Economics and Sociology at the University of Lodz. From September 2010 till April 2011 Agnieszka worked as an assistant professor in Entrepreneurship Unit at Aalto University School of Economics in Helsinki, Finland. In 2014/2015 she received a grant from the Polish Ministry of Science and Higher Education and spent 10 months at the University of Tampa (USA) conducting the research on academic entrepreneurship education. Agnieszka Kurczewska is a member of the Board of Directors of the European Council for Small Business \& Entrepreneurship (ECSB). She was also a holder of the Ministry of Science and Higher Education in Poland scholarship for young researchers and stipend holder of the Foundation of University of Lodz.

The heart of this monograph is to revisit existing knowledge on experiential pedagogy and then combine it with somehow forgotten concept of responsibility in order to enhance the fundaments of entrepreneurship education. This monograph aims to contribute to the dynamically developing fields of entrepreneurship and entrepreneurship education. This contribution is a refreshed, experience and responsibility-based, view into the learning process. Including these two concepts into theory and practice of entrepreneurship education and also investigating them from different perspectives may result in rethinking and advancing the way entrepreneurship education is executed. The monograph is an invitation to the discussion on entrepreneurship education and its foundations. It tries to provide some answers to numerous questions, but also leaves a lot of them open, thus stimulates further reflections and research, exploring different facets and nuances of experiences and responsibility and their roles in entrepreneurship education. 